BNL- -47219

DE92 014169

\title{
MATERIALS STUDIES FOR PREVENTING CORROSION IN CONDENSING ENVIRONMENTS
}

\author{
ANNUAL REPORT \\ (OCTOBER 1990 - SEPTEMBER 1991)
}

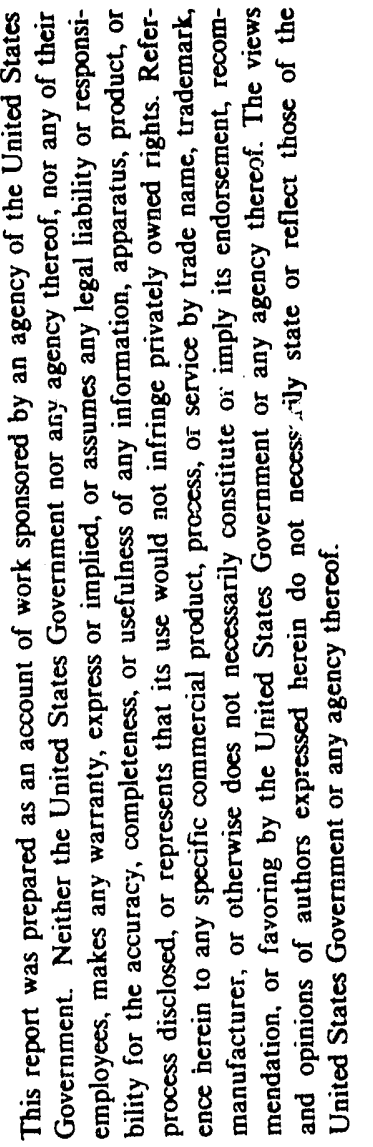

\author{
By \\ L.E. Kukacka and T. Sugama \\ ENERGY EFFICIENCY AND CONSERVATION DIVISION \\ DEPARTMENT OF APPLIED SCIENCE \\ BROOKHAVEN NATIONAL LABORATORY \\ ASSOCIATED UNIVERSITIES, INC. \\ UPTON, LONG ISLAND, NEW YORK 11973 \\ For \\ GAS RESEARCH INSTITUTE \\ Contract No. 5090-260-1948 \\ GRI Project Manager \\ Dr. Kevin Krist \\ Physical Sciences Department
}

October 1991

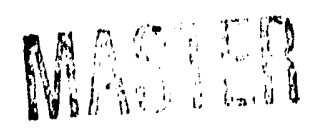

Sponsored in part under the auspices of the U.S. Department of Energy under contract No. DE- $1 \mathrm{CO} 2-76 \mathrm{CHOOO} 16$

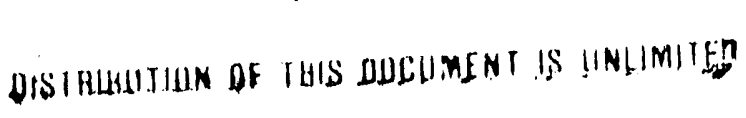


LEGAL NOTICE

This report was prepared by Brookhaven National Laboratory (BNL) as an account of work sponsored by the Gas Research Institute (GRI). Neither the GRI, member of GRI, nor any person acting on behalf of either:

a. Makes any warranty or representation, express or implied, with respect to the accuracy, completeness, or usefulness of the information contained in this report, or that the use of any apparatus, method, or process disclosed in this report may not infringe privately owned rights; or

b. Assumes any liability with respect to the use of, or for damages resulting from the use of, any information, apparatus, method, or process disclosed in this report.

Reference to trade names on specific commercial products, commodities, or services in this report does not represent nor constitute an endorsement, recommendation, or opinion of suitability by GRI or BNL of the specific commercial product, commodity, or service. 


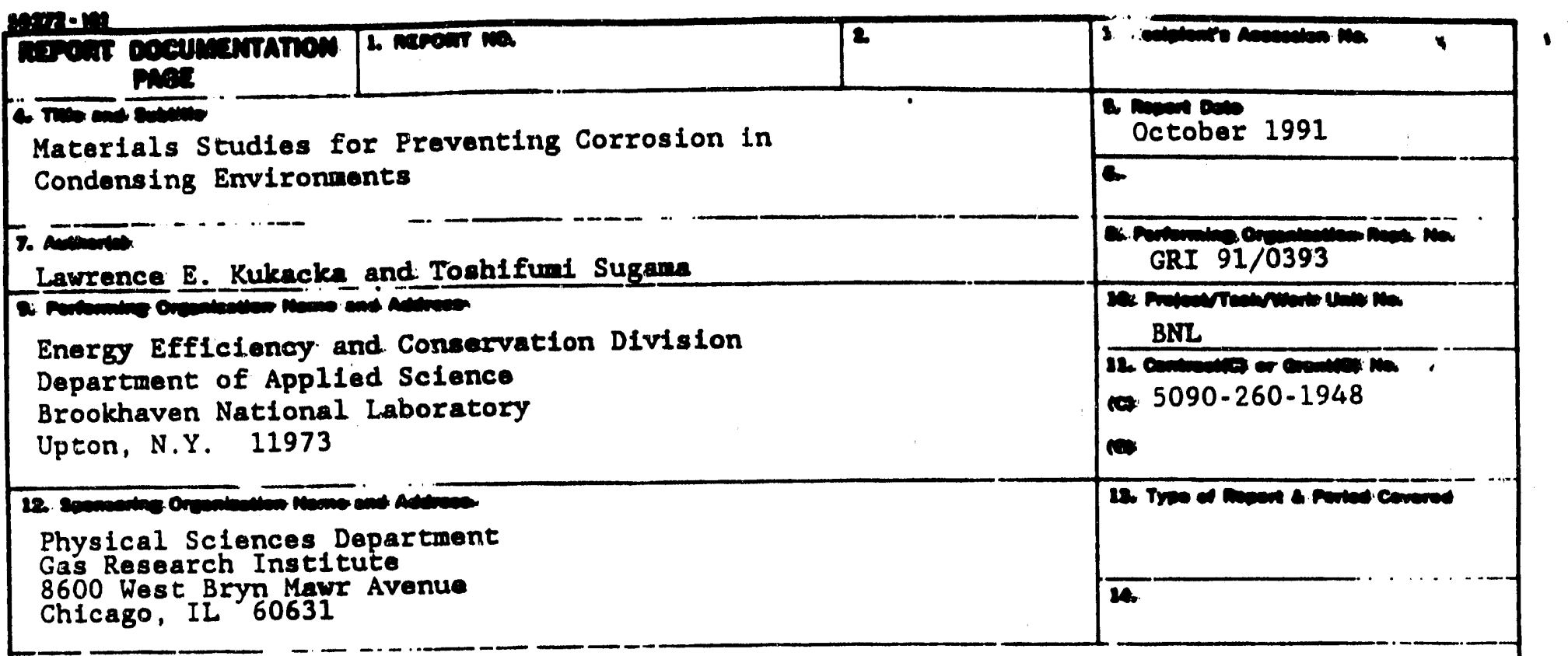

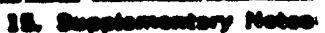

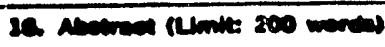

This R\&D effort is being focused to provide information regarding corrosion resistance, heat transfer, material cost, fabrication method and cost; and product reliability sinie all are important in the flrial design and production of a heat exchanger. Results to date indicate that organic and inorganic-type polymer coating systems applied to low cost metals such as mild steel and aluminum provide good corrosion protection. The thermal stability of these polymers plus the identification of the interfacial requirements needed to utilize them with reactive filler materials should also make their use as bulk composites feasible.

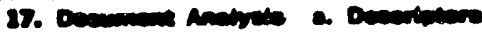

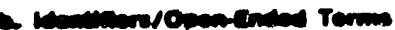

c. coran Nuremen

\begin{tabular}{|c|c|c|}
\hline \multirow[t]{2}{*}{ Release Unlimited } & 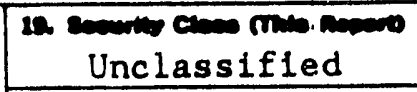 & 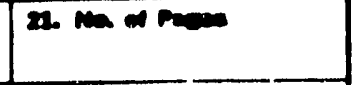 \\
\hline & 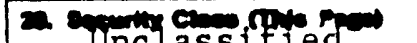 & 2. Nives \\
\hline (SeO Anab-20s.10) & enes & 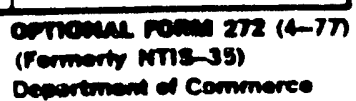 \\
\hline
\end{tabular}


Title Material Studies for Preventing Corrosion in Condensing Environments

Contractor

Principal

Investigator

Report

Period

Objective

Technical Perspective

Results
Associated Universities, Inc. Brookhaven National Laboratory GRI Contract No. 5090-260-1948

\section{L.E. Kukacka}

October 1990-September 1991 Annual Report

Determination of the fundamental interfacial requirements for low-cost, organic and inorganic materials resistive to corrosion in condensing furnace exhausts.

The 1987 National Appliance Energy Conservation Act requires that new gas furnaces exceed $78 \%$ efficiency by 1992 . Reductions in the inftial cost of more efficient gas furnaces may help to maintain their competitiveness. Corrosion can occur in high efficlency furnace systems due to wet/dry cycles that concentrate aqueous chloride on the surface of heat exchangers, vents, and flue linings. As a result, expensive, difficult to fabricate, AL 29-4C stainless steel is currently used to prevent corrosion in secondary heat exchangers. Costs below $\$ 2-3 / \mathrm{ft}^{2}$ (18 gauge material) for easily fabricable materials would reduce the cost of finned tube condensing heat exchangers by $\sim 50 \%$. This research is investigating organic and inorganic approaches to reducing the cost and improving the lifetime of these components.

Polymer coatings on heat exchangers and other types of chemical process equipment are used commercially on a routine basis, thereby suggesting that their use can be cost effective. Polypheylene sulfide (PPS) and other types of polyaryl-type polymers such as polyphenylethersulfone (PES) and polyphenyletheretherketone (PEEK) were selected for study in this program due to their high melting points $\left(>295^{\circ} \mathrm{C}\right)$ and acid resistance. All have common chemical features consisting of aromatic backbone chains coupled with oxygen, ketones, and/or sulphur. They are commercially available and can be applied as coatings using standard spray, dip and fluidized bed processes. When the polymers are mixed with fillers, extrudable composite tubing can be produced.

Screening test performed at Battelle Columbus indicated that BNL-supplied specinens consisting of a PPS topcoat dip applied to a carbon steel substrate containing a polyelectrolyte [p(AA)]-modified zinc phosphate ( $\mathrm{Zn} \cdot \mathrm{Ph}$ ) convelsion coating, had excellent durability in condensing flue gas enviromments. The durability displayed was equal or better 
than that obtained from a commercially supplied two layer PPS coating applied to Al using a fluidized bed technique. All other materials tested failed. Therefore, initial work at BNL was focused on the PPS system. Studies on PPS/A1 and polyzirconosiloxane (PZS)/Al systems were also initiated.

The results from the first years work indicate that the uti. lization of a $<5$ micron thickness of the BNL-developed $\mathrm{Zn} . \mathrm{Ph}$ as a chemically resistant coupling material between PPS and mild steel, produces a well bonded durable coating system. The PPS $/ \mathrm{Zn}$. Ph interaction also provides reaction phases at the PPS/metal interface which are more resistant to chemical attack, thereby providing extra protection in the event of pin holes in the coating or cracks forming due to mechanical and thermal stresses.

PPS coatings applied to $\mathrm{Zn}$. Ph-modified mild steel by first dipping the substrate into a PPS-alcohol slurry and subsequently heating in air at $300^{\circ}$ and $350^{\circ} \mathrm{C}$, exhibited bond strengths $\sim 37$ greater than those for PPS/steel interfaces. This imprcuement is attributable to three factors: 1) gas. solid interactions between $\mathrm{SO}_{2}$ emitted from the PPS and oxidized $\mathrm{Fe}$ compounds to form $\mathrm{FeS}, 2$ ) a polymer-to-polymer reaction between PPS and the poly(acid) anhydride existing on the outer surface of the $\mathrm{Zn}$. $\mathrm{Ph}$, and 3 ) mechanical anchoring resulting from the melted PPS penetrating into the open surface microstructure of the $\mathrm{Zn} \cdot \mathrm{Ph}$ layer.

When PPS was applied to unmodified surfaces of 6061-T6 aluminum, a hydrolyzable compound $\mathrm{Al}_{2}\left(\mathrm{SO}_{4}\right)_{3}$ was formed at the interface. Exposure of specimens for 8 days to a $80^{\circ} \mathrm{C} \mathrm{pH} 3$ $\mathrm{H}_{2} \mathrm{SO}_{4}$ solution containing $0.1 \mathrm{M} \mathrm{NaCl}$ resulted in complete delamination of the PPS film apparently due to the formation of $\mathrm{Al}_{2}(\mathrm{OH})_{4} \mathrm{SO}_{4} \cdot 7 \mathrm{H}_{2} \mathrm{O}$.

Studies in which PZS coatings were applied to aluminum commenced. These coatings were formed by hydrolysispolycondensation-pyrolys is synthesis of acid-base catalyzed sol precursors. Preliminary data indicated that thin $(\sim 1$ micron), impermeable and hydrophobic films can be produced which should provide good corrosion protection. The proportion of Si-O-Si to Si-O-Zr linkages in the film and the $\mathrm{pH}$ of the sol precursor are important parameters.

Technical Approach

A mechanistic approach is being used to obtain the fundamen tal knowledge needed to meet the research goals. Information elucidating interactions that occur between organic and inorganic polymer binders and reactive fillers in composites, and at polymer/conversion coating/metal and preceramic/metal interfaces is being obtained. Decomposition mechanisms occurring upon exposure to the test environinents are also determined. State-of-the-art analytical techniques being used in these studies include scanning electron microscopy (SEM) coupled with energy dispersive X-ray spectroscopy (EDX), transmission electron microscopy (TEM), 
Project

Implications
X-ray photoelectron spectroscopy (XPS), X-ray powder diffraction (XRD), fourler transform infrarad spectroscopy (FTIR), differential scanning calorimetry (DSC), thermogravimetric analysis (TGA), thermal mechanical analysis (TMA), and Auger electron spectroscopy (AES).

Test variables for the coating systems include metallic substrate composition, method of surface pretreatment, coating composition, and thickness. For the composites, variables include the composition and concentration of reinforcing particles and fibers, reinforcement surface pretreatment method, and polymer binder composition. Mechanical properties such as bond, flexure, tensile, and peel strengths, and impact resistance, are being measured in accordance with the appropriate ASTM Standards.

All of the data will be used to develop models which will describe the most effective interaction mechanisms, intermediate phase assemblages, and microstructure features at the interfaces and interphases responsible for the achievement of good interfacial bonding, strength and durability.

Brookhaven National Labortory (BNL) is establishing a funda mental basis for an improved, low-cost, corrosion-resistant, condensing heat exchanger for high efficiency gas furnaces. During the first year's research, BNL significantly advanced the understanding of the interfacial chemistry of polyphenylene sulfide (PPS) coated mild steel and obtained initial results for PPS and polyzirconosiloxane (PZS) coated aluminum. In addition to determining interfacial structure, composition, and chemistry, BNL established mechanisms of degradation at the coating-substrate interface under various conditions of $\mathrm{pH}$, salt concentration, and cathodic polarization. BNL developed: a zinc phosphate layer between PPS and steel to improve adhesion and minimize corrosion in the event of exposure of the interfacial region; and a dip method, which may minimize cost and enable coating of difficult geometries. Future research will study novel, thermally conductive composite materials and continue to examine PPS and PZS on aluminum surfaces. GRI plans to continue support of this research.

Dr. K. Krist

Senior Project Manager

Inorganic Chemistry 
TABLE OF CONTENTS

$I$

INTRODUCTION .

Page

II

PROJECT OBJECTIVE.

1

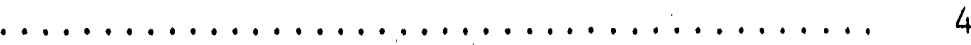

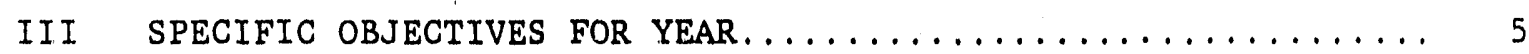

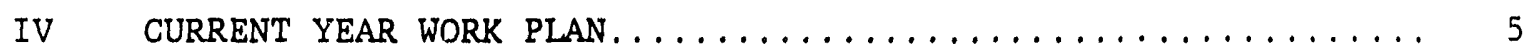

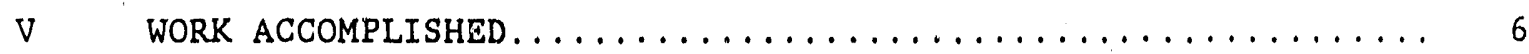

A. PPS/Steel Interfaces....................... 6

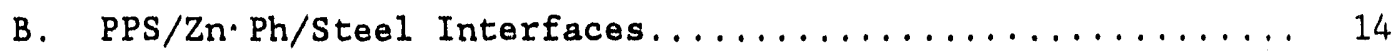

C. PPS/Aluminum Interfaces...................... 20

D. PZS/Aluminum Interfaces...................... 20

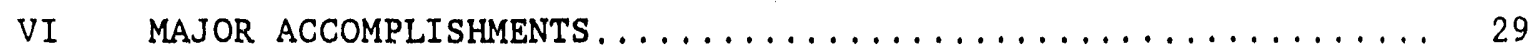

VII MAJOR PROBLEMS ENCOUNTERED ...................... 29

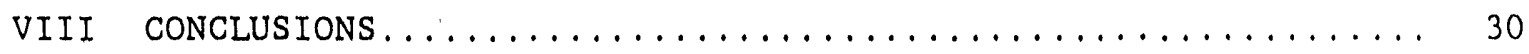

IX REFERENCES ............................. 33 
1. XPS Elemental Analysis of Bulk PPS and Substrates as Reference Surfaces........................ 36

2. Chemical Composition of Both Interfacial Sides for $\mathrm{N}_{2}$ - and $\mathrm{O}_{2}$-cured PPS/CRS Joint systems............ 36

3. Elemental Compositions of Interfacial PPS and SS Surfaces

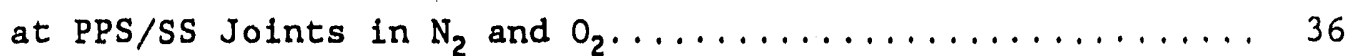

4. Atomic Concentration of $\mathrm{N}_{2}$ - and $\mathrm{O}_{2}$-Treated PPS/G-S Interfaces.................................. 36

5. Atomic Concentrations of Failed PPS and Steel Sides Before and After Exposure for 8 Days to $80^{\circ} \mathrm{C}_{2} \mathrm{SO}_{4}$ Solution.......

6. Chemical Composition of Both Interfacial Failure Sides Before and After Cathodic Delamination Tests for PPS/Steel

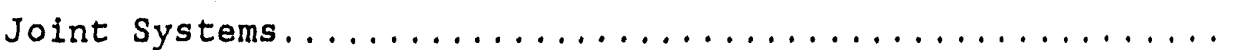

7. Chemical Composition of Both Interfacial Failure Sides Before and After Cathodic Delamination Tests for PPS/Zn. Ph

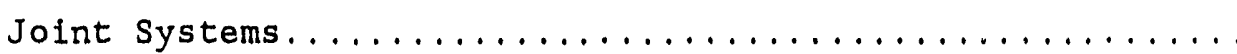

8. Compositions of Sol Precursor Solutions for a $\mathrm{pH}$ Range

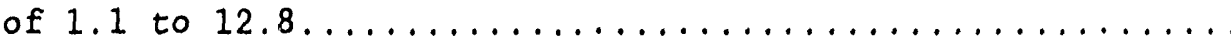


1. Lap Shear Bond Strength at Metal-to-metal PPS Adhesive

1. Lap Shear Bond Strength at Metal-to-metal PPS Adhesive
Joints after Exposure in $\mathrm{N}_{2}$ and $\mathrm{O}_{2}$ at $350^{\circ} \mathrm{C} \ldots \ldots \ldots \ldots$

Page

2. XPS High Resolution Spectra in $\mathrm{S}_{2 p}, \mathrm{Fe}_{2 p} 3 / 2$ and $\mathrm{Zn}_{2 p} 3 / 2$

Regions for Reference Polyphenylene Sulfide, Cold-rolled

Stee1, Stainless Stee1, and Galvanized Steel surfaces.....

3. $S_{2 p}$ Spectra at Failed Interfaces of PPS/CRS Joint System

Prepared in $\mathrm{N}_{2}$ and $\mathrm{O}_{2}$ Gases at $350^{\circ} \mathrm{C} \ldots \ldots \ldots \ldots \ldots \ldots$

4. $S_{2 p}$ Region at Interfacial Fallure Locus of PPS/SS Joint

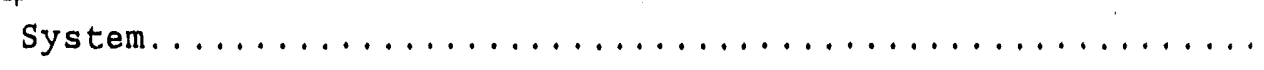

5. $S_{s p}$ Spectra at Failure Locus in PPS/G-S Joint System........

6. Lap-shear Bond Strength vs. Exposure Time to a $80^{\circ} \mathrm{C} \mathrm{pH} 3$

$\mathrm{H}_{2} \mathrm{SO}_{4}$ Solution Containing $0.1 \mathrm{M} \mathrm{NaCl} \ldots \ldots \ldots \ldots \ldots \ldots$

7. $S_{2 p}$ Region for PPS and Steel Interfaces Separated by

the Attack of Hot Acld Solution on the PPS/Steel Joint....

44

8. Schematic Diagram of Cathodic Delamination Test...........

9. $S_{2 p}$ Core Level Spectra for PPS Before and After Cathodic

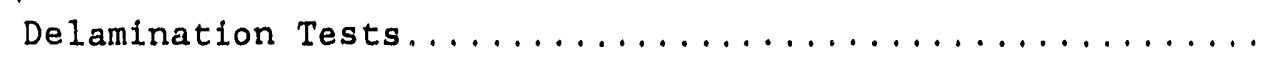

10. X-ray Diffraction Tracings for Original $\mathrm{Zn} \cdot \mathrm{Ph}$ Samples

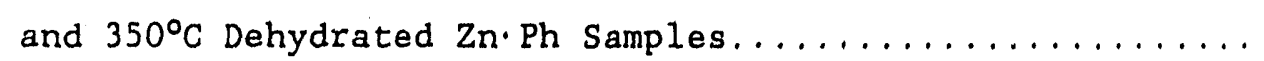

11. The Cathodic Delamination of PPS Films from Steel and

$\mathrm{Zn}$. Th-Deposited steel substrates in $1 \mathrm{M} \mathrm{NaCl} \ldots \ldots \ldots \ldots \ldots$

12. $\mathrm{P}_{2 p}$ and $\mathrm{Zn}_{2 p} 3 / 2$ Regions for Interfacial pPS Sides Before

and After Cathodic Delamination Tests...............

13. $\mathrm{Fe}_{2 p} 3 / 2$ and $\mathrm{S}_{2 p}$ Regions for Interfacial pPS Sides Before and After Cathodic Delamination Tests...............

14. Changes in $\mathrm{P} / \mathrm{Zn}, \mathrm{S} / \mathrm{Zn}$, and $\mathrm{Fe} / \mathrm{Zn}$ Atomic Ratios as a

Function of Exposure Time to $\mathrm{SO}_{2} \ldots \ldots \ldots \ldots \ldots \ldots \ldots$

15. SEM Microprobe Data and EDX Spectra of Cathodically

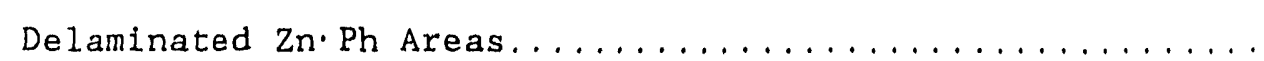

16. $C_{1 s}$ Spectra for Bulk PPS and PPS Interface Removed

from Poly (acid) anhydride-primed steel..............

17. Changes in Zeta Potential of Sol Precursors as a

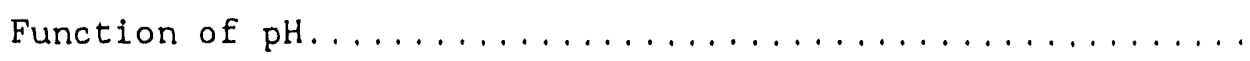


18. SEM Micrographs for $\mathrm{pH} 1.1$ Sol- and 2.6 Sol-derived

Xerogel Films Deposited on Aluminum Surfaces.............

19. SEM Micrographs for $\mathrm{pH} 8.6 \mathrm{Sol}$ - and 11.5 Sol-derived

Xerogel Films Deposited on Aluminum Surfaces............

20. TGA and DTA Curves for the Pyrolysis of Xerogels Heated in Air at a Rate of $10^{\circ} \mathrm{C} / \mathrm{Min} \ldots \ldots \ldots \ldots \ldots \ldots \ldots \ldots$

21. IR Absorption Spectra for $100^{\circ} \mathrm{C}$-Sintered Xerogels........... 58

22. IR Spectra for $300^{\circ} \mathrm{C}$-Pyrolyzed Xerogels.................. 59

23. SEM Micrographs for $300^{\circ} \mathrm{C}$-Pyrolyzed Xerogels.............. 60

24. EDX Spectra for $300^{\circ} \mathrm{C}$-Pyrolyzed Xerogel Film Surfaces....... 61

25. XRD Patterns for $300^{\circ} \mathrm{C}$-Pyrolyzed Xerogels.............. 62

26. SEM-EDX Inspection of $300^{\circ} \mathrm{C}$-Pyrolyzed pH $8.6 \mathrm{Film}$ Surface

After Rinsing with Water.....................

27. AES Depth-Profile of Pyrolyzed PZS-coated Aluminum After

Rinsing with water.......................

28. Effect of Temperature on the Water-wettability of Xerogel

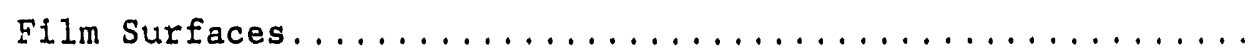

29. Changes in the Corrosion Current, $I_{\text {corr }}$ of PZS Xerogel-

coated Aluminum Substrates as a Function of Coating

Treatment ........................... 


\section{INTRODUCTION}

The 1987 National Appliance Energy Conservation Act requires that new gas furnaces exceed 788 efficiency by 1992 . In order to help maintain the competitiveness of units meeting this criterion, it is essential that costeffective materials of construction be available.

The corrosiveness of the fluids present in condensing heat exchangers for high efficiency gas furnaces is well documented. ${ }^{[1,2]}$ All traditional metals used for heat exchangers, and even some more exotic and much more expensive alloys are corroded by the acidic environments encountered. Some high temperature engineering plastics such as polyacrylsulfones, polyetherimides and polyketones exhibit good corrosion resistance to these environments, but their costs make them uneconomical for use as bulk materials ${ }^{[3]}$. Ceramics are brittle, and cxulbit similar cost constraints. Conventional chemical coupling systems needed to bond polymers to steel and aluminurn substrates of ten undergo hydrolytic decomposition, therefore making the use of polymeric coatings for corrosion protection unreliable.

Earlier work ${ }^{[4-7]}$ at Brookhaven National Laboratory (BNL) Identified several material systems which appeared to have potential for being low-cost solutions to this corrosion problem, therefore reducing the first cost increase of a condensing furnace over an induced draft noncondensing unit. The goal of one of these programs which was sponsored by the Army Research Office (ARO), was to obtain physico-chemical data needed to synthesize low cost organic crystalline and pre-ceramic-type polymer coatings which could provide corrosion protection to cold-rolled metals, clad aluminum, and magnesium upon exposure to acids, and alkali electrolytes containing high concentrations of $\mathrm{Na}^{+}$and $\mathrm{Cl}^{-}$ions at temperatures up to $200^{\circ} \mathrm{C}$.

The results indicated that upon exposure to concentrated $\mathrm{Cl}^{-}$ions at $200^{\circ} \mathrm{C}$, failures of conventional organic coatings applied to metallic substrates occur as a result of 1 ) the high segmental mobility of the molecular chains, 2) alkali catalyzed hydrolysis of polymers, 3) localized delamination caused by the cathodic half reaction $\mathrm{H}_{2} \mathrm{O}+1 / 2 \mathrm{O}_{2}+2 e^{*}-2 \mathrm{OH}^{*}$, which occurs under the coating in conjunction with the anodic half reaction $\mathrm{Fe} \rightarrow \mathrm{Fe}^{++}+2 \mathrm{e}^{-}$ , which takes place at the defect, 4) in confunction with failure mode 3 , alkali-catalyzed degradation of the polymers at the polymer-metal interface, and 5) interfacial dissociation of the metal oxide layer resulting from the chemisorption of $\mathrm{Cl}^{-}$ions that penetrate the organic film. ${ }^{[4]}$ Using these 
results, it appeared possible to define the requirements for the molecular design of optimized protective systems which will yield hydrolytically stable coatings for use in $\mathrm{pH} 2$ to 11 environments. These requirements include 1) formation of a highly cross-linked structure having low segmental mobility at $200^{\circ} \mathrm{C}$, 2) elimination of functional groups in the material network in which any two atoms selected from $N, O$, and $S$ are joined to the same carbon atom, and 3) formation of hydrophobic reaction products at the film-metal interface in order to inhibit cathodic reactions. It is assumed that all of the above design requirements must be attained in order to produce a protective film that will meet the requirements for high efficiency gas furnaces.

A noteworthy success in this earlier ARO-sponsored work was the development of polyelectrolyte-modified zinc phosphate ( $\mathrm{Zn} \cdot \mathrm{Ph}$ ) crystal conversion coatings for steel. [5] This BNL-patented process was the recipient of a 1988 R\&D 100 Award, and it has subsequently been licensed to two commercial firms. The $\mathrm{Zn} \cdot \mathrm{Ph}$ coating is prepared by immersing steel for approximately 5 to $20 \mathrm{~min}$ in a zinc phosphate solution containing a moderate amount of poly(acrylic acid) at approximately $80^{\circ} \mathrm{C}$. A thin (1-2 micron), flexible and ductile conversion coating is formed which has excellent corrosion resistance and adhesion with polymeric topcoats. The thickness of the crystal coating can be varied by changing the immersion time.

In order to establish the technical feasibility of using the $\mathrm{Zn} \cdot \mathrm{Ph}$ technology to impart corrosion protection to condensing heat exchangers, test specimens were supplied to Battelle Columbus for evaluation in a heat exchanger that reproduced the environment present in a condensing furnace. The samples supplied by BNL consisted of $15.9 \mathrm{~mm}$ - o.d. mild carbon steel tubing, the outer surfact of which had been modified by the application of the $\mathrm{Zn} \cdot \mathrm{Ph}$. An -1 mil thick PPS topcoat was then dip applied. Spin casting would be applicable for the placement of uniform dense coatings on inner tube surfaces. The results from this corrosion test series ${ }^{[2]}$ indicated that eight of the ten materials evaluated degraded in two months and were judged unsuitable for use in condensing heat exchangers. Only the BNL-supplied tubes and aluminum tubes coated with PPS by a commercial firm experienced no discernible degradation.

Pre-ceramic-type coatings consisting of polytitanosiloxane (PTS) polymers also appear to have potential for gas furnace condenser applications. These polymers are characterized by a three-dimensional network structure of 
Ti-crosslinked polysiloxane. These polymers are synthesized by hydrolysispolycondensation or hydrolysis-polycondensation-pyrolysis reaction processes starting with clear precursor sol solutions consisting of monomeric organosiloxanes, $\mathrm{Ti}\left(\mathrm{OC}_{2} \mathrm{H}_{5}\right)_{4}$, methanol, water, and hydrochloric acid. Deposition of films is accomplished by dipping the substrate into the precursor solution and subsequent heating. Although dependent upon the species of the organosiloxane used, heating at $2300^{\circ} \mathrm{C}$ is generally necessary to produce a hydrophobic PTS network structure. Key variables in the production of high quality thin ( 0.2 - 1.0 micron) coatings are the organosiloxane to $\mathrm{Ti}\left(\mathrm{OC}_{2} \mathrm{H}_{5}\right)_{4}$ ratio and the extent of the densification of the Si-O-Ti bonds in the PrS netrork. [']

PTS coatings applied to mild steel substrates containing the $\mathrm{Zn} \cdot \mathrm{Ph}$ conversion coating may represent another candidate protective coating system. In this case, improved bonding of the PZS to the steel may possibly be obtained and the $\mathrm{Zn} \cdot \mathrm{Ph}$ would provide additional low cost corrosion protection in the event of crack formation within the $\sim 1$ micron thick PZS layer, or the coatingmetal interface becomes exposed.

Polymer-matrix composites presently under investigation for use as corrosion resistant materials in geothermal processes, may also be suitable for GRI needs. ${ }^{[7]}$ These materials exhibit a corrosion resistance to hypersaline trine $\left(300,000 \mathrm{ppm}\right.$ total dissolved solids) at $250^{\circ} \mathrm{C}$ comparable to that of Hastelloy $C$. The cost is only marginally greater than that of carbon steel ${ }^{[8]}$, and possibly four times less than AL-29-4C, an alloy judged acceptable for concentrated condensate. ${ }^{[9]}$ Applications as corrosion resistant coatings or as bulk materials appear technically feasible.

Research to acquire the fundamental knowledge necessary to design, synthesize and evaluate low cost composite bulk materials; and composite, $\mathrm{Zn} \cdot \mathrm{Ph}$ and pre-ceramic coating systems which will provide corrosion protection to cold-rolled steel and aluminum substrates upon exposure to harsh condensing fluids was initiated by BNI, under GRI sponsorship on October 1, 1990. Attainment of these objectives will result in a comprehensive understanding of the principles governing the role of matrix to reactive additive or reinforcement interfaces and the interphases, and how they affect the mechanical and physical properties of organic and inorganic matrix composites and their ability to bond to metallic substrates. 
A mechanistic approach is being used to obtain the fundamental knowledge needed to meet the research goals. Information elucidating interactions that occur between organic and inorganic polymer binders and reactive fillers in composites and at polymer/conversion coating/metal and ceramic/metal interfaces is being obtained. Decomposition mechanisms occurring upon exposure to the test environments are also being determined. Techniques being used in these studies include scanning electron microscopy (SEM) coupled with the energy dispersive X-ray spectroscopy (EDX), transmission electron microscopy (TEM), X-ray photoelectron spectroscopy (XPS), X-ray powder diffraction (XRD), fourier transform infrared spectroscopy (FTIR), differential scanning calorimetry (DSC), thermogravimetric analysis (TGA), thermal mechanical analysis (TMA), and Auger electron spectroscopy (AES).

The planned 3 year program has been structured into four tasks: Task 1, Fundamental Studies; Task 2, Property Determinations; Task 3, Prototype Component Fabrication and Testing; and Task 4, Documentation. Work on Tasks 1, 2 and 4 commenced in FY 1991 and will be continued in 1992. Tasks 3 and 4 will be completed in FY 1993.

This report summarizes accomplishments in FY 1991. Fundamental data that characterize the interactions at PPS/steel, PPS/Zn.Ph/steel, PPS/Al, and polymetallosiloxane (PMS)/Al interfaces are given. Transport kinetics and decomposition mechanisms occurring upon their exposure to harsh acid environments are also discussed.

\section{PROJECT OBJECTIVE}

The objective of the research being performed is to acquire the fundamental knowledge necessary to design, synthesize, and evaluate low cost composite bulk materials; and composite $\mathrm{Zn} \cdot \mathrm{Ph}$ and pre-ceramic coating systems which will provide corrosion protection to cold-rolled steel and aluminum substrates upon exposure to harsh condensing fluids. Attainment of these objectives will result in a comprehensive understanding of the principles governing the role of matrix to reactive additive or reinforcement interfaces and the interphases, how they affect the mechanical and physical properties of organic and inorganic polymers and composites, and their ability to bond to metallic substrates. Such an understanding will significantly extend the science of polymer coatings and composite materials, and lead to the 
production of systems with enhanced strength, toughness, durability and impermeability, as compaced with those available today.

A near-term benefit of the research to the Gas Research Institute (GRI) will be the identification of low cost materials of construction for use in gas furnace condenser applications. This will reduce the first cost increase of a condensing furnace over induced draft noncondensing units, and provide basic information needed for use in solving other gas industry materials needs.

\section{SPECIFIC OBJECTIVES FOR YEAR}

The specific objective of the work scheduled to be performed in the first year of the three year program was to commence the accumulation of fundamental data that will lead to the development of models of the reaction product assemblages and bonding modes at matrix-reinforcement and coatingsubstrate interfaces. Such an understanding is essential for the design and construction of cost-effective and durable composites or coating systems for condenser applications and other gas industry needs.

IV. CURRENT YEAR WORK PLAN

Work was planned for Task 1, Fundamental Studies; Task 2, Property Determinations; and Task 4, Documentation. Descriptions of the work scheduled within each of these tasks are given below.

Task 1. Fundamental Studies

Data elucidating interactions that occur at polymer/conversion coating/metal and pre-cerpjic/metal interfaces were to be obtained. Transport kinetics and decomposition mechanisms resulting from exposures to test environments were also to be determined. Test variables were to include metallic substrate composition, method of surface pretreatment and coating composition.

\section{Task 2. Property Determinations}

Based upon the results from the fundamental studies performed in Task 1, corrosion-protective systems were to be designed and test specimens fabricated for use in characterizations of their mechanical, physical and chemical properties at conditions simulating those expected in gas furnace condenser applications. 


\section{Task 4. Documentation}

Quarterly progress reports and an Annual Report were to be prepared. Participation at the 1990 and 1991 Inorganic Chemistry Program Reviews was planned.

\section{WORK ACCOMPLISHED}

Experimental studies commenced on October 1, 1990. Earlier screening tests performed at Battelle Columbus under GRI sponsorship indicated that BNL-supplied specimens consisting of a PPS topcoat applied to a surface modified carbon steel substrate, had excellent durability in condensing flue gas environments. [2] Therefore, our initial investigations were focused on the interactions occurring within this system. Subsequently, interactions at PPS/A1 and PZS/AI interfaces were also elucidated. Each system is discussed separately below.

PPS was chosen for study in this program since high temperature hydrolytically stable acid resistant films can be produced. Also, its molecular structure ( S-j-n meets the criterion of not having a functional group in which two atoms of $\mathrm{S}, 0$, or $\mathrm{N}$ are attached to the same carbon atom. When heated to temperatures above the melting point of approximately $290^{\circ} \mathrm{C}$, high molecular weight structures are produced through mechanisms of crosslinking and chain extension. ${ }^{[10-12]}$ It is also known that oxidized metal surfaces have a strong affinity for the chemisorption of organic polymers containing func. tional groups. ${ }^{[13]}$ Therefore, it was anticipated that the fusing-curing process for the PPS would also result in thermal oxidization of the metal beneath the PPS, thereby enhancing the bond. Specimens cured in oxygen-free environments would be expected to yield lower values.

\section{A. PPS/Steel Interfaces}

Experiments were conducted to determine how the reaction products formed in oxygen $\left(\mathrm{O}_{2}\right)$ and nitrogen $\left(\mathrm{N}_{2}\right)$ environments at the critical interfacial contact zone between PPS and various metals influence adhesive bonding. X-ray photoelectron spectroscopy (XPS) was used as the primary analytical tool in these experiments.

Three metal substrates; AISI 1010 cold-rolled steel (CRS), AISI 304 stainless steel. (SS), and G-90 galvanized steel (G-S) were used. Prior to 
application of the PPS, the metal surfaces were wiped with acetone-soaked tissues to remove any surface contamination. The "as received" PPS was a tan colored powder having a high melt flow and a melting point of $288^{\circ} \mathrm{C}$. This was mixed with isopropyl alcohol at a ratio of 45 parts PPS to 55 parts isopropyl alcohol by weight to form a slurry. The metal substrates were dipped into the slurry at $25^{\circ} \mathrm{C}$ and then heated in either $\mathrm{O}_{2}$ or $\mathrm{N}_{2}$ at $300^{\circ} \mathrm{C}$ for $3 \mathrm{hr}$. This fused the PPS and volatilized the alcohol. The temperature was then increased to $350^{\circ} \mathrm{C}$ for $2 \mathrm{hr}$ in order to increase the macromolecular structure and to crosslink it.

The chemical compositions and states present on the bulk PPS, cleaned surfaces of the three metallic substrates, and on the bond failure side of PPS coated substrates were determined from the peak areas and binding energies (BE) obtained from XPS analyses. A V.G. scientific ESCA 3MK II spectrometer was used. An A1 $K_{\alpha}(1486.6 \mathrm{eV}) \mathrm{X}$-ray source operated at a constant power of $200 \mathrm{~W}$ was used to provide excitation radiation and the vacuum in the analyzer chamb $3 x$ of the instrument was $10^{-8}$ Torr. The atomic concentrations of the chemical elements were determined by comparing the XPS peak areas which were obtained from the differential cross-sections for core-level excitation, [14] To set a scale for the high-resolution XPS spectra, the BE was calibrated with the $C_{1 s}$ of the principal hydrocarbon-type carbon peak fixed at $285.0 \mathrm{eV}$ as an internal reference. A curve deconvolution technique was employed to find the respective chemica, components from the high resolution spectra of each element.

Strips of the various metals were also bonded together using a 1 to 3 mil film of PPS as an adhesive. The strips were $50 \mathrm{~mm}$ long and $15 \mathrm{~mm}$ wide, and the overlapped area was $150 \mathrm{~mm}^{2}$ (10 by $15 \mathrm{~mm}$ ). Lap shear tensile strength measurements of metal-to-metal adhesives were then made in accordance with ASTM Method D-1002.

The results from lap shear bond strength measurements for metal-tometal PPS adhesive joints are shown in Figure 1. The data clearly indicate that the presence of $\mathrm{O}_{2}$ during the curing of the PPS enhances the bonding to SS and CRS substrates, the former yielding the highest value. The PPS/G-S system cured in air exhibited the lowest bond strength.

To clarify the reasons for the above results, XPS was used to analyze failure surfaces prepared by pulling the PPS films from the substrate surfaces by tensile stresses. Reference data were obtained by first determining the 
chemical compositions and states of bulk PPS and the acetone cleaned metal surfaces. These data are given in Table 1 and Figure 2. Referring to Table 1 , the S/C atomic ratio of 0.19 for the $350^{\circ} \mathrm{C}$-cured bulk PPS surfaces was slightly higher than the value of 0.17 computed from the fundamental formula, $-($ S - $) n_{n}$, of PPS. The $S_{2 p}$ core-level spectrum (Figure 2) for the bulk PPS featured a syrmetric curve with a peak at the BE position of 163.8 $\mathrm{eV}$, originating from the $S$ of the $S-C$ bond in the PPS structure. ${ }^{[14]}$ CRS surfaces disclosed the presence of a large amount of oxygen, which can be associ. ated with the formation of $\mathrm{Fe}$ oxides additional to those originally present on the metal. In fact, the main core line at $710.9 \mathrm{eV}$ and the shake-up satellite at a high $B E$ st.te about $8 \mathrm{eV}$ away from the main line in the $\mathrm{Fe}_{2 p 3 / 2}$ region are assignable to the formation of ferric oxide $\left(\mathrm{Fe}_{2} \mathrm{O}_{3}\right)$. ${ }^{[15]}$ As is evident from a high carbon concentration of 58.38 , the SS surface seemed to be covered with carbon-based contaminants which could not be renoved by organic solvents. Regardless of coverage with the $\mathrm{C}$ contaminant, the $\mathrm{Fe}_{2 p 3 / 2}$ spectral feature verified that the underlying $\mathrm{Fe}$ compound was mainly $\mathrm{Fe}_{2} \mathrm{O}_{3}$. The presence of a concentrated $P$ atom suggested that the surface of the galvanized steel used in this study was treated by phosphate. The $2 n_{2 p 3 / 2}$ spectrum for the G-S substrates denoted the presence of a single $\mathrm{Zn}$ component at the $\mathrm{BE}$ position of $1022.1 \mathrm{eV}$. Since this $B E$ value corresponds to $\mathrm{Zn}$ in a $\mathrm{ZnO}$ forination ${ }^{[16]}$, the dominant $\mathrm{Zn}$ compound formed at the outermost surface of G-S was $\mathrm{ZnO}$.

The elemental compositions for failure surfaces obtained by pulling $\mathrm{N}_{2}$ and $\mathrm{O}_{2}$-cured PPS films from a CRS substrate are given in Table 2. In $\mathrm{N}_{2}$, the interface chemistry of the PPS side from the CRS substrate was characterized by a small amount of $\mathrm{Fe}$ and a large amount of $O$ compared with that of the bulk PPS (Table 1), in conjunction with $7.48 \mathrm{~S}$ and $42.58 \mathrm{C}$. Sulfur originating from the PPS was detected on the interfacial substrate surface. Since the $\mathrm{Fe}$ and $O$ elements that remained on the PPS side were associated with the $\mathrm{Fe}_{2} \mathrm{O}_{3}$ and/or the interfacial reaction products, the locus of failure might have occurred in either the mechanically mixed layer of PPS and $\mathrm{Fe}_{2} \mathrm{O}_{3}$, or in the reaction product layer formed by interaction between PPS and $\mathrm{Fe}_{2} \mathrm{O}_{3}$.

Strikingly different results were obtained from the $\mathrm{O}_{2}$-treated samples. Much more $F e$ was left on the interfacial coating sides, and no $S$ was found on the failed CRS sides. Therefore, a cohesive failure mode which occurred through the $\mathrm{Fe}_{2} \mathrm{O}_{3}$ layers close to the PPS was indicated. In terms of achieving a good bond, the introduction of $\mathrm{O}_{2}$ into the interfacial zones seemed to 
promote interactions between the PPS and $\mathrm{Fe}_{2} \mathrm{O}_{3}$. These reaction products appear to be much stronger than those of $\mathrm{Fe}_{2} \mathrm{O}_{3}$ layers.

To support these findings, inspections of the high-resolution $S_{2 p}$ spectra for both the PPS and CRS interfacial sides of $\mathrm{N}_{2}$-treated samples and the PPS interface for the $\mathrm{O}_{2}$-samples were made (Figure 3 ). The asymmetric feature of the resultant $S_{2 p}$ region for the $\mathrm{N}_{2}$-treated PPS interface revealed two resolvable Gaussian components at 161.8 and $163.8 \mathrm{eV}$. From the surface reference spectra (see Figure 2), the shoulder peak at $163.8 \mathrm{eV}$ is attri butable to $S$ in the PPS. Literature datal17] indicate that the principal line at $161.8 \mathrm{eV}$, which represents the main chemical component, can be ascribed to the formation of ferrous sulfide ( $\mathrm{FeS}$ ) as the reaction product at the interfaces between the PPS and the $\mathrm{Fe}_{2} \mathrm{O}_{3}$ in the $\mathrm{N}_{2}$ environment. The shoulder peak near $710.9 \mathrm{eV}$, reflecting the $\mathrm{Fe}$ in the $\mathrm{FeS}^{[18]}$, was also observed in the $\mathrm{Fe}_{2 p 3 / 2}$ region (not shown). Since the negative ion mass spectra (not shown) of the oxidized PPS surfaces indicated the presence of intense sulphur trioxide $\left(\mathrm{SO}_{3}\right)$ signals, such sulphur-related iron compounds can be formed by interfacial gas-solid reactions between the $\mathrm{Fe}_{2} \mathrm{O}_{3}$ and $\mathrm{SO}_{2}$ and $\mathrm{SO}_{3}$ gases emitted from PPS at high temperatures. An additional prominent line was seen at $1.68 .5 \mathrm{eV}$. This corresponds to a shift of about $6.7 \mathrm{eV}$ to the higher BE site than that of FeS on the $\mathrm{N}_{2}$-treated CRS interface. A shift of $6.7 \mathrm{eV}$ is large enough to distinguish the presence of ferrous sulphate $\left(\mathrm{FeSO}_{4}\right)^{[19]}$ from $\mathrm{FeS}$. $\mathrm{FeSO}_{4}$ can be formed through the following reaction ${ }^{[20]}: \mathrm{Fe}_{2} \mathrm{O}_{3}+\mathrm{SO}_{3}+\mathrm{SO}_{2}-2 \mathrm{FeSO}_{4}$. In coinparison with the data from the PPS side, a distinctive $S_{2 p}$ spectral feature can be seen $n$ the $\mathrm{O}_{2}$-treated PPS interface. We concluded that there was no evidence for the presence of $\mathrm{FeS}$ at $161.8 \mathrm{eV}$, while the pronounced peak at $168.5 \mathrm{eV}$, belonging to $\mathrm{FeSO}_{4}$, emerged at the high $\mathrm{BE}$ sites. Since the introduction of an abundance of oxygen promotes the conversion of $\mathrm{SO}_{2}$ to $\mathrm{SO}_{3}{ }^{[21]}$, it is reasonable to rationalize that an enrichment of $\mathrm{O}_{2}$ catalyst induced $\mathrm{SO}_{3}$ gas caused the formation of more $\mathrm{FeSO}_{4}$ than FeS. As a result, the formation of $\mathrm{FeSO}_{4}$ as the interfacial reaction product appeared to be responsible for the development of strong interfacial bonds.

Table 3 shows the elemental compositions at the cross-section areas of the PPS/SS joint system. In $\mathrm{N}_{2}$, the PPS interface removed from the $\mathrm{SS}$ was characterized by the absence of $\mathrm{Fe}$ and the presence of a small amount of 0 . Compared with the SS reference surface (Table 1), the interfacial SS surface had $4.48 \mathrm{~S}$, a higher $\mathrm{C}$ concentration, and lower $\mathrm{O}$ and $\mathrm{Fe}$ contents. The 
detection of $S$ and a higher concentration of $C$ reflected good adhesion of PPS to the $\mathrm{Fe}_{2} \mathrm{O}_{3}$ at the outermost surface of SS. Based upon the absence of $\mathrm{Fe}$ at the PPS side, a cohesive fallure mode, which occurred through the PPS layer adjacent to the $\mathrm{Fe}_{2} \mathrm{O}_{3}$, can be proposed for this joint system. Of particular interest is the chemical compositions at the interfaces of the $\mathrm{O}_{2}$-induced PPS/SS foint: 1) the presence of $S$ atoms in amounts similar to those observed on the PPS side, and 2) the introduction of a large amount of 0 into the SS side. These findings suggested that a substantial amount of interaction products containing $S, O$, and $F e$ atoms remained at the SS side, whereas there were few residual reaction products adhering to the PPS. Thus, the locus of failure appeared to occur through the reaction product layer near the PPS. Figure 4 shows the $S_{2 p}$ region for both interfacial sides after treatment in $\mathrm{N}_{2}$ and $\mathrm{O}_{2}$. The $\mathrm{S}_{2 p}$ spectrum for the PPS interface in the $\mathrm{N}_{2}$-treated joint system features a simple peak containing only a single line at $163.8 \mathrm{eV}$ originating from $S$ in the PPS. There is no indication of peaks at 161.8 and $168.5 \mathrm{eV}$, which reflect the formation of $\mathrm{FeS}$ and $\mathrm{Fe}_{2} \mathrm{O}_{3}$, respectively. In contrast, the emergence of pronounced lines at 161.8 and $169.0 \mathrm{eV}$, while maintaining the major line at $163.8 \mathrm{eV}$, was observed from the SS interface, thereby accounting for a certain amount of reaction products remaining on the interfacial sS surface. Regarding the reaction products, the new peak at $169.0 \mathrm{eV}$, corresponding to a position $0.5 \mathrm{eV}$ higher than that of $\mathrm{FeSO}_{4}$, was associated with the formation of ferric sulphate $\left[\mathrm{Fe}_{2}\left(\mathrm{SO}_{4}\right)_{3}\right]^{[22]}$, which could be generated by the reaction of $\mathrm{Fe}_{2} \mathrm{O}_{3}$ with three moles of $\mathrm{SO}_{3}$ on heating ${ }^{[23]}$. These changes in spectral fea:ures occurred as $\mathrm{O}_{2}$ was introduced into the critical interfacial zones. The particular feature of the $S_{2 p}$ signal at the $S S$ side was an intense single peak at $169.0 \mathrm{eV}$, suggesting that only $\mathrm{Fe}_{2}\left(\mathrm{SO}_{4}\right)_{3}$ as the interaction product was left on the SS side. The weak line at $169.0 \mathrm{eV}$ was also detected from the PPS interface away from the SS.

Considering that the PPS/SS joint system prepared in $\mathrm{O}_{2}$ displayed the highest bond strength in this series of tests, we concluded that the extent of PPS adhesive bonding to metal substrates depends primarily on the species, and on the amount of $\mathrm{S}$-related $\mathrm{Fe}$ compounds formed as interaction products at the critical interfacial contact zones between PPS and the substrate. The reaction products which play a major role in establishing the bond strength have the following order: $\mathrm{Fe}_{2}\left(\mathrm{SO}_{4}\right)_{3}>\mathrm{FeSO}_{4}>\mathrm{FeS}$. Thus, the $\mathrm{O}_{2}$-catalyzed reaction 
products at the interfaces are responsible for the improvement in bond strength of PPS/metal joints.

Table 4 gives the elemental compositions for both interfacial fallure sides in the PPS/G-S joint system. For the sample made in $\mathrm{N}_{2}$, the interfacial PPS surface had a composition closely resembling that of the G-S interface. The detection of a certain amount of $\mathrm{P}, \mathrm{Cr}$, and $\mathrm{Zn}$ on the PPS interface demonstrated that these elements migrate from the substrate to the coating sides during the fallure of the bond. The amount of $\mathrm{Zn}$ detected on the G-S side was considerably greater, and the amounts of $\mathrm{P}$ and $\mathrm{Cr}$ substantially less than those observed on the reference G-S surface (see Table 1). This finding suggested that the $S$ in PPS preferentially reacts with the $Z n$ in the substrate, rather than with $\mathrm{P}$ and $\mathrm{Cr}$. Hence, fallure occurred through the reaction product layers formed at the interface between PPS and G-S. A similar locus of fallure was observed on the $\mathrm{O}_{2}$-treated adhesion sample; the chemical compositions of both fallure surfaces ware similar. The only difference was that more $\mathrm{P}, \mathrm{O}, \mathrm{Cr}$, and $\mathrm{Zn}$ remained in the cross-section, wh.: le the amounts of $\mathrm{S}$ and $\mathrm{C}$ were reduced. In particular, the increased amounts of residual $\mathrm{Zn}$ and $\mathrm{O}$ atoms reflect the formation of oxygen-rich zinc compounds at the interfaces.

To identify the interaction products, we inspected the $S_{2 p}$ region for both the interfacial PPS and G-S surfaces (Figure 5). The resultant $S_{2 p}$ signal for the $\mathrm{N}_{2}$-treated cross-sections had at least two resolvable peaks at 163.8 and $161.9 \mathrm{eV}$. The former, as the major component, revealed the PPS, and the latter was assigned to the formation of S-related zinc compounds as interfacial reaction products. As reported by several investigators ${ }^{[15,19,23]}$, the line emerging at a low BE site, ranging from 160.5 to $162.0 \mathrm{eV}$, commonly relates to metal sulphide compounds. Hence, zinc sulphide ( $\mathrm{ZnS}$ ), reflected by the peak at $161.9 \mathrm{eV}$, was formed by the reaction of $\mathrm{ZnO}$ with $\mathrm{SO}_{2}$ and $\mathrm{SO}_{3}$ gases at the PPS/G-S interfacial regions. Since no Fe from the underlying steel was found on either interfacial side, we believe that the adhesion of the $\mathrm{ZnS}$ phase, formed as a reaction product, to the zinc layer was much poorer than the adhesion of zinc to the steel substrate.

Compared to the $\mathrm{N}_{2}$ sample, a quite different $\mathrm{S}_{2 p}$ signal was obtained from both $\mathrm{O}_{2}$-induced interfacial sides. The distinct spectral features were the growth of a prominent line at the high BE position of $169.5 \mathrm{eV}$, and a considerable attenuation of peak intensity at $161.9 \mathrm{eV}$ at the interfaces. It 
Is well known ${ }^{[24]}$ that when $\mathrm{ZnS}$ is exposed to air at an elevated temperature, oxidation leads to the transformation of $\mathrm{ZnS}$ into zinc sulphate $\left(\mathrm{ZnSO}_{4}\right)$. Assuming that such oxygen catalyzed $\mathrm{ZnS} \rightarrow \mathrm{ZnSO}_{4}$ conversion occurs at the interfaces, the strong line emerging at $169.5 \mathrm{eV}$ was due to the formation of $\mathrm{ZnSO}_{4}$. This conversion correlats directly with the marked decay of the $\mathrm{ZnS}$ Iine at $161.9 \mathrm{eV}$. Therefore, the interfacial $\mathrm{ZnS} \rightarrow \mathrm{ZnSO}_{4}$ phase transition appears to create detrimental boundary layers which play an active role in the catastrophic loss of bond strength of PPS/G-S joint samples prepared in an oxygen environment.

Tests were performed to determine the durability of steel/PPS adhesive bonds after exposure at $80^{\circ} \mathrm{C}$ to a $\mathrm{pH}^{3} \mathrm{H}_{2} \mathrm{SO}_{4}$ solution containing $0.1 \mathrm{M} \mathrm{NaCl}$. All of the edges on the PPS/metal joints were unprotected, thereby making them more susceptible to acid attack in this extremely harsh environment.

Measurements of the lap-shear bond strength were made in triplicate as a function of exposure time. These results, given in Figure 6 , indicate a rapid loss of strength. Compared to an initial bond strength of $6.4 \mathrm{MPa}$, the strength decreased to $4.0 \mathrm{MPa}$ after 1 day and to $0.6 \mathrm{MPa}$ in 8 days. The latter corresponds to a reduction of -908 . Visual examination of the exposed samples prior to the bond strength measurements indicated partial delamination of the PPS filius from the steel.

To elucidate the failure mode of acid damaged PPS/steel interfaces, the chemical composition at the separated PPS and steel interfaces was determined using XPS. These quantitative data are given in Table 5. Comparison with the control indicated that migration of $S$ from the PPS to the steel side and interfacial diffusion of $\mathrm{Cl}$ occurred upon exposure to $\mathrm{H}_{2} \mathrm{SO}_{4}$. There was no indication of $\mathrm{Na}$ resulting from the formation of $\mathrm{Na}$-related sulfur reaction compounds which could possibly diffuse into the interfacial boundary zones. Nevertheless, the locus of failure appeared to occur through the S-incorporated reaction product layers at the interface.

In an attempt to identify the reaction product which caused the bond failure upon acid exposure, the $S_{2, p}$ core-level spectra for both the separated PPS and the steel sides were evaluated. These results are shown in Figure 7. The $S_{2 p}$ region for both sides showed the emergence of a single peak at a $B E$ of $169 \mathrm{eV}$. This location represents a $0.5 \mathrm{eV}$ shift from the BE peak of $168.5 \mathrm{eV}$ for $\mathrm{FeSO}_{4}$ (see Figure 3a) which is formed by interaction between PPS and steel before acid exposure, and may represent the formation of ferric sulphate 


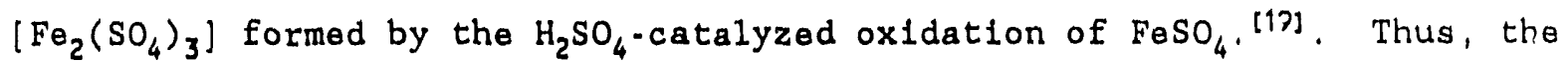
cause for the bond fallure upon exposure to the hot acid solution was the interfacial $\mathrm{FeSO}_{4} \rightarrow \mathrm{Fe}_{2}\left(\mathrm{SO}_{4}\right)_{3}$ phase transition.

Unmodified steel substrates containing PPS films were cathodically tested for perlods of up to 8 days in an alr-covered $1 \mathrm{M} \mathrm{NaCl}$ solution at $20^{\circ} \mathrm{C}$. A very high applied potential of $-1,5$ volts vs. SCE was used in an attempt to accelerate any deterioration process. This equipment is shown schematically in Figure 8. A defect in the PPS coating was made using a 1 mm-diameter drill bit. After exposure, the specimens were removed from the cell and allowed to dry. The PPS coating was then removed by cutting, revealing a delaminated region which appeared as a light gray area adjacent to the defect. After exposure for 1 day, $1.3 \times 10^{3} \mathrm{~mm}^{2}$ of PPS was delaminated from the original sample area of $10^{4} \mathrm{~mm}^{2}$. This progressed to $-6 \times 10^{3} \mathrm{~mm}^{2}$ after 8 days.

In an attempt to gain information regarding the reason for the rapid delamination rate, XPS was used to study both sides of the falled interfaces, For use as unexposed controls, PPS fllms were pulled from steel substrate surfaces by application of tensile forces. Test data from these studies are given in Table 6 . For the controls, the interface at the PPS side removed from the steel substrate consisted of $3.58 \mathrm{~S}, 42.18 \mathrm{C}, 44.08 \mathrm{O}$, and $10.48 \mathrm{Fe}$, The $S$ element refers to $S$ originating from the PPS while $C$ came from the PPS and contaminants. As mentioned earlier, the $\mathrm{Fe}$ and $\mathrm{O}$ elements remaining on the PPS side are associated with the interfacial reacticn products formed by interaction between the PPS coating and $\mathrm{Fe}_{2} \mathrm{O}_{3}$ existing on the steel surfaces. Sulfur was not found on the falled steel side. Thus, it appeared that the locus of fallure occurred through the reaction product layers close to the PPS.

The cathodically delaminated samples produced markedly different results. These differences are as follows: 1) a large amount of $\mathrm{Fe}$ and $\mathrm{O}$ was removed from the interfacial PPS sides, while the concentrations of $S$ and $C$ were markedly increased, 2) a small amount of $S$ remained on the steel sides, and 3) a certain amount of $\mathrm{Na}$ from the $\mathrm{NaCl}$ electrolyte was detected on both the delaminated PPS and steel sides. There was no evidence for the presence of $\mathrm{Cl}$ atoms. The first two results show that the cathodic reaction, $\mathrm{H}_{2} \mathrm{O}+1 / 2 \mathrm{O}_{2}+2 \mathrm{e}^{\circ}-2 \mathrm{OH}^{\circ}$, occurring at the defect in the PPS film, lead to the elimination of Fe-related reaction products. Since the ionic reaction between the $\mathrm{OH}^{-}$ions generated by the cathodic reaction and the $\mathrm{Na}^{+}$ions dissociated 
from the $\mathrm{NaCl}$ electrolyte ylelds a high concentration of $\mathrm{NaOH}$ in the area of the defect ${ }^{[24]}$, it is reasonable to assume that the creation of such an alkali environment at the interfacial regions caused $\mathrm{NaOH}$-catalyzed hydrolysis of the interfacial reaction products. Thus, the detection of $\mathrm{Na}$ atoms at the delaminated interfaces could be due to the penetration of the $\mathrm{NaOH}$ solution through the interfacial layers.

To support this hypothesis, inspections of the high-resolution $S_{2 p}$ corelevel spectra of the PPS and steel interfacial sides of specinens whe made before and after cathodic tests (see Figure 9). The $S_{2 p}$ region for the PPS interface of the control samples revealed two major components at 163.8 and $168.5 \mathrm{eV}$. The former is representative of the principal component, $S$, from the PPS, while the latter reflects the $S$ in the ferrous sulphate $\left(\mathrm{FeSO}_{4}\right.$ ) formed by the Interfacial gas-solid reaction between $\mathrm{Fe}_{2} \mathrm{O}_{3}$ and $\mathrm{SO}_{2}$ and $\mathrm{SO}_{3}$ gases emitted from PPS in air at high temperature. Compared to the control, a marked attenuation of peak intensity at 168.5 eV originating from the $\mathrm{Fe}$ in the $\mathrm{FeSO}_{4}$ reaction product can be observed on spectrum (b) of the cathodically delaminated PPS side. In spectrum (c), which depicts the delaminated steel side, the presence of the weak line at $168.5 \mathrm{eV}$ verifled that a small amount of intermediate $\mathrm{FeSO}_{4}$ adhering to the steel remained at the nterfacial steel side. There was no peak at $163.8 \mathrm{eV}$ which would correspond to PPS. Therefore, the major reason for the extreme cathodic delamination at PPS/steel interfaces cappeared to be the $\mathrm{NaOH}$-catalyzed hydrolysis of $\mathrm{FeSO}_{4}$ adjacent to the steel surfaces.

\section{B. PPS $/ \mathrm{Zn} \cdot \mathrm{Ph} / \mathrm{Steel}$ Interfaces}

St. dies Identical to those described above were conducted using $\mathrm{Zn}$. $\mathrm{Ph}$ modifled steel substrates. The conversion solution used to treat the metal consisted of 1.3 wto $z$ inc orthofhosphate dihydrate $\left[\mathrm{Zn}_{3}\left(\mathrm{PO}_{4}\right)_{2} \cdot 2 \mathrm{H}_{2} \mathrm{O}\right], 2.6$ wto $\mathrm{H}_{3} \mathrm{PO}_{4}, 2.0$ wtz 258 poly (acrylic)acid, $[\mathrm{p}(\mathrm{AA})], 1.0 \mathrm{wtg} \mathrm{Ni}\left(\mathrm{NO}_{3}\right)_{2} \cdot 6 \mathrm{H}_{2} \mathrm{O}$, and 93.1 . wto water. The average molecular weight of the $P(A A)$ polyelectrolyte, supplied by the Rohm and Haas Company, was $-60,000$. Prior to use, the steel was wiped wil. acetone-soaked tissues to remove surface contamination from mill oil.

Conventional zinc phosphate conversion processes generally produce a porous iron phosphate phase which provides 11 ttle resistance to chemical attack. In contrast, the BNL-developed process yields a dense crystalline zinc 
orthophosphate coating which is flexible, ductile, chemical resistant, and chemically bonds to polymeric topcoats.

Applicatiun of the $\mathrm{Zn} \cdot \mathrm{Ph}$ conversion coatings was performed by first immersing the steel in the conversion solution at $80^{\circ} \mathrm{C}$ for up to $20 \mathrm{~min}$. The specimens were then heated in an oven at $350^{\circ} \mathrm{C}$ for $2 \mathrm{hr}$ to form an anhydrous $\mathrm{Zn} \cdot \mathrm{Ph}$ layer. The PPS coating was then applied using the procedures described previously. Since earlier ARO sponsored work at BNL had shown that an anhydrous $\alpha-\mathrm{Zn}_{3}\left(\mathrm{PO}_{4}\right)_{2}$ phase derived from thermal dehydration of a $\mathrm{Zn}$. $\mathrm{Ph}$ hydrate phase had low susceptibility to alkali-catalyzed dissolution[25], Inftial work was to verify the formation of this phase on the test specimens. For analysis purposes, $\mathrm{Zn}$. Ph crystal layers were scraped from the steel surfaces before and after heating in air at $350^{\circ} \mathrm{C}$. The crystals were then ground to a size of 325 mesh $(0.044 \mathrm{~mm})$ and analyzed by X-ray powder diffraction (XRD).

Figure 10 illustrates XRD tracings for the original $\mathrm{Zn} \cdot \mathrm{Ph}$, denoted as sample ( $a$ ), and the anhydrous $\mathrm{Zn}$. Ph (sample b) prepared by heating the original sample at $350^{\circ} \mathrm{C}$. Two hydrous crystal phases were distinguishable in the original $\mathrm{Zn}$. Ph layers; namely, zinc orthophosphate dihydrate $\left[\mathrm{Zn}_{3}\left(\mathrm{PO}_{4}\right)_{2} \cdot 2 \mathrm{H}_{2} \mathrm{O}\right]$ present as the major component and hopeite $\left[\mathrm{Zn}_{3}\left(\mathrm{PO}_{4}\right)_{2} \cdot 4 \mathrm{H}_{2} \mathrm{O}\right]$ as the minor one. The pretominating phase of the anhydrous samples was identical to $\alpha-\mathrm{Zn}_{3}\left(\mathrm{PO}_{4}\right)_{2}$, and $\gamma-\mathrm{Zn}_{3}\left(\mathrm{PO}_{4}\right)$ was present as a secondary phase. This result was in agreement with that obtained in an earlier investigation ${ }^{[25]}$; that is, $\left.\mathrm{Zn}_{3}(\mathrm{PO})_{4}\right)_{2} \cdot 2 \mathrm{H}_{2} \mathrm{O}$ is converted into a $\alpha-\mathrm{Zn}_{3}\left(\mathrm{PO}_{4}\right)_{2}$ phase during hydration, and the $\mathrm{Zn}_{3}\left(\mathrm{PO}_{4}\right) \cdot 4 \mathrm{H}_{2} \mathrm{O}-\gamma-\mathrm{Zn}_{3}\left(\mathrm{PO}_{4}\right)_{2}$ phase transition is favored. Based upon this verification, good durability of the PPS/Zn.Ph/steel system in acid and alkali enviroriments was expected.

Durability tests in which the PPS/Zn. Ph/steel system was exposed to a $80^{\circ} \mathrm{C} \mathrm{pH} 3 \mathrm{H}_{2} \mathrm{SO}_{4}$ solution containing $0.1 \mathrm{M} \mathrm{NaCl}$ for periods of up to 8 days were peltioxmed. These initial results, summarized in Figure 6 , indicated a gradual deduction in bond strength during the first 4 days of exposure. Beyond this time to 8 days, there was 1ittle change. Compared to the data for PPS/steel surfaces, also shown in Figure 6, a significant improvement in durability, with the PPS/Zn.Ph system is apparent. Since the edges of both sets of test specimens were uncoated, the acid solution had direct access to the PPS/metal interface. Thus, the improved durability exhibited by the PPS/Zn.Ph/steel system can be attributed to the added chemical protection 
provided by the $\mathrm{Zn} . \mathrm{Ph}$. This will be Important if pinholes or cracks in the coating occur.

The rosults from cathodic delamination tests performed on PPS/Zn. $\mathrm{Ph}$ specimens are summarized in Figure 11. The method for performing this test was described previously. Also shown in the figure are results from previ. ously reported tests for PPS/steel samples. The PPS/Zn. Ph system exhlbited a delamination area of $-40 \mathrm{~mm}^{2}$ after exposure for 8 days, a value -150 times lower than the PPS/steel control.

In an attempt to gain information regarding the fallure modes, XPS analyses were performed on both interfacial sides of the PPS/Zn. Ph foint systems before and after the cathodic test. These data are given in Table 7. Similar data for the PPS/steel interface were given in Table 6. For the unexposed samples, the interfacial PPS surface had a composition closely resenbling that of the $\mathrm{Zn} \cdot \mathrm{Ph}$ Interface except that $\mathrm{S}$ was not present on the latter. The detection of $\mathrm{P}, \mathrm{Fe}$, and $\mathrm{Zn}$ on the PPS interface indicated that these elements which originated in the $\mathrm{Zn}$. $\mathrm{Ph}$ covered steel substrate, adhered to the PPS during bond fallure. Therefore, failure must have occurred through the $\mathrm{Zn} \cdot \mathrm{Ph}$ layer and not at the PPS $/ \mathrm{Zn} \cdot \mathrm{Ph}$ interface.

A dramatic change in composition was apparent on both interfacial sides after cathodic delamination. As seen in Table 7, significant reductions in $\Gamma$, $O, \mathrm{Fe}$, and $\mathrm{Zn}$ occurred, and $\mathrm{Na}$ was detected. The removal of $\mathrm{P}$ and $\mathrm{Zn}$ may have been due to the dissolution of $\mathrm{Zn}$. $\mathrm{Ph}$ layers caused by the attack of the alkall solution generated by the oxygen reduction reaction at the site of the defect. Since the evolved $\mathrm{OH}^{*}$ Ions lonically react with $\mathrm{Na}^{+}$dissociated from $\mathrm{NaCl}$, the incorporation of $\mathrm{Na}$ relates directly to the penetration of $\mathrm{NaOH}$ yielded by this charge balance into the fallure zones. Such alkali dissolution of the $\mathrm{Zn} \cdot \mathrm{Ph}$ layers was reflected by an increase in concentration of $S$ and $C$ atoms in the PPS. But an important question still remained to be answered. Why was the rate of elimination of Fe-related compounds considerably higher than that of the $\mathrm{Zn} \cdot \mathrm{Ph}$ ? To answer this question, we inspected the high-resolution $\mathrm{P}_{2 \mathrm{p}}$ ' $\mathrm{Zn}_{2 p 3 / 2}, \mathrm{Fe}_{2 p 3 / 2}$, and $\mathrm{s}_{2 p}$ spectra of the cathodically delaminated PPS side and the PPS fallure surface that was made by pulling the PPS film from the $\mathrm{Zn} \cdot \mathrm{Ph}$ before the cathodic tests. Figure 12 illustrates the resultant $P_{2 p}$ and $2 n_{2 p 3 / 2}$ reglons of these samples. The control sample (before cathodic test) denoted as $d$, had a main line at $134.2 \mathrm{eV}$ for the $P_{2 p}$ and at $1023.3 \mathrm{eV}$ for the $7 n_{2 p 3 / 2}$ 
spectra. These reflect the $\mathrm{P}$ and $\mathrm{Zn}$ atoms in $\mathrm{Zn} \cdot \mathrm{Ph}^{[5]}$. Peak features and intensities similar to those of the control were observed for both the $P_{2 p}$ and the $2 n_{2 p 3 / 2}$ regions of the sample (e) after the cathodic tests. In the $\mathrm{Fe}_{2 p 3 / 2}$ region (Figure 13), the control sample (d) displayed a strong signal at the $B E$ position of $710.7 \mathrm{eV}$. This corresponds to the formation of $\mathrm{Fe}_{2} \mathrm{O}_{3}{ }^{[15]}$. Since an electrochemical reaction between the steel and $\mathrm{Zn} \cdot \mathrm{Ph}$ solution at an early stage of $\mathrm{Zn} \cdot \mathrm{Ph}$ precipitation leads to the liberation of free Fe ions from the steel surface ${ }^{[26]}$, it was not surprising that $\mathrm{Fe}_{2} \mathrm{O}_{3}$ was formed by the oxidation of free $\mathrm{Fe}$ present in the $\mathrm{Zn}$. $\mathrm{Ph}$ layers during the $\mathrm{Zn}_{3}\left(\mathrm{PO}_{4}\right)_{2} \cdot 2 \mathrm{H}_{2} \mathrm{O}-\alpha-\mathrm{Zn}_{3}\left(\mathrm{PO}_{4}\right)_{2}$ phase conversion in air at $350^{\circ} \mathrm{C}$ before the PPS coating was deposited. In fact, we observed color changes in the $\mathrm{Zn} \cdot \mathrm{Ph}$ coatings which ranged from a dark gray at $100^{\circ} \mathrm{C}$ to a 1 ight brown at $350^{\circ} \mathrm{C}$. A striking decrease in the $\mathrm{Fe}_{2 \mathrm{p} 3 / 2}$ signal intensity was observed from the cathodically delaminated PPS interface (e) (the reason will be fiscussed later). The $S_{2 p}$ region for the control (d) (see Figure 13) revealed two resolvable components at 163.7 and $162.1 \mathrm{eV}$. The former peak is att:ibutable to the $S$ in the PPS, and the latter belongs to the $S$ in the $\mathrm{FeS}^{[17]}$. This information seemed to suggest that the $\mathrm{SO}_{2}$ gas emitted from the PPS in the vicinity of the $\mathrm{Zn}$. Ph layer preferentially reacted with $\mathrm{Fe}_{2} \mathrm{O}_{3}$ in the $\mathrm{Zn} \cdot \mathrm{Ph}$ layers, rather than with the $\alpha$ - and $\gamma-\mathrm{Zn}_{3}\left(\mathrm{PO}_{4}\right)_{2}$ phases. To confirm this, anhydrous $\mathrm{Zn}$. $\mathrm{Ph}$ coatings were exposed in $\mathrm{SO}_{2}$ gas at $350^{\circ} \mathrm{C}$ (flow rate $\approx 200 \mathrm{cc} / \mathrm{min}$ ) for up to $120 \mathrm{~min}$. The chemical compositions of the exposed coating surfaces were investigated by XPS, and then the internally generated $\mathrm{P}_{2 p}, \mathrm{~S}_{2 \mathrm{p}}, \mathrm{Fe}_{2 p}$, and $\mathrm{Zn}_{2 p 3 / 2}$ peak areas were used to calculate the atomic percent ratios. Figure 14 shows the variation in $\mathrm{P} / \mathrm{Zn}, \mathrm{S} / \mathrm{Zn}$, and $\mathrm{Fe} / \mathrm{Zn}$ ratios as a function of exposure time. The data indicate that the $S / Z n$ ratio increased with exposure time and the $\mathrm{Fe} / \mathrm{Zn}$ ratio decreased. In contrast, the $\mathrm{P} / \mathrm{Zn}$ ratio remained relatively constant. Thus, these data strongly support the idea that $\mathrm{SO}_{2}$ was taken up by the $\mathrm{Fe}_{2} \mathrm{O}_{3}$ present in the $\mathrm{Zn}$. $\mathrm{Fh}$ layers.

Returning to the $S_{2 p}$ spectrum in Figure 13, significant changes in spectral features occurred as the cathodic reaction was initiated at the defect. In particular, the $S_{2 p}$ signal at the cathodically delaminated PPS side (e) was characterized by the appeacance of new peaks at $161.4,166.3$, and $170.0 \mathrm{eV}$. The first was the most intense. Considering that there was so little residual Fe atom at the delaminated PPS side, these new lines did not reflect the formation of $\mathrm{Fe}-\mathrm{related}$ sulfur compounds. However, since a large amount of $\mathrm{Na}$ remained on the delaminated PPS interface, these lines possibly could be 
assigned to Na-related sulfur compounds derived from the cathodic reaction. Assuming that these predicted assignments are correct, other authors [19] have suggested that the predominare line at $161.4 \mathrm{eV}$ is due to the $\mathrm{S}$ in sodium sulphide $\left(\mathrm{Na}_{2} \mathrm{~S}\right)$ as the major by-product of the cathodic reaction. The other lines at 166.3 and $170.0 \mathrm{eV}$ were ascribed to sodium sulphite $\left(\mathrm{Na}_{2} \mathrm{SO}_{3}\right)$ and sulphate $\left(\mathrm{Na}_{2} \mathrm{SO}_{4}\right)$, respectively.

The striking reduction in the $\mathrm{Fe}_{2 p 3 / 2}$ signal (see Figure 13-e) for the cathodically delaminated PPS side was interpreted as follows; the $\mathrm{Fe}_{2} \mathrm{O}_{3}$ in the $\mathrm{Zn} \cdot \mathrm{Ph}$ layer reacted with PPS to form FeS, one of several s-related iron reaction compounds. However, it was very difficult to distinguish the photoelectron line of $\mathrm{FeS}$ from the $\mathrm{Fe}_{2} \mathrm{O}_{3}$ line in the $\mathrm{Fe}_{2 p 3 / 2}$ region, because the signal orifinating from $\mathrm{Fe}$ in $\mathrm{FeS}$ was at a $\mathrm{BE}$ position only $\sim 0.3 \mathrm{eV}$ lower than that of $\mathrm{Fe}_{2} \mathrm{O}_{3}$. Nevertheless, the decreased $\mathrm{Fe}_{2 p 3 / 2}$ signal indicated the loss of a great deal of $\mathrm{FeS}$ caused by $\mathrm{NaOH}$-catalyzed hydrolysis.

The morphology and elemental distribution on the cathodically failed $\mathrm{Zn} \cdot \mathrm{Ph}$ side was investigated using SEM and EDX (Figure 15). As seen in the bottom lert photograph, SEM topography reveals the existence of two distinctive areas; site $A$ represents an acea approximately $1000 \mu \mathrm{m}$ in diameter surrounding the defect, while the cther, site $B$, is at the edge of the delaminated PPS. The $C$ area in the top photograph, which is an enlargement of site $A$, discloses the presence of the PPS adhering localiy to the substrate. As is evident from the EDX elemental data from this region, a small part of the PPS film that remained on the substrate contained not only $S$, but also other elements such as $\mathrm{Na}, \mathrm{Fe}$, and $\mathrm{Zn}$. The EDX spectrum of area D in the same photograph, indicates the presence of only $\mathrm{Fe}$, and relates to the steel substrate. These findings strongly suggest that almost all of the crystalline conversion coating surrounding the defect was dissolved in the $\mathrm{NaOH}$ solution resulting from the cathodic reaction occurring beneath the PPS film. The right-bottom SEM microstructure (an enlargement of site $B$ ) is an image of the morphology of a normal $\mathrm{Zn} \cdot \mathrm{Ph}$ crystal coating, which had not been attacked by $\mathrm{NaOH}$.

A certain amount of the $\mathrm{p}(\mathrm{AA})$ polyelectrolyte that was included in the zinc phosphate conversion coating solution is present at the outermost surface sites of the $\mathrm{Zn} \cdot \mathrm{Ph}$ layers ${ }^{[27]}$. Therefore, it was important to determine if interactions between $\mathrm{P}(\mathrm{AA})$ and PPS occurred. In an attempt to obtain this information, samples were prepared in the following way. First, steel strips 
were dipped for 5 min into a $1.08 \mathrm{p}(\mathrm{AA})$ aqueous solution. The steel was dried in an oven at $350^{\circ} \mathrm{C}$ for $1 \mathrm{hr}$ to transform the $\mathrm{p}(\mathrm{AA})$ macromolecule from the poly(acid), having $\mathrm{COOH}$ pendent groups, to the poly(acid)anhydride having $0^{C} / 8$ and $\mathrm{COOH}$ groups ${ }^{[28]}$. A PPS slurry was then deposited on the poly(acid)anhydride macromolecule film surfaces, followed by curing in air at $350^{\circ} \mathrm{C}$. Finally, the PPS site removed from the poly(acid)anhydride-primed steel was inspected by XPS. Figure 16 shows the XPS spectra for the $C_{1 s}$ region of the bulk PPS film ( $f$ ) and for the interfacial PPS site $(g)$. For the bulk PPS, the single peak at $285.0 \mathrm{eV}$ revealed the aromatic hydrocarbon in PPS. In comparison with the symmetry of the curve for bulk PPS, the curve for samples from the interfacial PPS site had an asymmetric tailing toward the higher $B E$ side. This tail, which separates from the primary peak of aromatic hydrocarbon at $285.0 \mathrm{eV}$, contained at least two resolvable peaks. Based upon published data ${ }^{[29]}$, the lines at 288.1 and $289.3 \mathrm{eV}$ represent the carbon in the carboxyl $(\mathrm{C}=0)$ group and the carboxylic acid $(\mathrm{COOH})$ group, respectively, thereby suggesting that bond failure occurred through mixed layers of PPS and poly(acid)anhydride. Although there was no evidence about the interfacial bond structure and the chemical or physical interactions, it appears that the poly(acid)anhydride macromolecule had a strong affinity for PPS.

The rough surface structure of crystalline $\mathrm{Zn} \cdot \mathrm{Ph}$ is another factor which contributes to the mechanical anchoring of the P.PS polymer. This results from penetration of the melted polymer into the open surface microstructure and microfissures in the $\mathrm{Zn}$. Ph layers. Consequently, the combination of chemical and physical bonds plays a major role in yielding good adhesion at PPS-to- $\mathrm{Zn}$. Ph joints.

Larger-scale durability testing of PPS/Zn Ph/steel systems was started. For use in these tests, the outside surfaces of 12 -mm-diam by $20-\mathrm{cm}$-long tubing were treated with the PPS/Zn. Ph process. The specimens are being exposed in an autoclave to $\mathrm{HCl}$-acidified steam $(\mathrm{pH} 2)$ at a temperature of $200^{\circ} \mathrm{C}$. Weight, dimension, and surface appearance changes are being monitored. To date, after exposure for 2 months, no changes in the diameter and weight of tr.e specimens have been detected, and the surface appearance is unchanged from that of the controls. These tests are continuing. 


\section{PPS/AI Interfaces}

Studies of the interactions at PPS/A1 interfaces were also performed. A 6061-T6 Al sheet which had the following composition was used in these experiments: 96.3 wtz Al, 0.6 wtz S1, 0.7 wtz $\mathrm{Fe}, 0.03$ wtz $\mathrm{Cu}, 0.2$ wto $\mathrm{Mn}, 1.0$ wto $\mathrm{Mg}, 0.2$ wto $\mathrm{Cr}, 0.3$ wtz $\mathrm{Zn}, 0.2$ wtz $\mathrm{TI}$, and 0.2 wtz other. The PPS films was applied by dipping the Al sheet into a slurry consisting of 45 wto PPS and 55 wto 1sopropyl alcohol at $25^{\circ} \mathrm{C}$. The slurry-coated substrates were then heated in air at $350^{\circ} \mathrm{C}$ for $2 \mathrm{hr}$.

Initial analytical studies focused on identification of the interaction products at the interface. The results from XPS analysis of the $S_{2 p}$ core level spectra indicated the presence of aluminum sulfate $\left(\mathrm{Al}_{2}\left(\mathrm{SO}_{4}\right)_{3}\right)$, a hydro. lyzable compound. This was verifled when samples were exposed for 8 days to a $80^{\circ} \mathrm{C} \mathrm{pH} 3 \mathrm{H}_{2} \mathrm{SO}_{4}$ solution containing $0.1 \mathrm{M} \mathrm{NaCl}$. In these tests the bond line between the PPS and AI was directly exposed to the acid environment. Complete separation of the PPS film from the substrate occurred due to the formation of $\mathrm{Al}_{2}(\mathrm{OH})_{4} \mathrm{SO}_{4} \cdot 7 \mathrm{H}_{2} \mathrm{O}$, a reaction product yielded by the hydration of $\mathrm{Al}_{2}\left(\mathrm{SO}_{4}\right)_{3}$.

At first, it would appear that the above results are in contradiction with those obtained earlier at Battelle Columbus. In their tests, Al tubes electrostatically coated with PPS by a commercial firm exhibited good durabil. ity when exposed to a condensing flue gas environment. [2] This result verifies the acid resistance of the PPS. Since in the BNL tests, the PPS/AI in. terface was intentionally exposed to hot acid, thereby simulating a pinhole or a joint, susceptibility of the interface to attack was demonstrated. Since pinholes or cracks in coatings often occur, these results indicate the necessity of surface modification and tailoring of the PPS to avoid direct contact of PPS with A1. These studies will commence next year.

\section{PZS/AI Interfaces}

Another approach being considered for providing corrosion protection to aluminum and steel substrates is the use of inorganic polymetallosiloxane (PMS) films ${ }^{[30,31]}$. These films are produced by the pyrolysis of sol precursor-induced organopolymetallosiloxane xerogels. The chemical components of the precursor solutions consist of monomeric organosilanes, metal alkoxides $\left[\mathrm{M}_{\left(\mathrm{OC}_{3} \mathrm{H}_{7}\right)}\right)_{4}$ where $\mathrm{M}$ is $\left.\mathrm{Zr}, \mathrm{TI}, \mathrm{Ge}\right]$, methanol, water, and hydrochloric acid.

Studies were started to investigate th characteristics of polyzirconosiloxane (PZS) coating films derived from two-step, acid-base-catalyzed pre. 
cursors consisting of $\mathrm{N}-[3-(\operatorname{triethoxysily1)propy1]-4,5-dihydroimidazole~}$ (TSPI), $\mathrm{Zr}\left(\mathrm{OC}_{3} \mathrm{H}_{7}\right)_{4}$, methanol, and water, over a broad pH range of 1.0 to 13.0 . To understand the characteristics of the sol precursors and sol-derived coating films, the work was focused on the electrostatic properties of colloidal states as a function of $\mathrm{pH}$, on thermal behavior (changes in molecular structure at temperatures up to $300^{\circ} \mathrm{C}$ ), microstructural images, elemental compositions, water wettability of the xerogel, and on pyrolyzed xerogel films. These data will then be correlated with the effectiveness of the PZS films to provide corrosion protection to aluminum.

N-[3-(iriethoxysily1)propyl]-4,5,-dihydroimidazole (TSPI), and zirconium (IV)-isopropoxide $\left[\mathrm{Zr}\left(\mathrm{OC}_{3} \mathrm{H}_{7}\right)_{4}\right]$ were used as network-forming monomeric materials. A film-forming mother-1iquor, which served as the precursor solution, was prepared by incorporating a TSPI- $\mathrm{Zr}\left(\mathrm{OC}_{3} \mathrm{H}_{7}\right)_{4}$ mixture into a methyl alcohol/water mixture containing $\mathrm{HCl}$ as a hydrolysis accelerator. HClcatalyzed hydrolysis of the alkoxy groups in the TSPI and $\mathrm{Zr}\left(\mathrm{OC}_{3} \mathrm{H}_{7}\right)_{4}$ provided a clear colloidal precursor solution. To increase the $\mathrm{pH}$ of the acid solution, $\mathrm{NaOH}$ was added to the mother-liquors as a condensation promoter. Table 8 shows the compositions of the precursor solutions prepared using the twostep acid-base-catalyzed method, as a function of $\mathrm{pH}$.

The Al was then coated with PZS xerogels using the following sequence. First, the metal surface was wiped with acetone-soaked tissues to remove any gross surface contaminants. The substrate was then dipped into the colloidal precursor solution at ambient temperature. After dipping, the substrate was withdrawn slowly from the soaking bath, and then preheated in an oven for 30 min at $100^{\circ} \mathrm{C}$ to yleld a xerogel coating film. The film was subsequently pyrolyzed for $30 \mathrm{~min}$ in air at temperatures of $250^{\circ}-300^{\circ} \mathrm{C}$.

The stability of the sol precursor solutions was determined using a Micrometrics Zeta Potential Analyzer. Important physico-chemical factors for the original xerogel and pyrolyzed xerogel films such as thermal decomposi. tion, microstructure, elemental components, and chemical conformation and profiles, were obtained using TGA, DTA, IR, XRD, SEM, EDX and AES. The wettability by water of the film surfaces formed at temperatures up to $300^{\circ} \mathrm{C}$ was determined by measuring the contact angles. Electrochemical corrosion tests were also conducted.

As the initial phase of this work, studies were performed to determine the best conditions for producing the sol precursor solutions. Measurements 
of the Zeta potential ( $z-p$ ) (the electric potential at the boundary between the particle surface, charged by electrochemical adsorption of atmospheric ions, and the surrounding electrolyte medium) were used in these determina. tions. Figure 17 shows the effect of $\mathrm{pH}$ on the $z-p$ values for the precursor solutions. It was known from earlier BNL studies ${ }^{[30]}$ that the addition of $\mathrm{HCl}$ to the solution promotes the hydrolysis of: both the monomeric TSPI and $\mathrm{Zr}\left(\mathrm{OC}_{3} \mathrm{H}_{7}\right)_{4}$; then, the monomeric species containing hydroxyl groups is produced. Such a hydrolysis-induced monomeric species is slowly converted into a polymeric cluster by alcohol- or water-producing condensation reactions between the hydrolysates. The particle size of these clusters in an aqueous solution may range from $\approx 1$ to $\approx 20 \mathrm{~nm}$.

Referring to Figure 17 , at $\mathrm{pH} 1.1$ the protons, $\mathrm{H}^{+}$, in the solution attack the negative hydroxyl groups on the cluster particles. Consequently, the overall net effective charge on the polydispersities measured $+25.7 \mathrm{mV}$. When $\mathrm{NaOH}$ was incorporated into this acid precursor solution, the presence of $\mathrm{OH}^{*}$ led to a charge reversal. As shown, the $z-p$ value decreased with increased $\mathrm{pH}$ of the solutions. The isoelectric point (IEP), where there is no net charge (zero $\mathrm{mV}$ of $\mathrm{z}-\mathrm{p}$ ) on the particle surfaces, occurred around $\mathrm{pH} 9.5$. With further increase in $\mathrm{pH}$, the $z-\mathrm{p}$ charge became negative. Beyond a $\mathrm{pH}$ of 11.5 , the surface charge shifts to near zero potential in the negative regions.

To better understand these data, the microstructure of xerogel films deposited on the Al substrates was observed with SEM. The films were prepared in a vacuum oven at $70^{\circ} \mathrm{C}$. The surface images of films from sols with pHs ranging from 1.1 to 11.5 , are shown in Figures 18 and 19 . The SEM micrograph (Figure, 18a) of the $\mathrm{pH} 1.1$ sol-derived xerogel displays the continuous features of a smooth transparent film. This suggests that inter-cluster crosslinking leads to the formation of transparent: xerogels. As seen in Figure 18b, an increase in the $\mathrm{pH}$ from 1.1 to 2.6 resulted in a change in morphology. Two different cluster species, a randomly distributed branch-type polymer, and a transparent-type polymer, are apparent. With a sol of pH 8.6, which is near the IEP, the microtexture of the film (Figure 19c) disclosed a compacted version of highly branched clusters which completely covered the Al. substrate. There were no transparent-type clusters present. This change implies that, under basic conditions, the condensation reaction is much faster, and quickly consumes newly generated monomeric species. Such 
progression of condensation on the peripheral sites of growing branches leads to the formation of strong interclusters, in terms of the fractal polymeric clusters. Thus, use of a combination of acid and base catalysts promotes decoupling between hydrolysis and condensation. However, the incorporation of an excessive amount of $\mathrm{NaOH}$ which gives a very high rate of condensation, resulted in the formation of an entirely different xerogel. At $\mathrm{pH} 11.5$, the SEM Image (Figure 19d) showed that the film had a large number of microcracks. We belleve that highly progressive condensation leads to bond breakage and reformation of the primary building polymer conformation caused by the deprotonation of hydroxylated cluster species. These results verified that the chemical nature of the sol strongly depends on the $\mathrm{pH}$ of the solution. A stable sol, with a substantially larger polymeric cluster, can be prepared in near zero $z \cdot p$ regions on the positive side.

Before surveying the properties of pyrolyzed PZS films deposited on Al substrates, we investigated the thermal behavior of $\mathrm{Zr}$-incorporated organosilanes derived from sols with different pHs, using TGA-DTA. Figure 20 illustrates TGA and DTA curves which reveal the decomposition characteristics during pyrolysis of samples of $150^{\circ} \mathrm{C}$-preheated xerogel powders. All of these samples displayed a slight weight loss in the initial temperature range of $30^{\circ}$ to $100^{\circ} \mathrm{C}$. This weight loss, which is associated with the endothermic peak at $70^{\circ} \mathrm{C}$, may reflect the liberation of moisture chemisorbed onto the dried xerogels. The curves indicated that the amount of molsture liberated decreased with increasing $\mathrm{pH}$ of the sol. This suggests that the highly condensed xerogels formed by adding a $\mathrm{NaOH}$ catalyst are not susceptible to moisture attack. The TGA curve for the sol-derived xerogel samples at $\mathrm{pH} 1.1$ indicated that there are three decomposition states; the first begins at the onset temperature $\left(\mathrm{T}_{\mathrm{d} 1}\right)$ near $250^{\circ} \mathrm{C}$, the second occurs between $\approx 380^{\circ}$ and $\approx 470^{\circ} \mathrm{C}$, and the third from $\approx 500^{\circ}$ to $\approx 610^{\circ} \mathrm{C}$. The first and second decompositions, reflecting the DTA endothermic peaks at $320^{\circ}$ and $420^{\circ} \mathrm{C}$, respectively, are due to the removal of hydrocarbon species from the xerogels. The third, corresponding to the DTA peak at $550^{\circ} \mathrm{C}$, may be caused by the elimination of excess carbon species. Beyond the pyrolyzing temperatures of $\approx 610^{\circ} \mathrm{C}$, there was little weight loss with temperature. Compared to the TGA curve for the pH 1.1 sample, the curves for the $\mathrm{NaOH}$-incorporated samples change shape. There are three notable differences: 1) an increase in the $\mathrm{pH}$ of the sol. lowers the onset of thermal decomposition temperature in the third stage, 2) the 
intensity of the DTA peak at $420^{\circ} \mathrm{C}$, corresponding to the second decomposition, decreases significantly, and 3 ) the total weight loss of samples at $610^{\circ} \mathrm{C}$ decreases with increasing $\mathrm{pH}$. These findings imply that $\mathrm{NaOH}-\mathrm{catalyzed}$ condensation plays an important role in forming xerogels that contain low concentrations of removable carbonaceous groups and moisture, and in promoting the conversion of organic-inorganic mixed phases into an inorganic phase at a relatively low temperature.

The above information was considered when xerogel films were deposited on Al substrates. Films dried at $100^{\circ} \mathrm{C}$ had a thickness as measured with a surface profile system, that ranged from 0.6 to $1.2 \mu \mathrm{m}$. The pyrolytic changes and rearrangement in conformation of $100^{\circ} \mathrm{C}-$ sintered film samples at $300^{\circ} \mathrm{C}$ were investigated with specular reflectance IR. Figure 21 shows the IR absorption spectra over the wavenumber region of 1350 to $700 \mathrm{~cm}^{-1}$ for such films from sols with pHs up to 12.8 . The spectrum of the $\mathrm{pH} 1.1 \mathrm{film}$ (a) had six pronounced bands. As described previously ${ }^{[30]}$, HCl-catalyzed hydrolysis of TSPI promotes the cleavage of the $\mathrm{N}-\mathrm{CH}_{2}$ linkage. Breakage of this bond then leads to the formation of the imidazoline derivative and organosilanol compounds containing $\mathrm{Cl}$-substituted end groups. Thus, the band at $1300 \mathrm{~cm}^{-1}$ is due to the $\mathrm{Zr}-\mathrm{O}-\mathrm{C}$ Iinkages formed by the dehydrochlorinating reaction between the $\mathrm{Cl}$. substituted end groups in the organosilanol and the hydroxy groups in the hydrated $\mathrm{Zr}$ compounds. In an IR study of alkall silfcate glass, several investigators ${ }^{[32-34]}$ reported that the band near $940 \mathrm{~cm}^{-1}$ reveals the stretching vibration of $\mathrm{Si}-\mathrm{O}$ in the $\mathrm{Si- \textrm {O } ^ { * }} \mathrm{M}^{+}$( $\mathrm{M}$ : alkali metals) groups containing nonbridging oxygens. Therefore, the peak at $930 \mathrm{~cm}^{-1}$ may be due to the nonbridging si-O stretching mode in the $\mathrm{S1}_{-0^{*}} \mathrm{Zr}^{+}-$groups. The other four bands are assigned to the following absorbing species: the Si-C band stretching in the Si-joined propyl groups at $1190 \mathrm{~cm}^{-1[35]}$, the $S i-0-C$ stretching in the Siethoxide at $1100 \mathrm{~cm}^{-1}[36]$, and the asymmetric and symmetric stretchings of $\mathrm{Si}$. $0-S i$ linkages at 1030 and $770 \mathrm{~cm}^{-1}$, respectively ${ }^{[37,38]}$. The Si-0-S1 1inkages reflect the formation of polymeric organosiloxane, induced by dehydratingpolycondensation reactions between the neighboring silanol functions. As reported by some investigators ${ }^{[39-41]}$, the dehydrating condensation reactions between the hydrous zirconias $(2 \mathrm{r}-\mathrm{OH})$ containing non-bridging hydroxo groups allow the formation of $\mathrm{Zr}-\mathrm{O}-\mathrm{Zr}$ linkages. The absorption band pertinent to this linkage occurs at $710 \mathrm{~cm}^{-1}$. However, no such $\mathrm{Zr}-0-\mathrm{Zr}$ band was found in this spectrum. 
When $\mathrm{NaOH}$ was added to the acid-catalyzed sol at 10.48 by weight of total amount of TSPI and $\mathrm{Zx}\left(\mathrm{OC}_{3} \mathrm{H}_{7}\right)_{4}$, striking changes occurred in the spectral. features. These are shown in Figure 21-b. Compared with the spectrum at $\mathrm{pH}$ 1.1: 1) there was a decrease in the intensities at $1300,1190,1100$, and 770 $\mathrm{cm}^{-1}$, and 2) there was a shift in the S1-0-Si absorption band at $1030 \mathrm{~cm}^{-1}$ and the S1-0 $\mathrm{Zr}^{+}$- band at $930 \mathrm{~cm}^{-1}$ to $1010 \mathrm{~cm}^{-1}$ and $960 \mathrm{~cm}^{-1}$, respectively. Referring to the first change, a further decrease in the intensity of these frequencies was observed as the $\mathrm{pH}$ of the sol was increased. The disappearance of $\mathrm{Zr}-0-\mathrm{C}$ groups at $1300 \mathrm{~cm}^{-1}$ can be seen in the spectra ( $d$ and e) of films made at $\mathrm{pH} 11.5$ and 12.8. Since the bands around $970 \mathrm{~cm}^{-1}$ are attribut. able to the vibrational mode involving the oxygen-bridging Si-0-metal Iinkages ${ }^{[42,43]}$, we believe that the shift in the band to $960 \mathrm{~cm}^{-1}$ (the second result), reveals the conversion of the nonbridging $\mathrm{Si}-0^{*} \mathrm{Zr}^{+}$groups into bridged Si-0-Zr linkages. The spectrum (c) for the $\mathrm{pH} 8.6$ film showed that the Si-0-Zr band at $960 \mathrm{~cm}^{-1}$ shifts further to high frequency sites. Special attention was paid to the changes in intensity of the shifted Si-O-Si and Si$0-\mathrm{Zr}$ bands as a function of the $\mathrm{pH}$ value of the sol. Namely, the Si-0-Zr band becomes stronger than that of Si-O-Si, while the intensity of both bands grows markedly with increasing $\mathrm{pH}$.

These IR results strongly suggest that the highly progressive condensation of $\mathrm{Zr}$-incorporated organosilane, brought about by adding a large amount of $\mathrm{NaOH}$ catalyst, not only preferentially promotes the formation of $\mathrm{Si}-0 . \mathrm{Zr}$ linkages rather than Si-0-Si linkages in the organopolyzirconosiloxane structures, but also leads to the formation of $100^{\circ} \mathrm{C}$-volatilizable by-products such as alcohol and water. The latter is reflected directly in the TGA-DTA data; the weight loss of $150^{\circ} \mathrm{C}$-treated high $\mathrm{pH}$ xerogels is much lower than that of low $\mathrm{pH}$ xerogels.

Figure 22 shows the IR spectral features of $300^{\circ} \mathrm{C}$-pyrolyzed xerogel films. The spectral structures of the $\mathrm{pH} 1.1 \mathrm{film}$ (a), differ from those of the $100^{\circ} \mathrm{C}$-preheated sample in the following ways: 1) the elimination of the peaks at frequencies of 1300 and $1190 \mathrm{~cm}^{-1}$ which originate from the $2 \mathrm{r}-0-\mathrm{C}$ and $\mathrm{Si}-\mathrm{C}$ bands, respectively, 2) a shift in the absorption of the Si-0-C band, while its peak intensity becomes much weaker, and 3) a shift in the Si-O $\mathrm{Zr}^{+}$ = band from 930 to $970 \mathrm{~cm}^{-1}$. The first two results are indicative of the removal of many carbonaceous groups from the polymeric organozirconosiloxane network. Such pyrolytic phenomena will lead to the third result, namely, the 


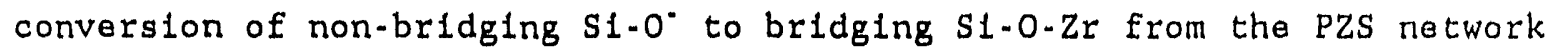
structure at $300^{\circ} \mathrm{C}$. For all of the $\mathrm{NaOH}$ catalyst-induced fllms, spectral features resembling those for the $100^{\circ} \mathrm{C}$-dried films can be seen in the frequency ranges of 1100 to $900 \mathrm{~cm}^{-1}$. The peak absorbance of the Si-0. $\mathrm{Zr}$ band at 970 $\mathrm{cm}^{-1}$ grows conspicuously with an increase in concentration of $\mathrm{NaOH}$, suggesting that the extent of densification of Si-0-Zr linkages in the formed PZS filing is strongly related to the $\mathrm{pH}$ of the sol. On the other hand, the signal intensity of the Si-0.S1 band at $1010 \mathrm{~cm}^{-1}$ declines with an increase in $\mathrm{pH}$. Figure 23 shows SEM micrographs for vallous $100^{\circ} \mathrm{C}$-sintered films after pyrolysis for $30 \mathrm{~min}$ at $300^{\circ} \mathrm{C}$. Although unfform-continuous coating filins were produced from the $100^{\circ} \mathrm{C}-\mathrm{sintered} \mathrm{pH} 1.1$ xerogel, (see Figure 18-a), pyrolysis at $300^{\circ} \mathrm{C}$ led to the development and propagation of microcracks and local sepa. ration of the film from the substrate. The mafor cause for this failure was assumed to be the pyrolytic liberation of a relatively large amount of carbonaceous species from the sintered films. This induces large stress cracks caused by the high degree of shrinkage in the film layers. Surface microstructures similar to those of the $100^{\circ} \mathrm{C}$-dried films were observed for films produced at pHs ranging from 2.2 to 8.6 . In considering the ability of these coatings to provide corrosion protection, the dense microstructure of fractal clusters linked together ( $c$ and $d$ ) that was seen in films derived from sols at $\mathrm{pH} 7.1$ and 8.6 , is of particular interest. There was no evidence of film damage, nor of local separation of the film from the substrate. In addi. tion, there was no evidence of porosity created by the packing of these frac. tal clusters, which suggests that they are space-filing. In contrast, an undesirable porous film which had many crater-like pits, was fabricated from the sol at $\mathrm{pH} 12.8$ (see Figure 23 ?. The degree of densification of the S1. $0-\mathrm{Si}$ and $\mathrm{Si-O-Zr}$ linkages in the xerogel structures seem to have a strong influence on the film-forming performance of the pyrolyzed PZS xerogels. Extremely dense S1-O-Zr linkages resulted in poor cluster films. Therefore, the proper proportions of S1-O-SI and S1-O-Zr are important factors in produc. ing good films. These can be produced using $\mathrm{pH} 7.1$ and 8.6 sols.

Figure 24 gives the EDX spectra for $300^{\circ} \mathrm{C}$-pyrolyzed film surfaces at pH 1.1, 2.6, and 8.6. The spectrum identified as (a) which is for a pH $1.1 \mathrm{ftim}$, had three prominent lines which correspond to Si, $\mathrm{Zr}$, and $\mathrm{Cl}$. The Si and $\mathrm{Zr}$ elements relate to the PZS, while the Cl originated from the HCl used as a hydrolysis promoter for the alkoxy groups in the TSPI and $\mathrm{Zr}\left(\mathrm{OC}_{3} \mathrm{H}_{6}\right)_{4}$. When 
the pH of this HCl catalyst-induced sol was adfusted to 2.6 by adding NaOH, the spectral structure (b) was characterized by a large increase in the stgnal. intensity of $\mathrm{Cl}$, and the Immergence of $\mathrm{Na}$. Further addition of $\mathrm{NaOH}$ to the sol system [Spectrum (c)] resulted in Increased intensification of both lines. Thus, acceleration of the rate of the condensation reaction by the addition of $\mathrm{NaOH}$ not only increases the densification of S1-0-Zr 1inkages, but also pro. motes the formation of Na-related Cl compounds as by-products in the PZS layers.

To 1dentify the phase of such a by-product, the same samples used in the EDX Inspections were examined by XRD over the diffraction range 0.509 to $0.154 \mathrm{~nm}$. These results are shown in Figure 25. For the pH 1.1 film [Pattern (a)], no peaks were detected, thereby indicating that the PZS was essentlally amorphous. In contrast, reflections at $0.326,0.282,0.199$, and 0.163 nm were observed in the film produced from the $\mathrm{pH} 2.6$ sol [Pattern (b)]. These spacings clearly reveal the formation of hallte (crystalline $\mathrm{NaCl})^{[44]}$. Increasing the $\mathrm{pH}$ to 8.6 (c) resulted in further intensiflcation of these spacings.

Therefore, the addition of $\mathrm{NaOH}$ to the HCl-catalyzed sol systems leads to the formation of well-crystalized halite particles in the amorphous PZS layers. Since $\mathrm{NaCl}$ is an electrolyte species which promotes the corrosion of metals, the presence of $\mathrm{NaCl}$ in the films is undesirable. Fortunately, it can readily be eliminated by rinsing the film with the water. This was shown by ringing a $\mathrm{pH} 8.6 \mathrm{fl} 1 \mathrm{~m}$ with tap water. The subsequent EDX spectrum coupled with a SEM micrograph revealed no $\mathrm{Na}$ and only a weak $\mathrm{Cl}$ line. In addition, there were no specific changes in the morphology and topography of the fllm. These results are shown in Figure 26.

To further demonstrate that the $\mathrm{NaCl}$ by product can be removed from the PZS layers, the depth-elemental composition profile in water-ringed pH 8.6 film layers and in PZS/A1 interfacial reglons was determined using AES in confunction with Ar ion sputter-etching. The sputter rate for the depth profiling was $-30 \mathrm{~nm} / \mathrm{min}$. Figure 27 depicts the changes in auger peak heights of: representative elements such as $0, \mathrm{S1}, \mathrm{Zr}, \mathrm{Cl}$, and $\mathrm{Al}$ versus sputter time for a $\mathrm{pH} 8.6 \mathrm{fllm}$ deposited on A1. The peak helghts of three major elements, 0 , $S 1$, and $\mathrm{Zr}$ which reflect the PZS $\mathrm{f1} 1 \mathrm{~m}$, were gradually reduced as the sputtering time increased. After $27 \mathrm{~m} / \mathrm{n}$, the $\mathrm{St}$ - and $\mathrm{Zr}$-related auger peaks had completely disappeared, while the helght of the 0 slgnal levelied off. The signal of $A 1$, which is associated with the Al substrate, energed at a depth of: 
$-630 \mathrm{~nm}$ from the surface and Inoreased rapldly with sputtering time unt1 it stablilzed after $27 \mathrm{~min}$. The stabilization of the 0 signal and the elimination of $\mathrm{S} 1$ and $\mathrm{Zr}$ atoms suggest that the presence of $\mathrm{A} 1$ and $O$ elements at depths $>810 \mathrm{~nm}$ is due mainly to aluminum oxide phases on the surface of the A1 substrate. Thus, the depth ranging from -630 to $-810 \mathrm{~nm}$ seems to represent a PZS/Al $\mathrm{O}_{3}$ mixed layer in the interfaclal zone. The $\mathrm{Cl}$ at the surface of the filin (zero sputter time) had the lowest peak, corresponding to a minor atomic presence. The helght of the peak decreased with sputter times and then dis. appeared at a depth of $-540 \mathrm{~nm}$. This indicates that there was no $\mathrm{Cl}$ in the PZS layers adjacent to the Al substrate.

In making water-impermeable xerogel films, the magnitude of wettability of the coating's surface by water is one of the most important factors governing good protective performance. Therefore, the water-wettability of xerogel film surfaces was estlmated from the average value of the advancing contact angle on these surfaces. Figure 28 shows a plot of che contact angles as a function of the fllm-treating temperature for a $\mathrm{pH} 8.6 \mathrm{fllm}$. Since a high contact angle correlates with a low rate of wetting, the data show that film surfaces treated at high temperature are less wettable. As the film was exposed to high temperatures, the original hydrophilic xerogel surfaces were converted to hydrophoblc surfaces. The results suggest that PZS films having mintmum water-wetting characteristics can be prepared by pyrolysis at temperatures of $2250^{\circ} \mathrm{C}$.

All of the above data were correlated with the corrosion protection provided by pyrogenic PZS cluster coatings on A1. The corrosion data were obtained from the polarization curves for PZS-coated Al samples exposed to an aerated $0.5 \mathrm{M}$ sodium chloride solution at $25^{\circ} \mathrm{C}$. The typical cathodic-anodic polarization curves exhibited a short Tafel region in the cathodic polarization, but no Tafel region was found at the anodic sites. To evaluate the protective performance of coatings, the corrosion current, $I_{\text {corr }}$, values were measured by extrapolation of the cathodic Tafel slope. Figure 29 1llustrates the variation in the $I_{\text {corr }}$ value for Al. substrates as a function of the treatment temperature for several sol-derived PZS coating filing. The pro. tective ability of the coatings depends primarliy on the pH value of the sol precursors and the treatment temperature of the films. The $I_{\text {corr }}$ value for the coatings preheated at $100^{\circ} \mathrm{C}$ ranged from 1.2 to $1.9 \mu \mathrm{A}$, too high to predict good corrosion protection. The major reason for the poor protection is the 
hydrophilic nature of the coatings. All of these fllms dissolved after they were Immersed in water at $25^{\circ} \mathrm{C}$ for $10 \mathrm{hr}$. Lower current densities were measured for all but the pH 12.8 films treated at $200^{\circ} \mathrm{C}$. As discussed earlier, the filins formed in sol with a high pH (211,5) developed numerous stress cracks, probably caused by the formation of highly condensed polymertc structures. Thus, the $I_{\text {oor }}$ value for the $\mathrm{pH} 12.8$ coatings remalned essentially constant within the range from $100^{\circ}$ to $300^{\circ} \mathrm{C}$. For the other coatings, increasing the treatment temperature to $250^{\circ} \mathrm{C}$ acted to further: reduce the $I_{\text {corr. }}$. Above this temperature, there was only a slight decrease. Therefore, flims treated at temperatures $2250^{\circ} \mathrm{C}$ have the maximum ability to protect Al substrates. In cuntrast, the $I_{\text {corr }}$ of $\mathrm{pH} 1.1$ films tended to increase with increased temperature above $200^{\circ} \mathrm{C}$. This can be assoctated with fallure of the film caused by high shrinkage that is related to the 1 iberation of many carbonaceous groups at elevated temperatures. The lowest $I_{\text {corr }}$ value of $0.5 \times 10^{-1}$, corresponding to the best protection, was measured on the $300^{\circ} \mathrm{C}$-treated $\mathrm{pH} 8.6$ flims. This value was approximately one order of magnitude less than for the $300^{\circ} \mathrm{C}$-treated film at $\mathrm{pH} 1.1$. The ability of $300^{\circ} \mathrm{C}$ treated fllms to protect Al was rated in the following order: $\mathrm{pH} 8.6>7.1>$ $2.6>12.8>1.1$. This finding strongly suggested that a dense PZS fractal cluster coating contalning a proper proportion of S1-0.Si to S1-0-Zr linkages provides an effective corrosion barrier for Al substrates.

\section{VI, MAJOR ACCOMPLISHMENTS}

Elucidation of some of the fundamental interactons that take place at PPS/stee1, PPS/Zn.Ph/stee1, PPS/A1 and PZS/A1 substrate Interfaces upon exposure to harsh acidic and alkaline environments has been accomplished. These clata indicate that thin inorganic and organic polymer coatings have high potentials for use as low-cost corrosion resistant materials in condensing flue gas applications.

\section{MAJOR PROBLEMS ENCOUNTERED}

To date, no major problems have been encountered. The work is on schedule and within the spending rate projections. 


\section{VIII, CONCLUSIONS}

This R\&D effort is being focused to provide information regarding corrosion resistance, heat transfer, material cost, fabrication method and cost, and product reliablifty since each of these is important in the final design and production of a heat exchanger. Results to date indicate that organic and Inorganic-type polymer coating systems applied to low cost metals such as mild steel and aluminum provide good corrosion protection.

Polymeric coatings on heat exchangexs and other types of chemlcal process equipment are used commercialiy on a routine basis, thereby suggesting that their use can be cost effective. Polyphenylene sulfide (PPS) and other types of polyaryl-type polymers such as polyphenylethersulfone (PES) and polyphenyletheretherketone (PEEK) were selected for study in this program due to their high melting points $\left(>295^{\circ} \mathrm{C}\right)$ and acld resistance. All have common chemlcal features consisting of aromatic backbone chains coupled with oxygen, ketones, and/or sulphur. They are commercially avallable and can be applied as coatings using standard spray, dip and fluidized bed processes. When the polymers are mixed with fillers, extrudable composite tubing can be produced.

Although the unit mass cost of high performance organic and pre-ceramic coating materlals is high and the heat transfer properties poor, the thin (micron order) coating sections required and the relative ease of application using a dip and bake process yleld preliminary coating costs of $<10 \mathrm{c} / \mathrm{ft}^{2}$. The thin section and the ability to vary the wetting characteristics of the coating also minimize heat transfer losses. Other advantages accrued by the use of thin coatings are increased flexibility and reduced thermal stresses.

Thin coatings also have the potential for being porous or containing pinholes due to inadequate distribution of the film. Optimization of the corrosion protective ablifty with respect to thickness, upplication method and cost is therefore essential. The ability to reproduce the results on a larger-scale must also be demonstrated.

Composites consisting of high performance polymers used in confunction with high thermal conductivity fillers also offer the potential to significantly reduse the cost of heat exchangers relative to those constructed from high alloy steels or bulk plastics. A thermal conductivity approaching that of stainless steel is attainable and concerns regarding pinholes in thin cont. ings are eliminated. Although fabrication costs will probably be greater than 
those for bulk polymers, processes such as spin casting, extrusion and injection molding can be utilized.

Experimental work for the program was initiated on October 1, 1990. To date, four polymer/metal systems have been investigated. Based upon the studies conducted to date, the following conclusions can be made.

When high-temperature performance PPS polymer coatings are applied directly to cold-rolled steel surfaces, the chemical reaction at $350^{\circ} \mathrm{C}$ between the $\mathrm{Fe}_{2} \mathrm{O}_{3}$ at the outerinost surface of the steel and the PPS in air results in the formation of $\mathrm{FeSO}_{4}$ at the critical interfacial zones. Although the intermediate $\mathrm{FeSO}_{4}$ larers, as interfacial reaction products, play an important role in developing bond strength at the PPS/steel joint, alkali-catalyzed hydrolysis of $\mathrm{FeSO}_{4}$ caused by the cathodic reaction, $\mathrm{H}_{2} \mathrm{O}+1 / 2 \mathrm{O}_{2}+2 \mathrm{e}^{\circ}=2 \mathrm{OH}^{-}$, at any defects in the coating film, will cause catastrophic cathodic delamination of the PPS film from the steel. Therefore, to avoid the direct contact of PPS with steel, a $\mathrm{P}(\mathrm{AA})$-modified $\mathrm{Zn} \cdot \mathrm{Ph}$ conversion coating should be deposited on the steel surfaces. The chemical resistance of this BNL-developed conversion coating is greater than that resulting from magnesium or iron phos. phate systems and gives better adhesion to polymer topcoats. Before applying the PPS, the $\mathrm{Zn}_{3}\left(\mathrm{PO}_{4}\right)_{2} \cdot 2 \mathrm{H}_{2} \mathrm{O}$ which is the major phase in the $\mathrm{Zn} \cdot \mathrm{Ph}$ layers can be converted into an $\alpha-\mathrm{Zn}_{3}\left(\mathrm{PO}_{4}\right)_{3}$ phase by thermal dehydration at $350^{\circ} \mathrm{C}$. This thermal treatment also promotes the transformation of the poly(acid) structure within the $\mathrm{p}(\mathrm{AA})$ into a poly(acid)anhydride, and the oxidation of free $\mathrm{Fe}$ atoms dissociated from the steel surfaces during the precipitation of the crystalline $\mathrm{Zn} \cdot \mathrm{Ph}$ coating. It was also determined that $\mathrm{SO}_{2}$ emitted from the PPS at the PPS-to- $\mathrm{Zn}$. Ph boundary regions preferentially reacts with oxidized $\mathrm{Fe}$ compounds, rather than with $\mathrm{Zn}$ and $\mathrm{P}$ atoms in the $\mathrm{Zn} \cdot \mathrm{Ph}$ crystals. Such a gas-solid interaction between $\mathrm{SO}_{2}$ and the oxidized $\mathrm{Fe}$ compound at $350^{\circ} \mathrm{C}$ causes the formation of a $\mathrm{FeS}$ reaction product. In addition, two other interactions have been observed: one is a polymer-to-polymer reaction between the PPS and the poly(acid)anhydride existing at the outer surface of the $\mathrm{Zn}$. $\mathrm{Ph}$ layers; the other is the physical interlocking associated with the mechanical anchoring of the PPS polymer. This results from the penetration of melted polymer into the open surface microstructure of the $\mathrm{Zn}$. Ph layers. These physico-chemical factors contribute to the development of adhesion force at the PPS/ $\mathrm{Zn}$. Ph interfaces, and are responsible for the high lap-shear bond strength of phosphated metal/PPS/phosphated metal specimens. 
Once a cathodic reaction occurs at a defect in the $\mathrm{PPS} / \mathrm{Zn} \cdot \mathrm{Ph}$ system, the action of $\mathrm{NaOH}$ derived from the cathodic reaction results in the dissolution and hydrolysis of the anhydrous $\mathrm{Zn} \cdot \mathrm{Ph}$ and $\mathrm{FeS}$ interaction product. Such an alkali-induced dissociation results in the formation of Na-related sulfur compounds, such as $\mathrm{Na}-$ sulphide, $\mathrm{Na}-\mathrm{sulphite}$ and $\mathrm{Na-sulphate.} \mathrm{However,} \mathrm{the}$ rate of cathodic delamination of PPS in the PPS $/ \mathrm{Zn}$. Ph system is considerably lower than that in the PPS/steel system.

Adhesive bonds in the PPS/ $\mathrm{Zn} \cdot \mathrm{Ph}$ systems display outstanding durability against attack by hot $\mathrm{H}_{2} \mathrm{SO}_{4}$ solutions containing $\mathrm{NaCl}$. In contrast, the bonds of PPS/steel systems failed after exposure for only 8 days to this hot acid solution. The major reason for this fallure is the $\mathrm{FeSO}_{4} \rightarrow \mathrm{Fe}_{2}\left(\mathrm{SO}_{4}\right)_{3}$ phase transformation in the iatermediate layers. The formation of $\mathrm{Fe}_{2}\left(\mathrm{SO}_{4}\right)_{3}$ may be deduced from the acid-catalyzed oxidation of the $\mathrm{FeSO}_{4}$ reaction product formed at the PPS/steel interfaces.

PPS and PZS coatings were applied to unmodified 6061-T6 aluminum surfaces. With the former, a hydrolyzable compound aluminum sulfate was formed at the PPS/AI interface. Upon exposure of these specimens to a $80^{\circ} \mathrm{C} \mathrm{pH} 3$ $\mathrm{H}_{2} \mathrm{SO}_{4}$ solution containing $0.1 \mathrm{M} \mathrm{NaCl}$, complete delamination of the films occurred within 8 days. Fallure was due to the hydration of the $\mathrm{Al}_{2}\left(\mathrm{SO}_{4}\right)_{3}$ to yield $\mathrm{Al}_{2}(\mathrm{OH})_{4} \mathrm{SO}_{4} \cdot 7 \mathrm{H}_{2} \mathrm{O}$. Surface modification of the Al prior to the application of the PPS appears necessary.

Thin ( $\approx 1$ micron) PZS coatings appear to provide good corrosion protection to Al. These dense and hydrophobic coatings can be formed by hydrolysis. polycondensation-pyrolysis synthesis of acid-base catalyzed sol precursors. When amorphous PZSs were applied to $\mathrm{Al}$ as protective coatings against $\mathrm{NaCl}$ induced corrosion, the most effective film was derived from a sol having a $\mathrm{pH}$ near the isoelectric point in the positive zeta potential region. The following four factors play important roles in producing protective PZS coating films: 1) a proper rate of condensation, 2) a moderate ratio of Si-O-Si to Si-0-Zr linkages in the PZS network, 3) hydrophobic characteristics, and 4) a specific microstructural geometry, in which large fractal clusters are linked together. Xerogel films produced from sols of $\mathrm{pH} 8.6$ and subsequently pyrolyzed at $250^{\circ} \mathrm{C}$ gave the best corrosion protection. 


\section{REFERENCES}

1. Proc, 1987 International Symposium on Condensing Heat Exchangers, Battelle Columbus Laboratories, BNL 52069 and GRI-87/0091.2, Vols. 1 and 2, April 1987.

2. Agrawal, A. K. and Hindin, B. Evaluation of alternative materials for condensing heat exchangers, Final Report, August 1989 - August 1990, Battelle Columbus Division, GRI-90/0219, September 24, 1990.

3. Morra, B. S. and Plucinsky, S. R. High temperature engineering plastics for use in condensing heat exchangers, Proc. 1987 International Symposium on Condensing Heat Exchangers, Battelle Columbus Laboratories, BNL 52068 and GRI-87/0091.2, 235-252, April 1987.

4. Sugama, T., Kukacka, L. E., Carciello, N. R, , and Warren, J, B. Physico-chemical factors affecting hydrothermal resistance and bonding of polymeric composites to steel surfaces, BNL 37376, Nov. 1985.

5. Sugama, T., Kukacka, L. E., Carciello, N., and Warren, J, B. Use of polyacrylic acid electrolytes diffused in zinc phosphate conversion coatings for the corrosion protection of steel, J. of Coatings Technology, Vo1. 61, No. 771, 43-57, Apr. 1989.

6. Sugama, T., Kukacka, L. E., and Carciello, N. Polytitanosiloxane coatings derived from $\mathrm{Ti}\left(\mathrm{OC}_{2} \mathrm{H}_{5}\right)$-modified organosiloxane precursors, Int1. J, Progress in Organic Coatings, 18, (1990) pp. 173-196.

7. Fontana, J. J., Reams, W., and Cheng, H. C. Potential polymer concrete heat exchanger tubes for corrosive environments, BNL 28945, Proc. 5th International Congress on Polymers in Concrete, Brighton Polytechnic, Brighton, U.K., Sept. 1987.

8. Kaeding, A. 0. Polymer concrete lined pipe for use in geothermal applications, Proc. Geothermal Engineering and Materials Program Conference, U.S. DOE, San Diego, 107-112, Oct. 1982.

9. Farnsworth, C. A. Materials and design options for avoiding corrosion in condensing appliance heat exchangers and vent systems, Proc. 1987 International Symposium on Condensing Heat Exchangers, Battelle Columbus Laboratories, BNL 52068 and GRI-87/0091.2, 115-126, Apri1 1987

1.0. Lenz, R. W., Handlovity, C. E. and Smith, H. A. Phenylene sulfide polymers. III. The synthesis of linear polyphenylene sulfide. $J$. Polym. Sci. 58, 351-367 (1962).

11. Port, A. B. and Still, R. H. Synthesis and characterization of poly(phenylene sulfide) poly(2-methylphenylene sulfide), and poly(2,6dime thylphenylene sulfide). J. App1. Polym. Sci. 58, 1145-1164 (1979).

12. Lovinger, A. J., Davis, D. D. and Padden, F. J., Jr. Kinetic analysis of the crystallization of poly(phenylene sulfide) polymer. 26, 1595 . 1604 (1985). 
13. Bolger, J. C. In Adhesion Aspects of Polymeric Coatings, K. L. Mittal, Editor, pp. 3-18, Plenum Press, New York, 1983.

14. Riga, J., Boutique, J. P., Piereaux, J. J., and Verbist, J, J. In Physico-chemical Aspects of Polymer Surfaces, K. L. Mittal, Editor, pp. 45-52, Plenum Press, New York, 1983.

15. McIntyre, N. S. and Zetaruk, D. G. X-ray photoelectron spectroscopic studies of iron oxicles. Anal. Chemi. 49, 1521-1529 (1977).

16. Gaarenstroom, S. W. and Winograd, N. Initial and final state effects in the ESCA spectra of cadmium and silver oxides. J. Chem. Phys. 67, $3500-3506$ (1977).

17. Binder, $H$. Application of $x$-ray photoelectron spectroscopy to the elucidation of the bonding in iron-sulfur compounds. $Z$. Naturforsch., Teil B28, 255-262 (1973).

18. Carver, J. C., Schweitzer, G, K, and Carlson, T. A. Use of x-ray photoelectron spectroscopy to study bonding in chromium, manganese, iron, and cobalt compounds. J. Chem. Phy., 57, 973-982 (1972).

19. Lindberg, B. J., Hamrin, K., Johansson, G., et al. Molecular spectroscopy by means of ESCA [electron spectroscopy for chemical analysis] II. Sulfur compounds. Correlation of electron binding energy with structure. Phys. Scr., 1, 286-298 (1970).

20. Tanabe, K., Hattori, H, and Yamaguchi, T. Surface properties of solid superacids. Critical Rev. Surface Chem., 1, 1-25 (1990).

21. Sneed, M. C. and Maynard, J. L. General Inorganic chemistry. D. Van Norstrand Company, Inc., New York 1952.

22. Moody, B. J, Comparative inorganic chemistry. Edward Arnold Publishers, Ltd. London, 1965.

23. Shalvoy, R. B., Fisher, G. B., and Stiles, P, J. X-ray photoemission studies of the valence bands of nine [group] IV-VI compounds. Phys. Rev. B15, 2021-2024 (1977).

24. Leidheiser, $H$, and Wang, W. Corrosion control by organic coatings. NACE, Houston, 70-77 (1981).

25. Sugama, T. and Pak, J. Adv. Mater. Mfg. Pro, , 6, 227 (1991).

26. Sugama, T., Kukacka, L. E., Carciello, N., and Warren, J, B. J, Mater. Sci, , 22, 722 (1987).

27. Sugama, T., Kukacka, L. E., Carciello, N., and Warren, J. B. J. Mater. Sc1., 23, 101 (1988).

28. Sugama, T., Kukacka, L. E., Clayton, C. R., and Hua, H. C. J. Adhesion Sci. Tech., 1, 265 (1987). 
29. Briggs, D. and Seah, M. P. Practical surface analysis by auger and $x$ ray photoelectron spectroscopy. John Wiley, New York, 385, 1985.

30. Sugama, T., Kukacka, L. E., and Carciello, N. Prog. Org. Coat, , 11, 173 (1990).

31. Sugama, T., Carciello, N, , and Taylor, C. J. Non-Cryst. Solids, (in press).

32. Su, G. J., Borelli, N. F., and Miller, A. R. Phy. Chem. Glasses, 3 , 167 (1962).

33. Gan, F., Huang, G., and S. Chen. J. Non-Cryst. Solids, 52, 203 (1982).

34. Uchino, T., Sakka, T,, and Iwasak1, M. J. Am. Ceram. Sc1., 74, 306 (1991).

35. Smith, A. L. Spectochim. Acta, 16, 87 (1960).

36. Bellamy, L.J. The infra-red sjectra of complex molecules. Chapman and Hall, London (1975).

37. R, Hanna, J, Am. Ceram. Soc, , 48, 595 (1965).

38. Bansal, N. P. J. Am. Ceram. Soc., 71, 666 (1988).

39. Haberko, K. Ceramurgia Int., $\underline{5}, 148$ (1979).

40. Kendall, K., Alford, N. M., and Birchall, J. D. Proc. Br. Ceram. Soc., 37, 255 (1986).

41. Johes, S. L. and Norman C. J. J. Am. Ceram. Soc., 71, c-190 (1988).

42. Best, M. F, and Condrate Sr, , R. A. J. Mater. Sci. Letter, 4, 994 (1985).

43. Lee, S. W. and Condrate Sr., R. A. J. Mater. Sc1., 23, 2951 (1988).

44. Joint Committee on Powder Diffraction Standards, Card 5-628. 
Table 1. XPS Elemental Analysis of Bulk PPS and Substrates as Reference Surfaces.

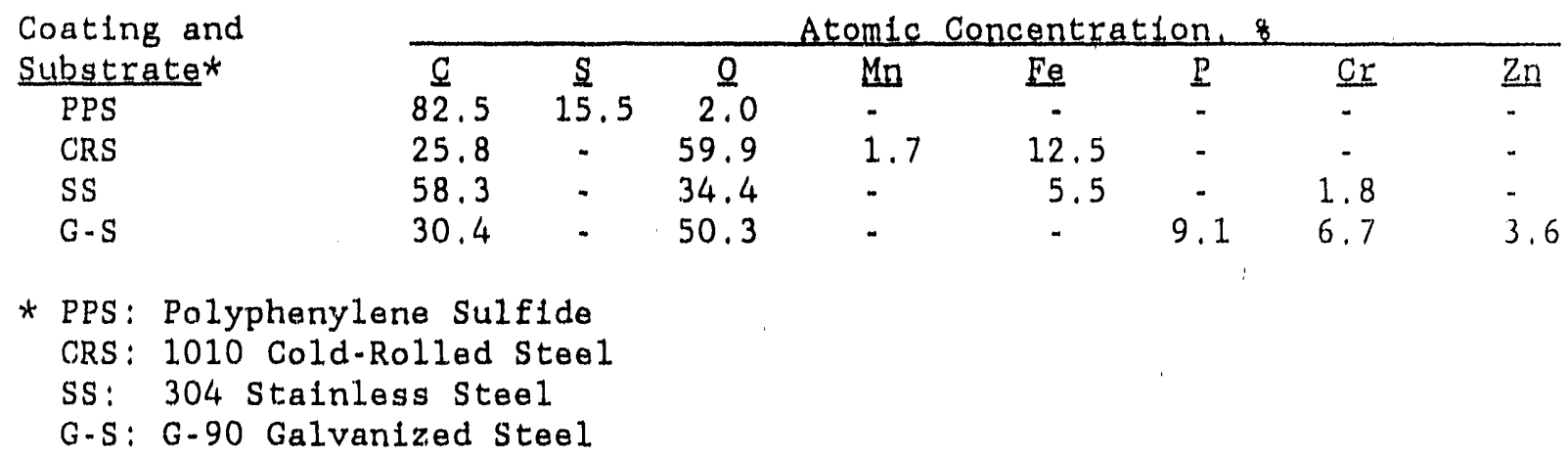

Table 2. Chemical Composition of Both Interfaclal Fallure Sides for $\mathrm{N}_{2}$ - and $\mathrm{O}_{2}$-cured PPS/CRS Joint Systems

\begin{tabular}{cc} 
Heating Environment & Falled Side \\
\cline { 2 - 2 } $\mathrm{N}_{2}$ & PPS \\
in $\mathrm{N}_{2}$ & CRS \\
in $\mathrm{O}_{2}$ & PPS \\
in $\mathrm{O}_{2}$ & CRS
\end{tabular}

\begin{tabular}{ccccc}
\multicolumn{5}{c}{ Atomic Concentration, 8} \\
\hline$\underline{\mathrm{S}}$ & $\underline{\mathrm{C}}$ & $\underline{0}$ & $\underline{\mathrm{Mn}}$ & $\underline{\mathrm{Fe}}$ \\
7.4 & 42.5 & 41.5 & - & 8.6 \\
4.3 & 40.8 & 43.9 & 0.3 & 10.7 \\
3.5 & 42.1 & 44.0 & - & 10.4 \\
- & 31.3 & 55.5 & 0.7 & 12.6
\end{tabular}

Table 3. Elemental Composition of Interfaclal PPS and SS Surfaces at PPS/SS Joints in $\mathrm{N}_{2}$ and $\mathrm{O}_{2}$

\begin{tabular}{cc} 
Heating Environment & Failed Side \\
\cline { 2 - 2 } in $\mathrm{N}_{2}$ & PPS \\
in $\mathrm{N}_{2}$ & SS \\
in $\mathrm{O}_{2}$ & PPS \\
In $\mathrm{O}_{2}$ & SS
\end{tabular}

\begin{tabular}{|c|c|c|c|}
\hline$\underline{\mathbf{S}}$ & $\underline{\mathrm{C}}$ & $\underline{0}$ & $\underline{\mathrm{Fe}}$ \\
\hline 12.7 & 83.9 & 3.4 & - \\
\hline 4.4 & 82.3 & 12.7 & 0.5 \\
\hline 13.3 & 81.0 & 5.6 & 0.1 \\
\hline 14.3 & 24.4 & 56.5 & 4.8 \\
\hline
\end{tabular}

Table 4. Atomic Concentration of $\mathrm{N}_{2}$ - and $\mathrm{O}_{2}$-Treated PPS/G-S Interfaces

\begin{tabular}{|c|c|c|c|c|c|c|c|}
\hline \multirow[b]{2}{*}{ Heating Environment } & \multirow[b]{2}{*}{ Failed Side } & \multicolumn{6}{|c|}{ Atomic Coricentration, 8} \\
\hline & & $\underline{P}$ & $\underline{\mathbf{S}}$ & $\underline{\mathrm{C}}$ & $\underline{\mathrm{O}}$ & $\underline{\mathrm{Cr}}$ & $\underline{\mathrm{Z}}$ \\
\hline in $\mathrm{N}_{2}$ & PPS & 9.3 & 8.3 & $5 \overline{1.0}$ & 24.9 & $\overline{1.1}$ & 5.4 \\
\hline i. $\mathrm{N}_{2}$ & $G \cdot S$ & 10.5 & 7.5 & 48.0 & 26.0 & 1.9 & 6.2 \\
\hline $\operatorname{in~} \mathrm{O}_{2}$ & PPS & 13.6 & 3.2 & 36.0 & 37.0 & 2.3 & 7.8 \\
\hline $\ln \mathrm{O}_{2}$ & $G-S$ & 16.0 & 3.8 & 35.7 & 33.8 & 2.3 & 8.5 \\
\hline
\end{tabular}


Table 5. Atomic Concentration of Falled PPS and Steel Sides Before and After Exposure for 8 Days to $80^{\circ} \mathrm{C}-\mathrm{H}_{2} \mathrm{SO}_{4}$ Solution

$\begin{array}{cc}\text { Exposure to } \mathrm{H}_{2} \mathrm{SO}_{4} & \text { Failed Sides } \\ \text { Before } & \text { PPS } \\ \text { Before } & \text { G-S } \\ \text { After } & \text { PPS } \\ \text { After } & \text { G-S }\end{array}$

\begin{tabular}{cccccc}
\multicolumn{6}{c}{ Atomic Concentration. 8} \\
\hline$\underline{\mathrm{S}}$ & $\underline{\mathrm{C}}$ & $\underline{0}$ & $\underline{\mathrm{Mn}}$ & $\frac{\mathrm{Fe}}{10.4}$ & $\underline{\mathrm{C} 1}$ \\
3.5 & 42.1 & 44.0 & - & - \\
- & 31.3 & 55.5 & 0.7 & 12.6 & - \\
6.7 & 20.9 & 63.0 & - & 7.8 & 1.6 \\
3.1 & 18.4 & 65.0 & - & 11.2 & 2.3
\end{tabular}

Table 6. Chemical Composition of Both Interfaclal Fallure Sides Before and After Cathodic Delamination Tests for PPS/Steel Joint Systems

\begin{tabular}{ccrccccc} 
& & \multicolumn{6}{c}{ Atomic Concentration, 8} \\
\cline { 3 - 8 } Cathodic test & Falled Sides & $\underline{\underline{S}}$ & $\underline{\underline{C}}$ & $\underline{0}$ & $\underline{M n}$ & $\underline{F e}$ & $\underline{\text { Na }}$ \\
\hline Before & PPS & 3.5 & 42.1 & 44.0 & - & 10.4 & - \\
Before & Steel & - & 31.3 & 55.5 & 0.7 & 12.6 & - \\
After & PPS & 10.7 & 80.9 & 6.1 & - & 1.5 & 0.8 \\
After & Steel & 1.3 & 23.3 & 59.6 & 1.3 & 13.3 & 1.2 \\
\hline
\end{tabular}

Table 7. Chemical Composition of Both Interfacial Fallure Sides Before and After Cathodic Delamination Tests for PPS/Zn. Ph Joint Systems

\begin{tabular}{|c|c|c|c|c|c|c|c|c|}
\hline \multirow{3}{*}{$\frac{\text { Cathodic test }}{\text { Before }}$} & \multirow{3}{*}{$\frac{\text { Failed side }}{\text { PPS }}$} & \multicolumn{7}{|c|}{ Atomic Concentration, 8} \\
\hline & & $\underline{p}$ & $\underline{\mathbf{S}}$ & $\underline{\mathrm{C}}$ & $\underline{0}$ & Fe & $\underline{\mathrm{Zn}}$ & $\underline{\mathrm{Na}}$ \\
\hline & & 8.5 & 2.5 & $3 \overline{2} .0$ & $4 \overline{7} .1$ & 6.1 & 3.8 & - \\
\hline Before & $\mathrm{Zn} \cdot \mathrm{Ph}$ & 5.3 & - & 35.9 & 47.7 & 8.1 & 3.0 & \\
\hline After & PPS & 3.4 & 4.1 & 56.2 & 26.9 & 0.4 & 2.1 & 6.9 \\
\hline After & $\mathrm{Zn} \cdot \mathrm{Ph}$ & 2.1 & 1.5 & 56.8 & 31.5 & 0.9 & 2.5 & 4.7 \\
\hline
\end{tabular}

Table 8. Compositions of Sol Precursor Solutions for a pH Range of 1.1 to 12.8

\begin{tabular}{|c|c|c|c|c|c|c|}
\hline & TSPI & $\mathrm{Zr}\left(\mathrm{OC}_{3} \mathrm{H}_{7}\right)_{4}$ & $\mathrm{CH}_{3} \mathrm{OH}$ & Water & $\mathrm{HCl} / \mathrm{TSPI}+$ & $\mathrm{NaOH} / \mathrm{TSPI}+$ \\
\hline $\mathrm{pH}$ & wto & $\begin{array}{c}\text { wt8 } \\
\text { w }\end{array}$ & wt & wt & $\underline{\mathrm{Zr}}\left(\mathrm{OC}_{3} \underline{\mathrm{H}}_{7}\right)_{4}$ & 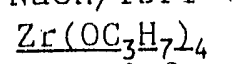 \\
\hline 1.1 & $\overline{7.7}$ & 5.1 & 7.7 & 79.5 & 50.0 & 0.0 \\
\hline 2.6 & 7.7 & 5.1 & 7.7 & 79.5 & 50.0 & 10.4 \\
\hline 7.1 & 7.7 & 5.1 & 7.7 & 79.5 & 50.0 & 14.0 \\
\hline 8.6 & 7.7 & 5.1 & 7.7 & 79.5 & 50.0 & 18.0 \\
\hline 11.5 & 7.7 & 5.1 & 7.7 & 79.5 & 50.0 & 26.0 \\
\hline 12.8 & 7.7 & 5.1 & 7.7 & 79.5 & 50.0 & 39.0 \\
\hline
\end{tabular}


Figure 1. Lap shear bond strength at metal-to-metal PPS adhesive joints after exposure in $\mathrm{N}_{2}$ and $\mathrm{O}_{2}$ at $350^{\circ} \mathrm{C}$.

Figure 2. XPS high-resolution spectra in $\mathrm{S}_{2 \mathrm{p}}, \mathrm{Fe}_{2 \mathrm{p} 3 / 2}$ and $\mathrm{Zn}_{2 \mathrm{p} 3 / 2}$ regions for reference polyphenylene sulfide (PPS), cold-rolled steel (CRS), stainless steel (SS) and galvanized steel (G-S) surfaces.

Figure 3. $S_{2 p}$ spectra at failed interfaces of PPS/CRS joint system prepared in $\mathrm{N}_{2}$ and $\mathrm{O}_{2}$ gases at $350^{\circ} \mathrm{C}$.

Figure 4. $S_{2 p}$ region at interfacial failure locus of PPS/SS joint system.

Figure 5. $S_{2 p}$ spectrz at failure locus in PPS/G-S joint system.

Figure 6. Lap-shear bond strength vs. exposure time to a $80^{\circ} \mathrm{C} \mathrm{pH} 3 \mathrm{H}_{2} \mathrm{SO}_{4}$ solution containing O.M NaCl.

Figure 7. $S_{2 p}$ region for PPS ( $h$ ) and steel (i) interfaces separated by the attack of hot acid solution on the PPS/steel joint.

Figure 8. Schematic diagram of cathodic delamination test.

Figure 9. $S_{2 p}$ core level spectra for the PPS side (a) removed from the steel before cathodic delamination tests, and the delaminated PPS (b) and steel (c) sides after cathodic tests.

Figure 10. XRD tracings for original $\mathrm{Zn} \cdot \mathrm{Ph}$ samples (a), and $350^{\circ} \mathrm{C}$-dehydrated $\mathrm{Zn} \cdot \mathrm{Ph}$ samples (b).

Figure 11. The cathodic delamination of PPS films from steel and $\mathrm{Zn} \cdot \mathrm{Ph}$ deposited steel substrates in $1 \mathrm{M} \mathrm{NaCl}$. 


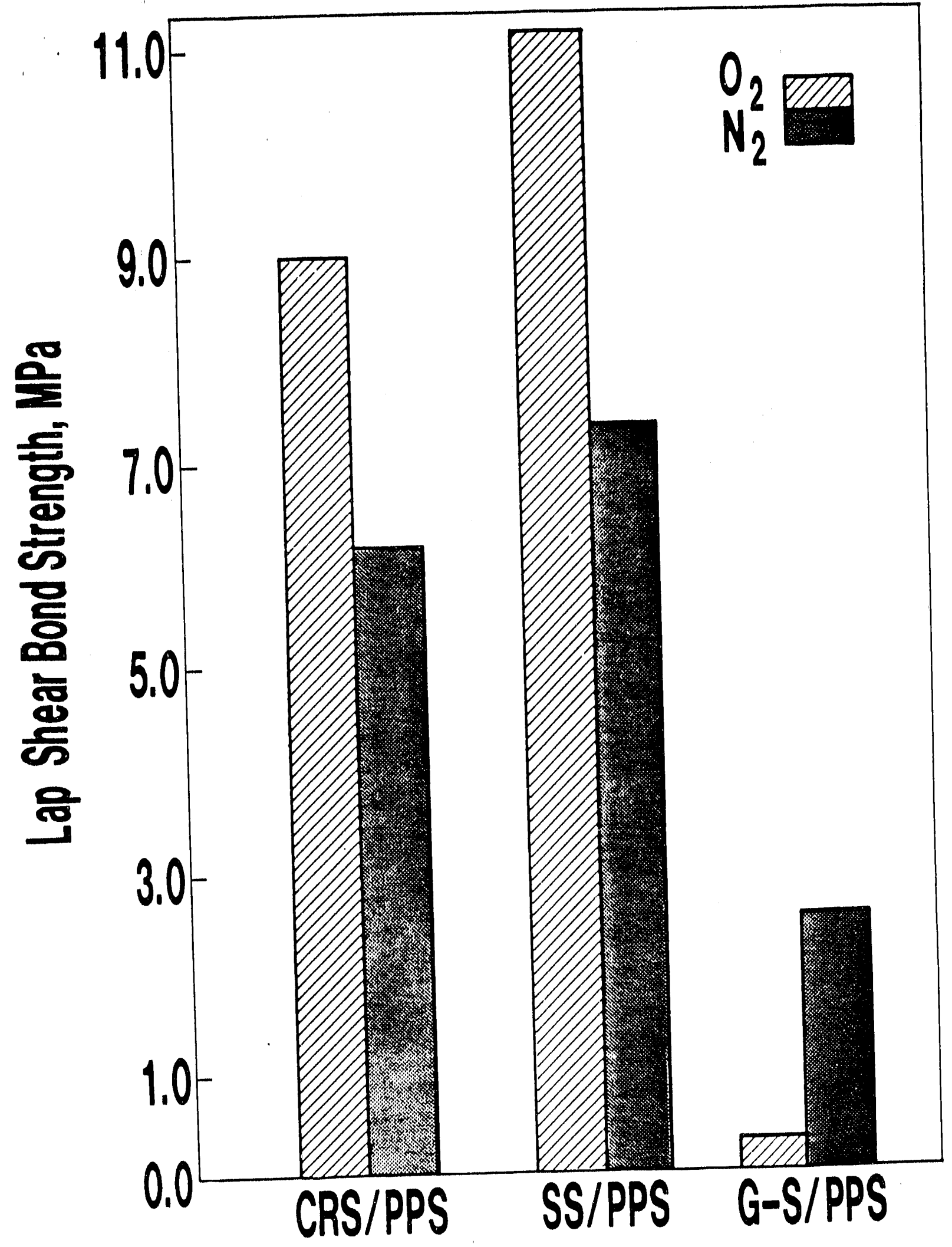

Figure 1. Lap shear bond strength at metal-to-metal PPS adhesive joints after exposure in $\mathrm{N}_{2}$ and $\mathrm{O}_{2}$ at $350^{\circ} \mathrm{C}$. 

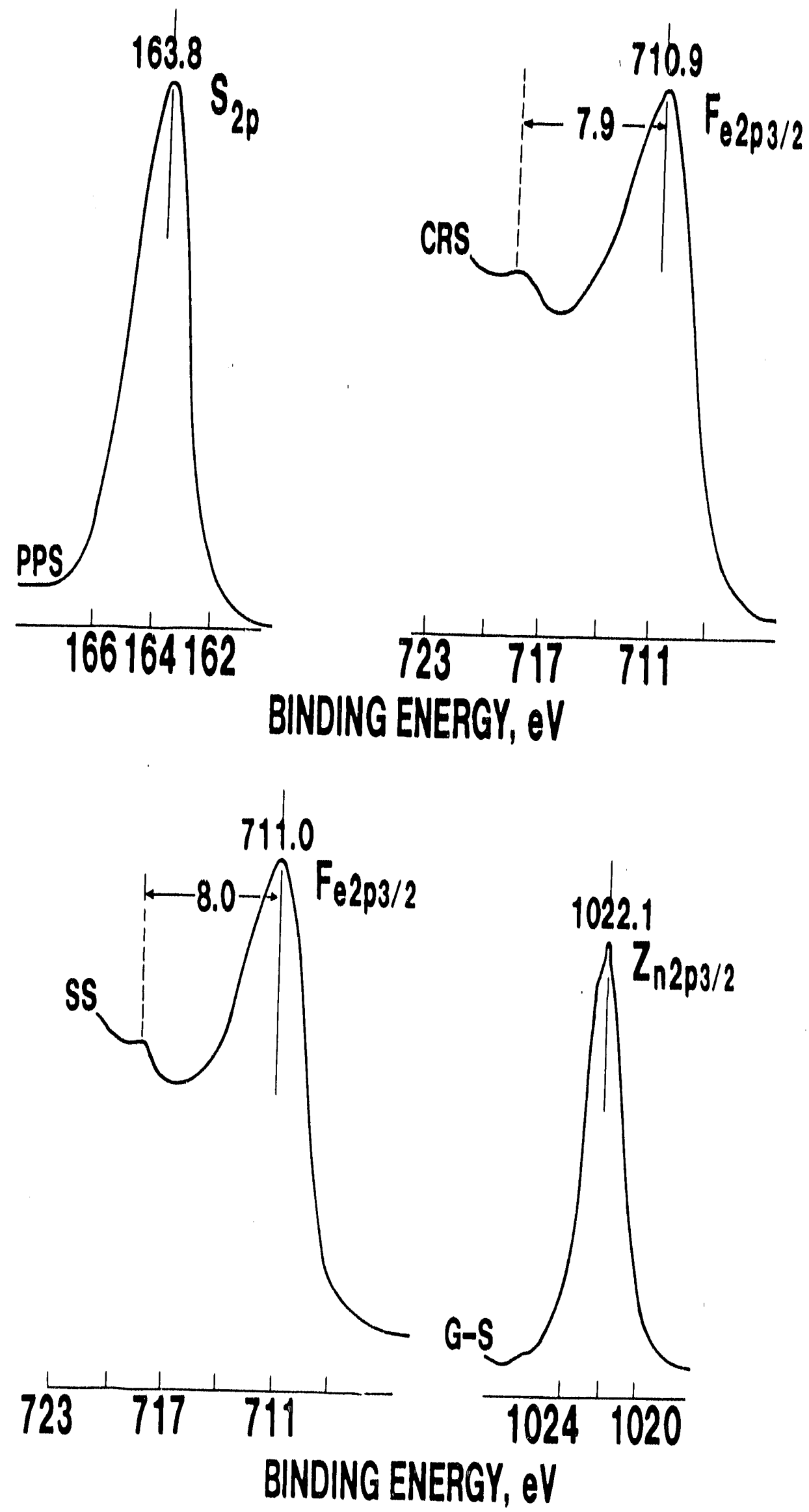

Figure 2. XPS high-resolution spectra in $S_{2 p}, F_{2 p 3 / 2}$ and $Z_{2 p 3 / 2}$ regions for reference polyphenylene sulfide (PPS), cold-rolled steel (CRS), stainless steel (SS) and galvanized steel (G-S) surfaces. 


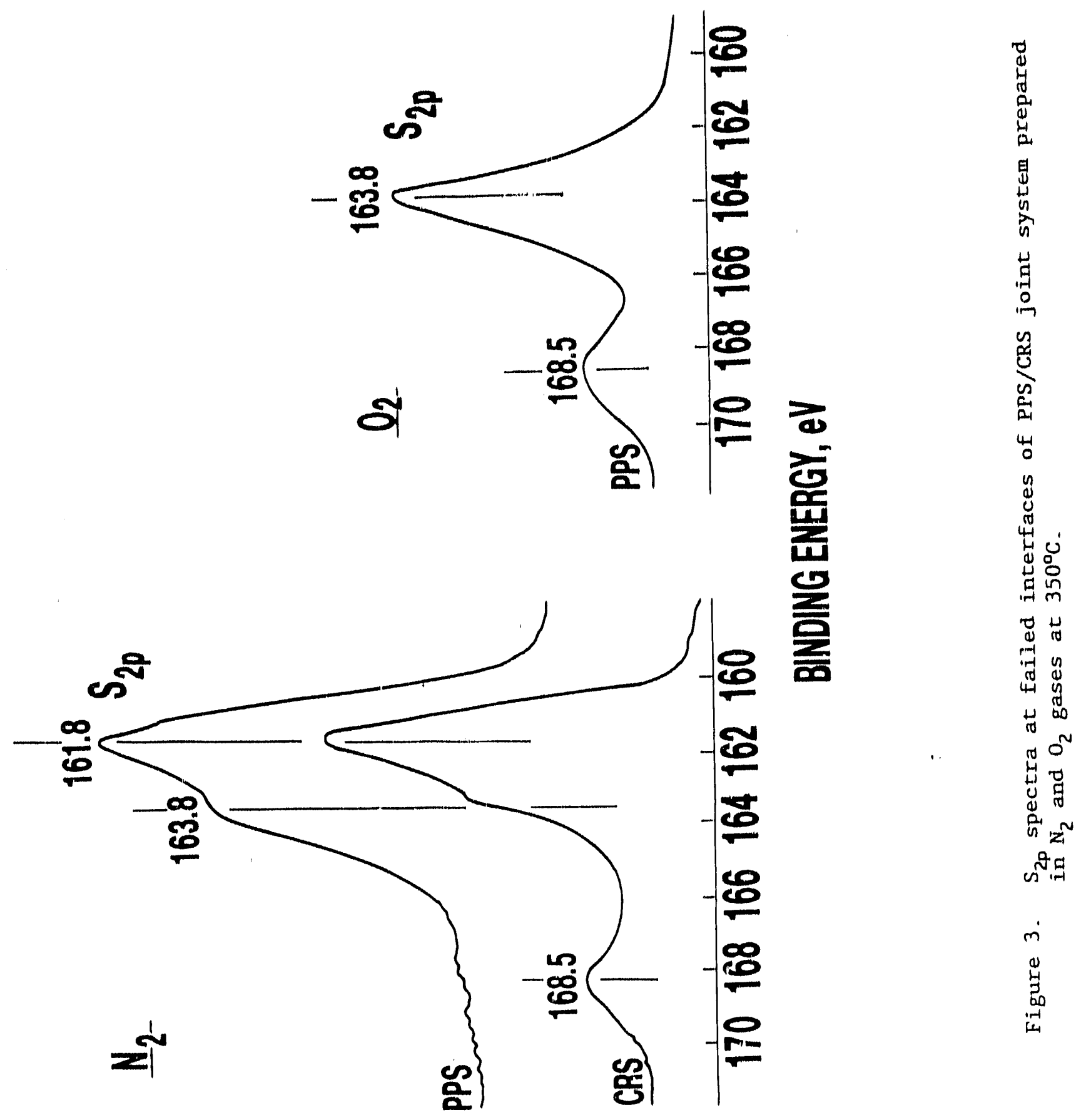



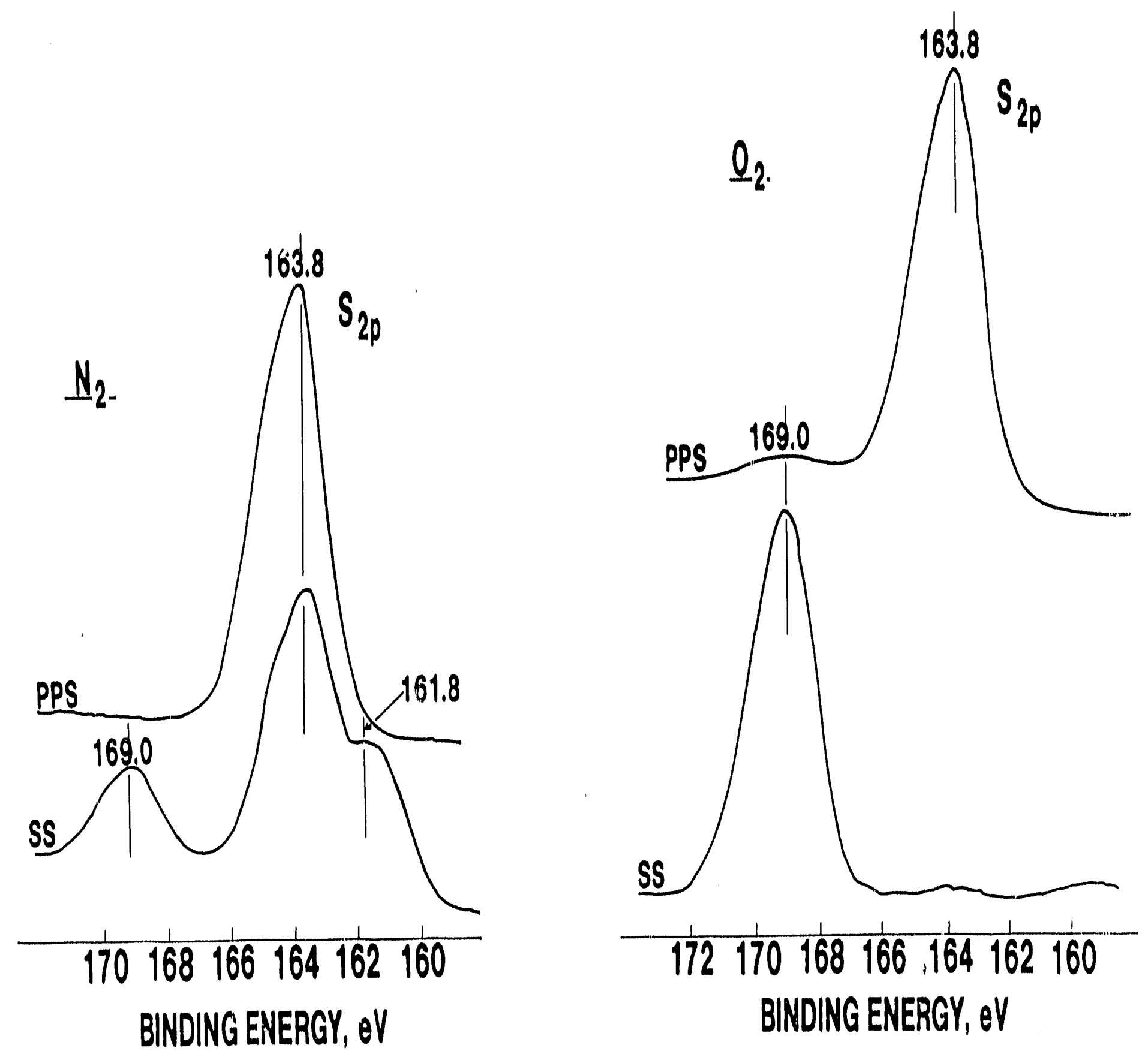

Figure 4, S $S_{2 p}$ reglon at Intorfadial fallure locus of PPS/SS joint system. 


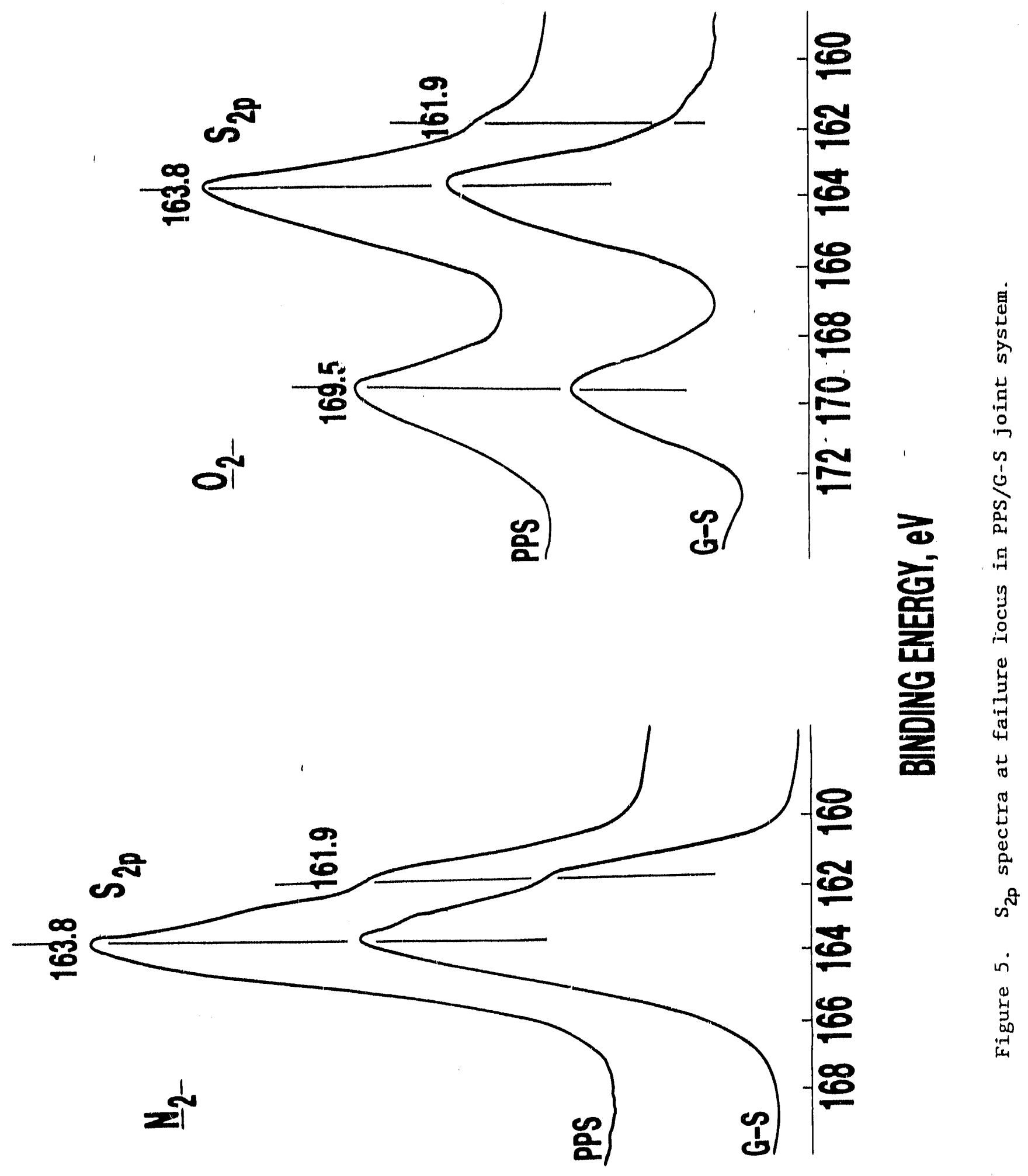




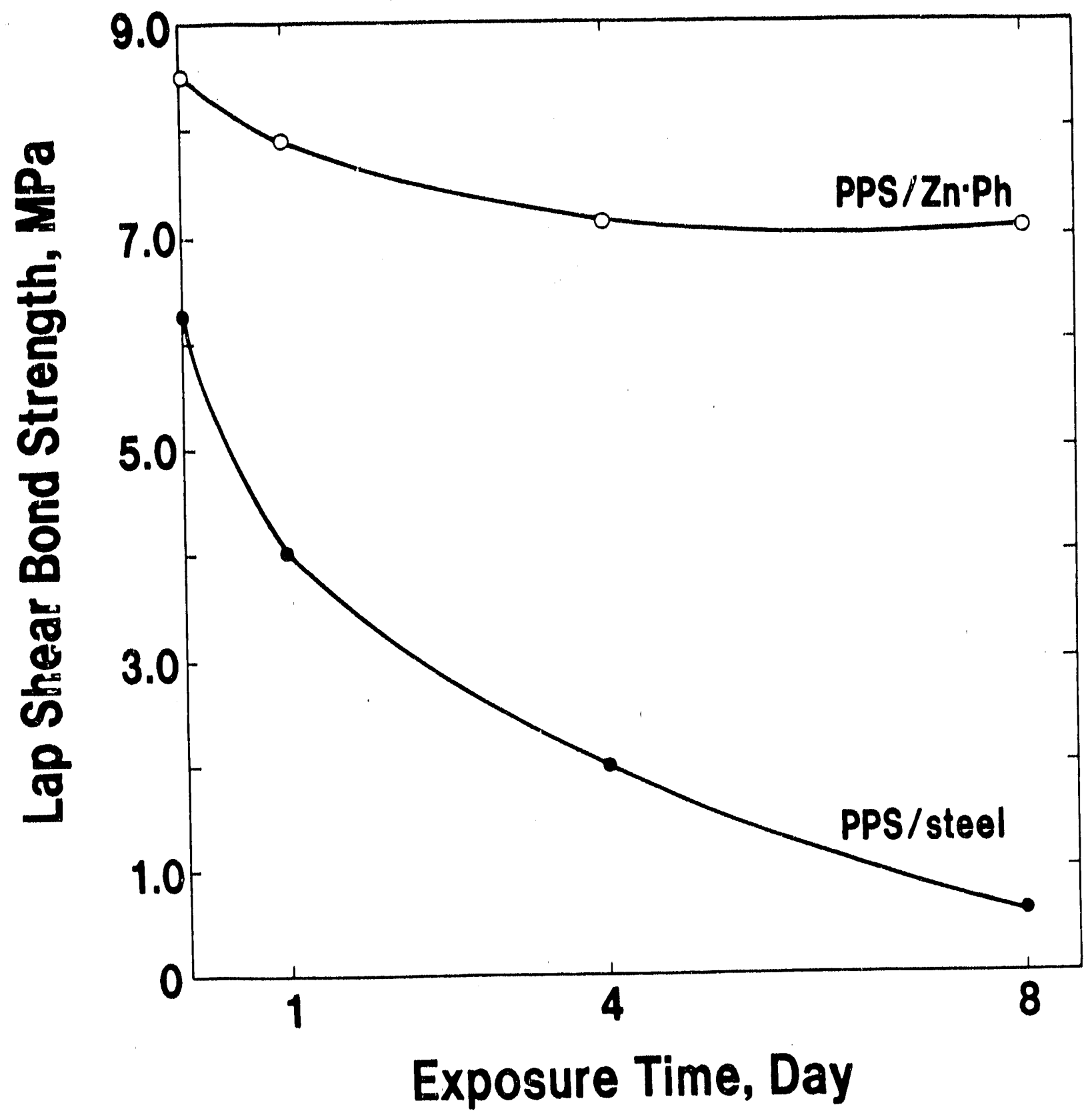

Figure 6. Lap-shear bond strength vs, exposure time to a $80^{\circ} \mathrm{C} \mathrm{pH}_{3} \mathrm{H}_{2} \mathrm{SO}_{4} \mathrm{solu}$ tion containing $0 . \mathrm{M} \mathrm{NaCl}$. 


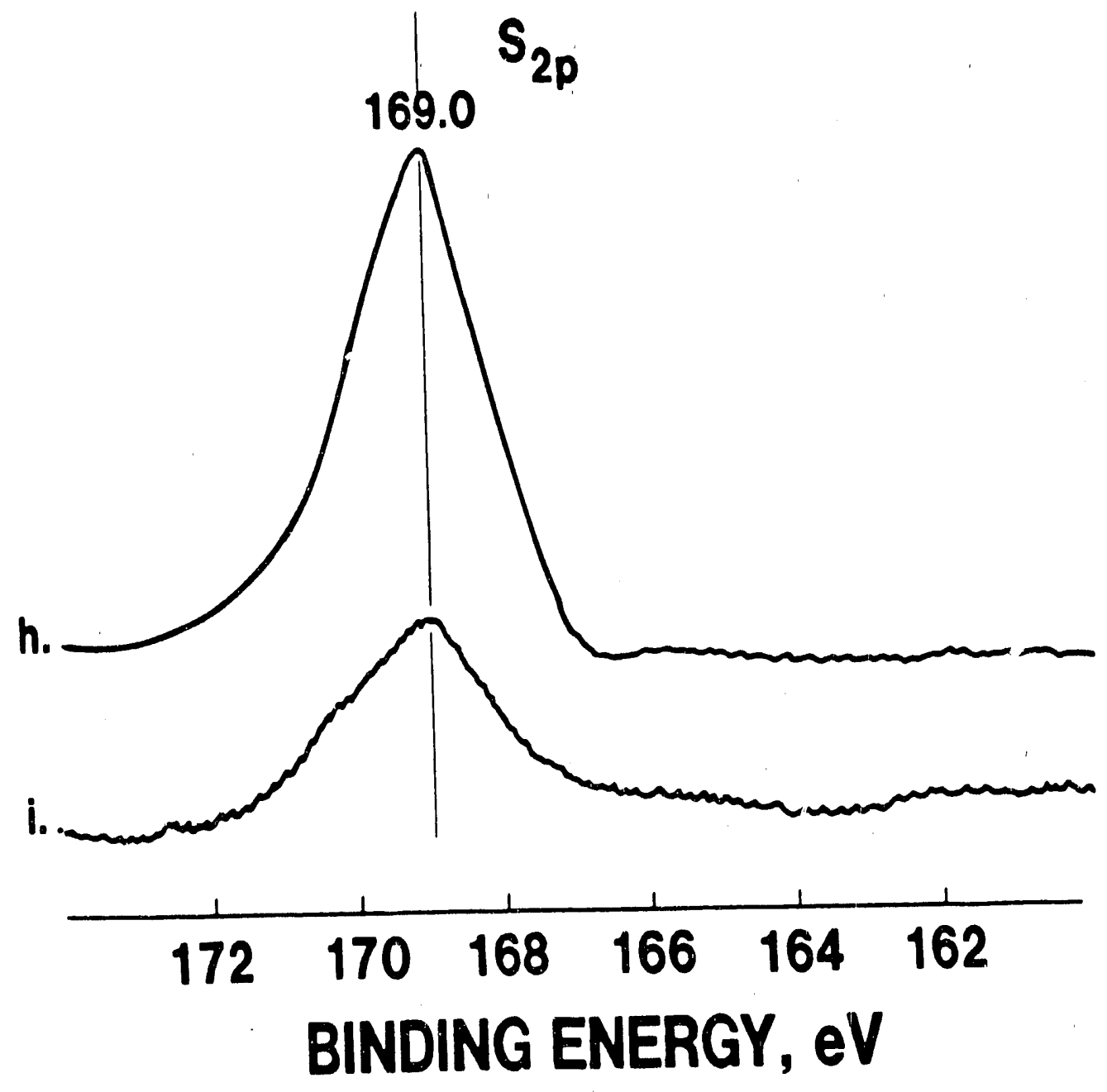

Figure 7. $S_{2 p}$ region for PPS $(h)$ and steel ( 1 ) interfaces separated by the attack of hot acid solution on the PPS/steel joint. 


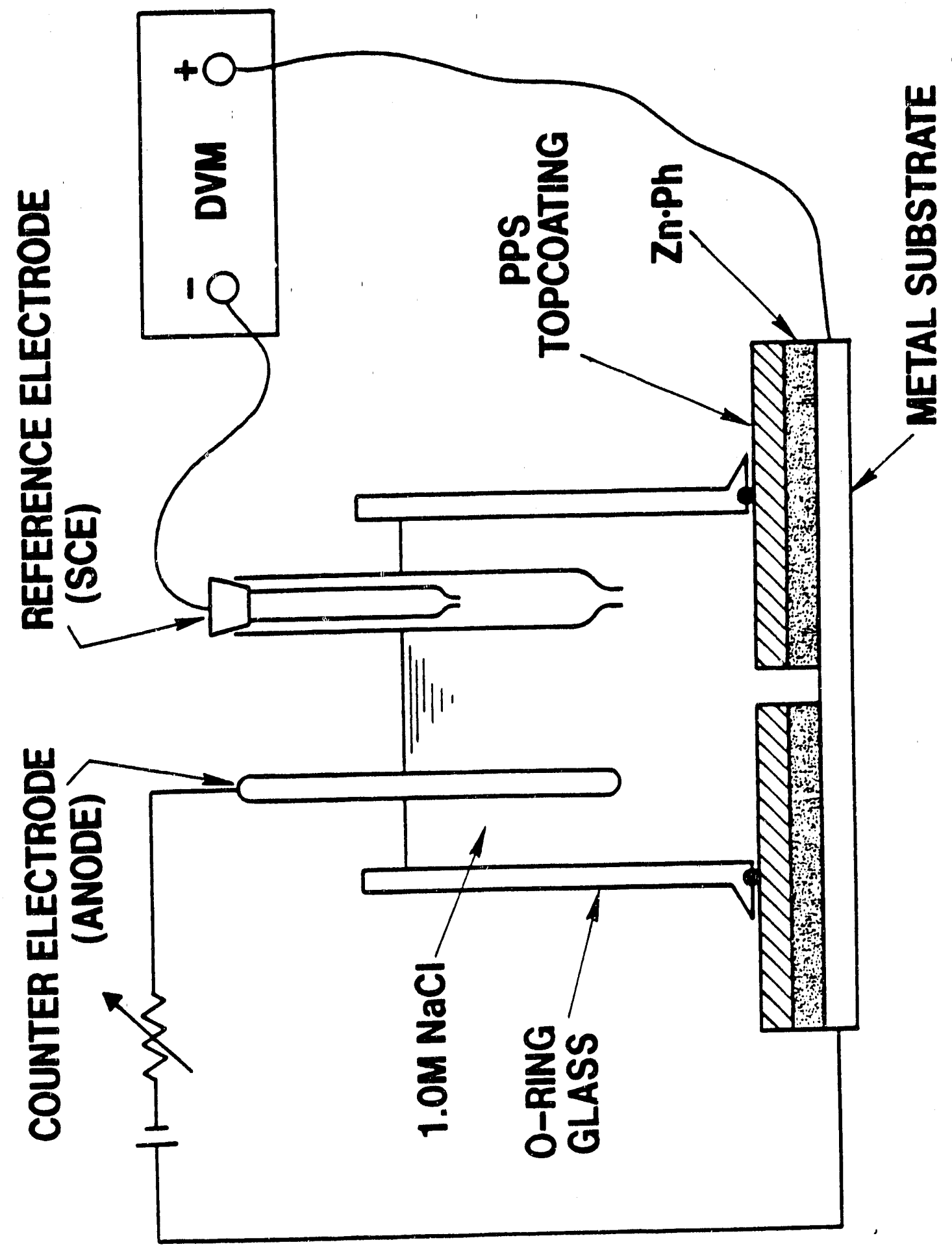

D 


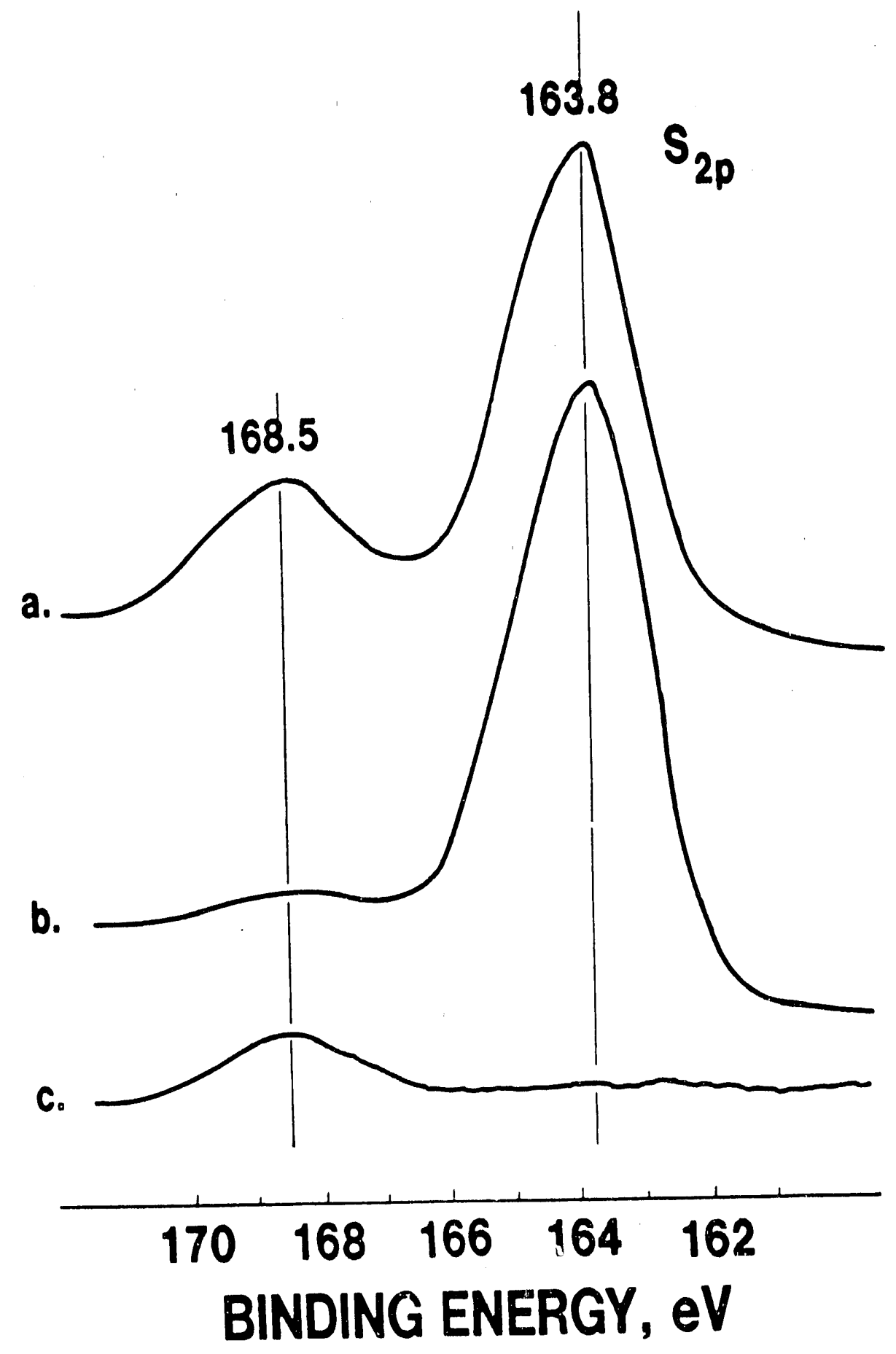

Figure 9. $S_{2 p}$ core level spectra for the PPS side (a) removed from the steel before cathodic delamination tests, and the delaminated PPS (b) and steel (c) sides atter cathodic tests. 

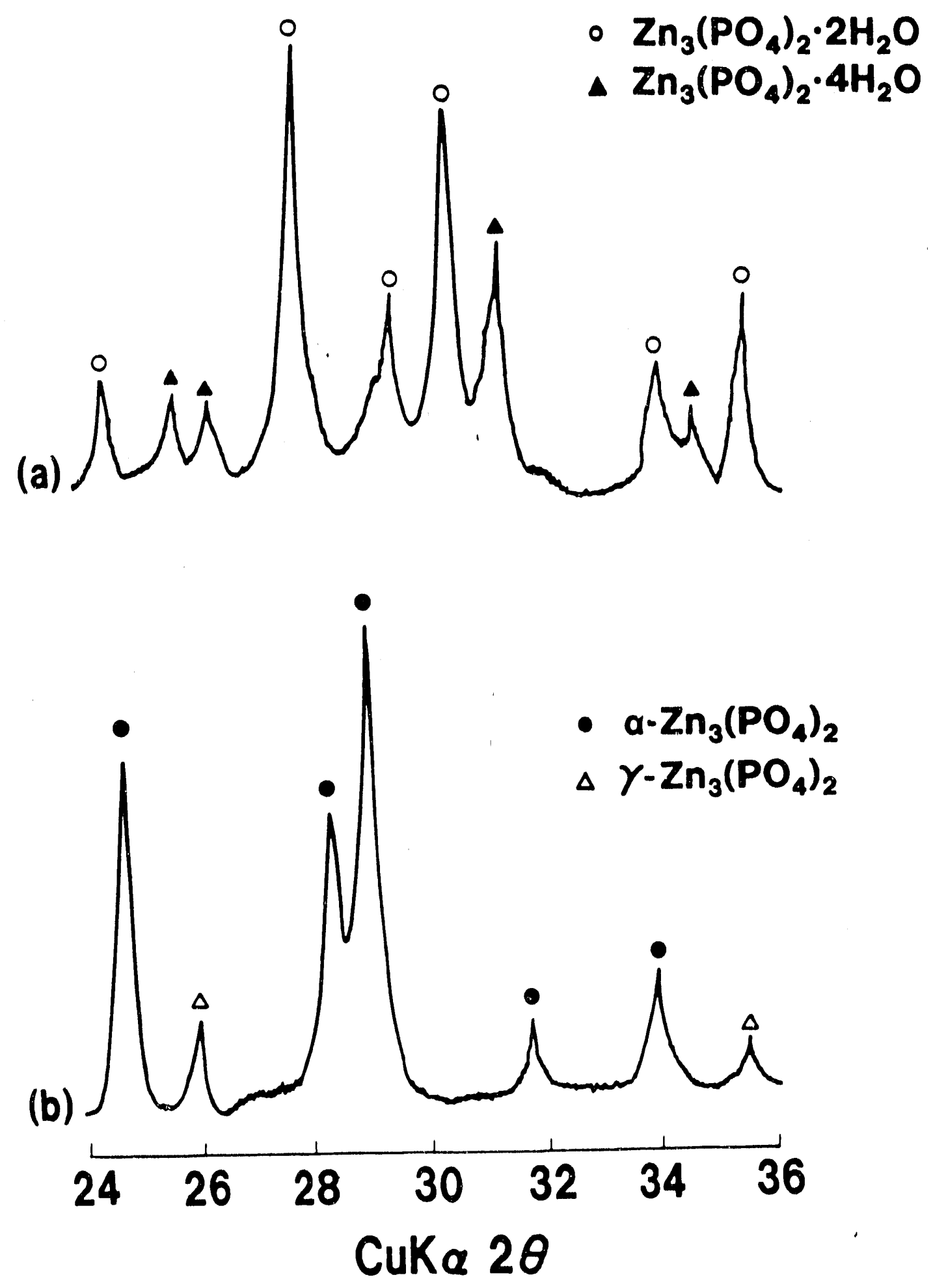

Figure 10. XRD tracings for original $\mathrm{Zn} \cdot \mathrm{Ph}$ samples (a), and $350^{\circ} \mathrm{C}$-dehydrated $\mathrm{Zn} \cdot \mathrm{Ph}$ samples (b). 


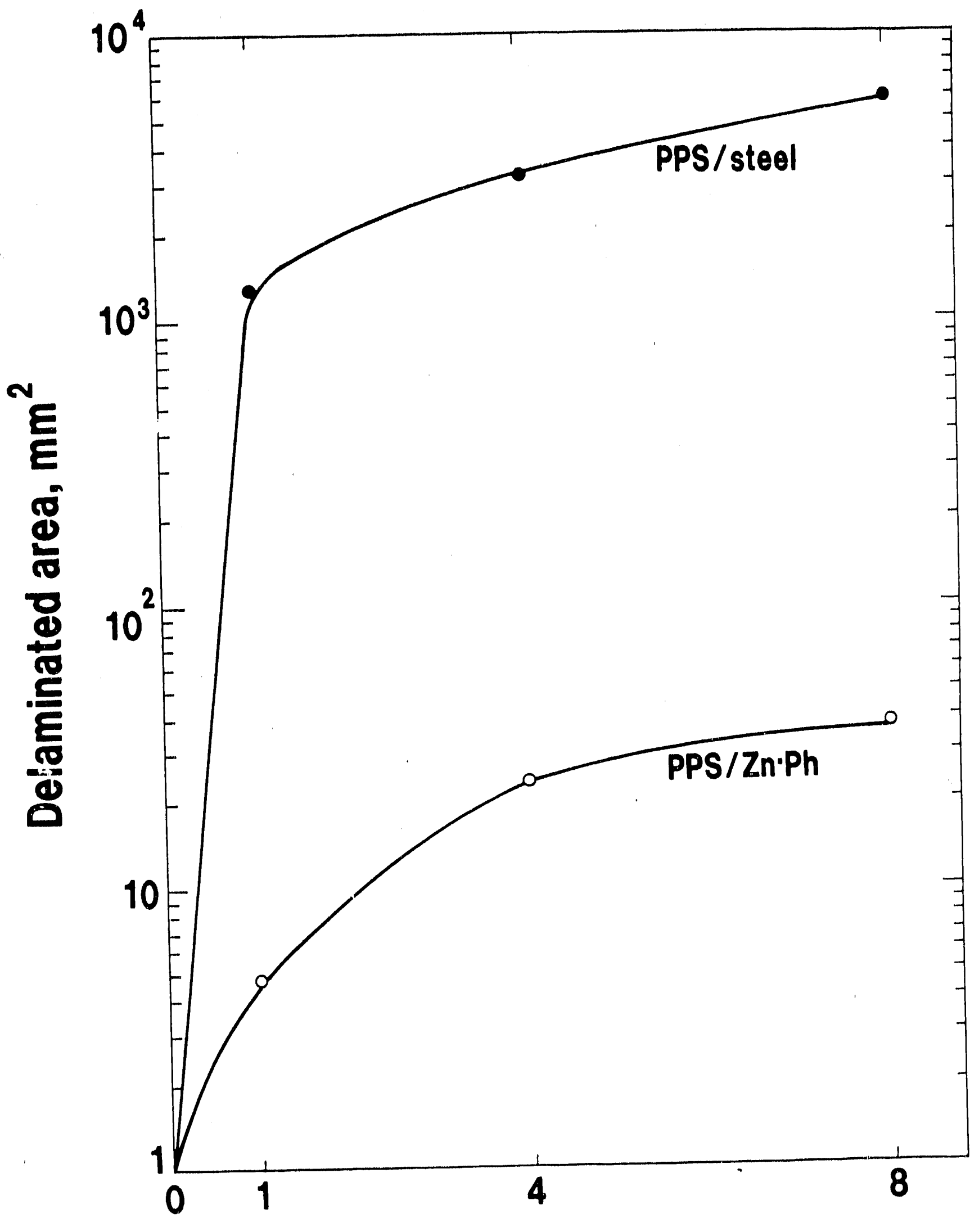

TIME, days

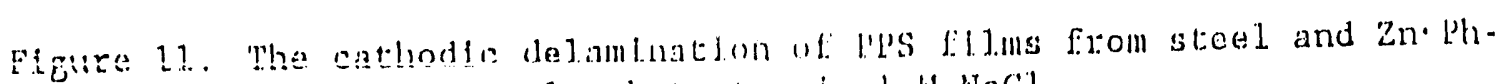
depositad steel substialies inl $1.4 \mathrm{HaCl}$. 

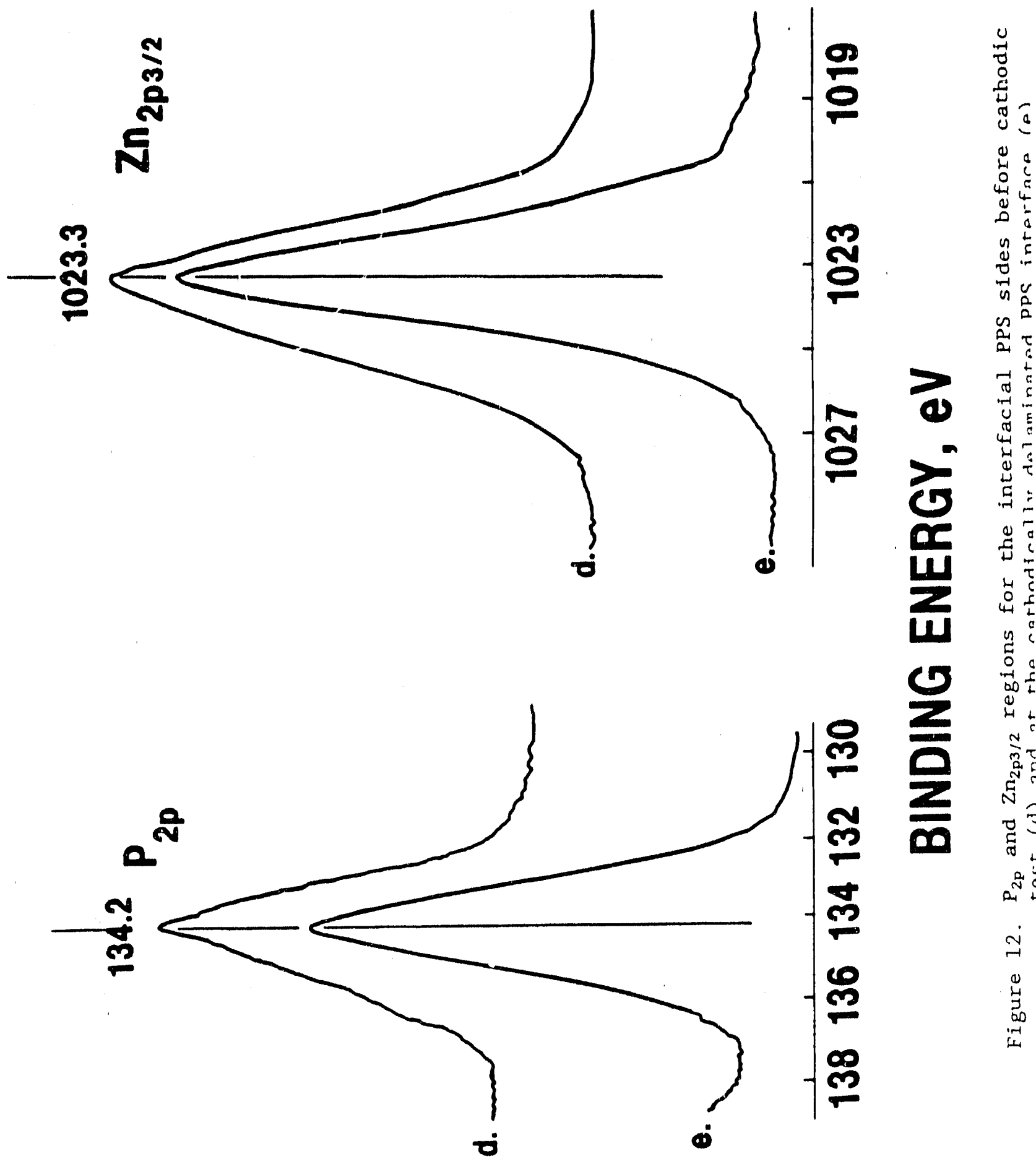


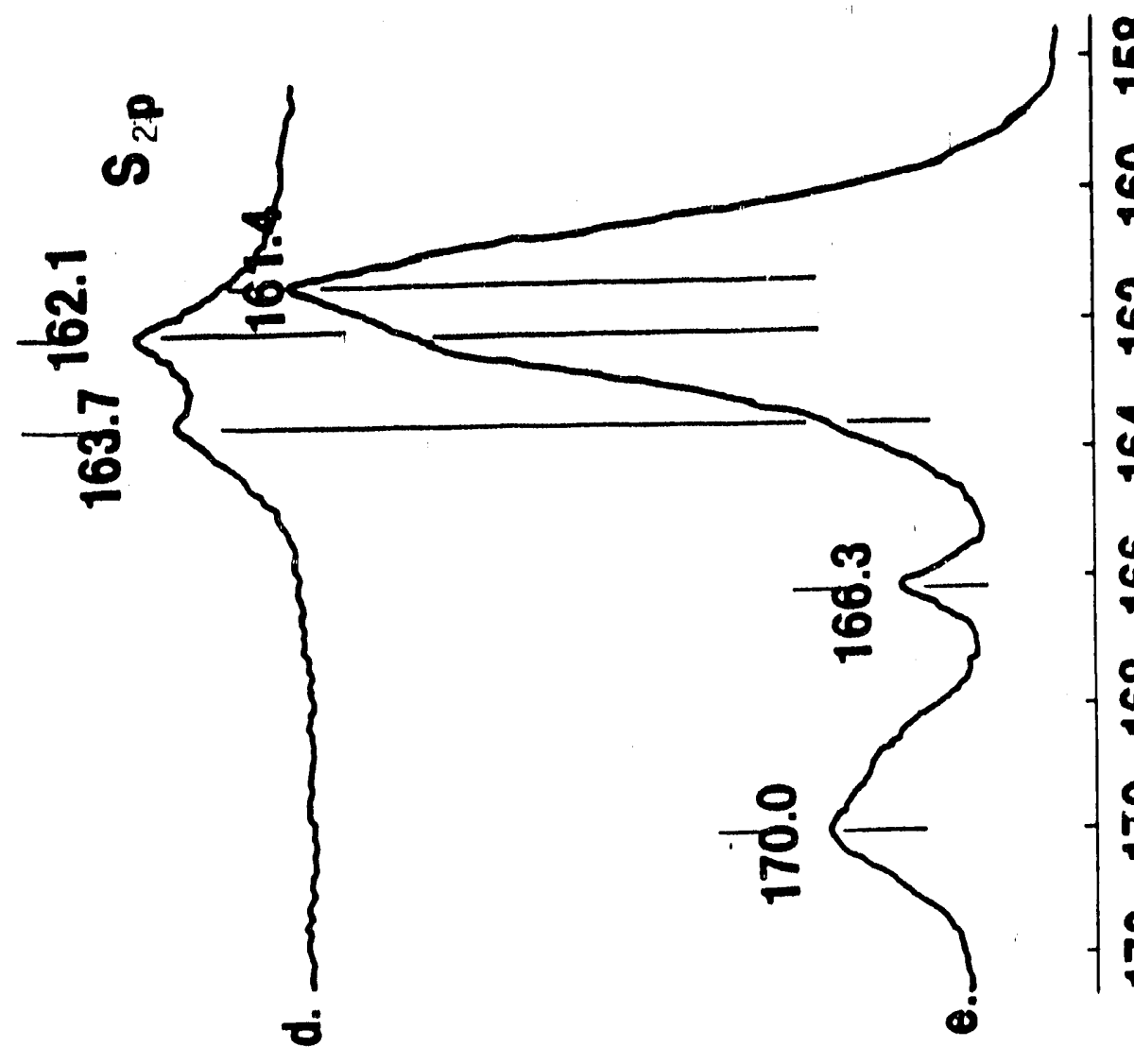

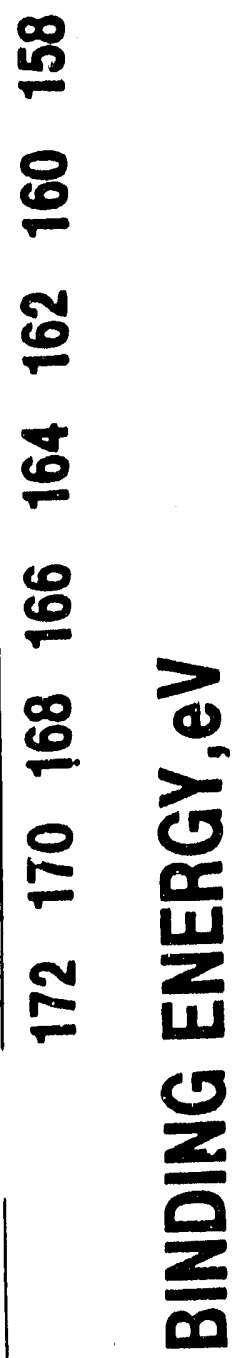

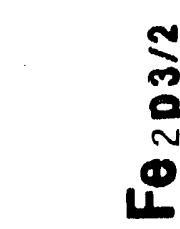

E

$\stackrel{r}{r}$

$\frac{2}{2}$

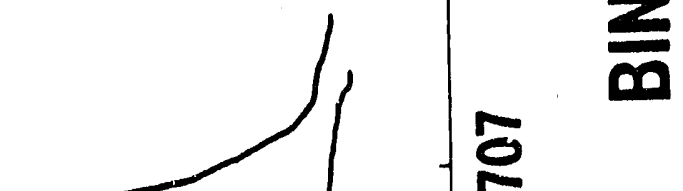

ำ

5

गु

峁出

岸品

م

\&

Q

垴

结

م.

गु

ชิ

出会

梁

0

ㄴ.
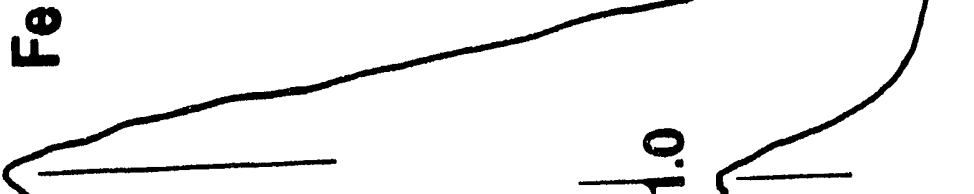

용

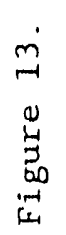

i

d

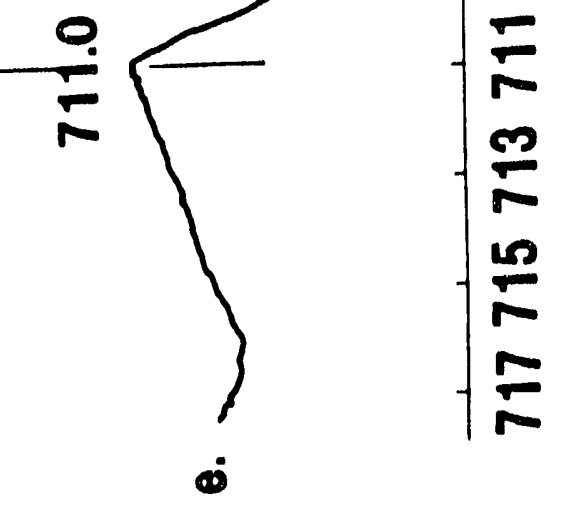




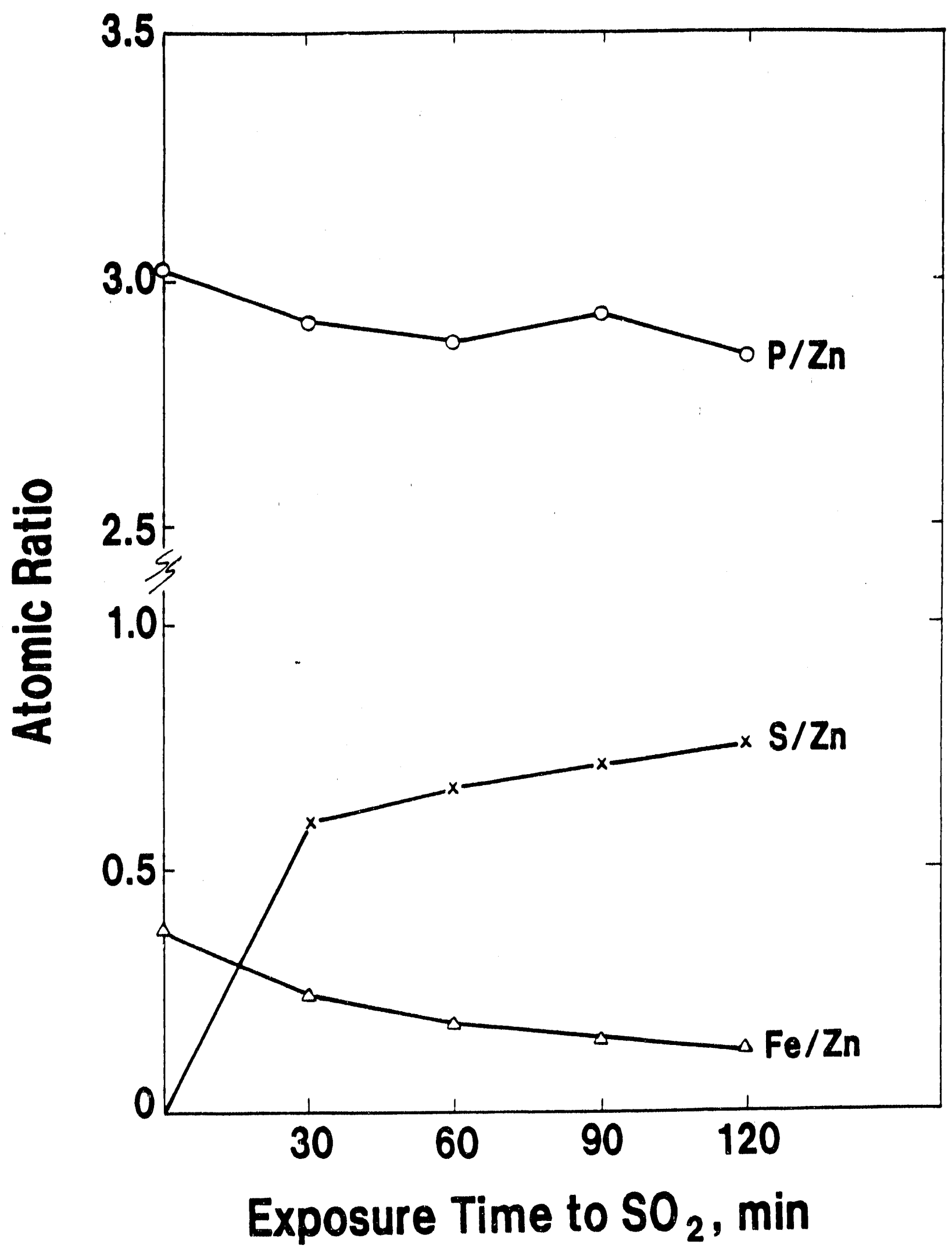

Figure 14. Changes in $\mathrm{P} / \mathrm{Zn}, \mathrm{S} / \mathrm{Z} \| 1$, and f'e/Zn atomic ratios as a function of exposure time to $\mathrm{SO}_{2}$. 


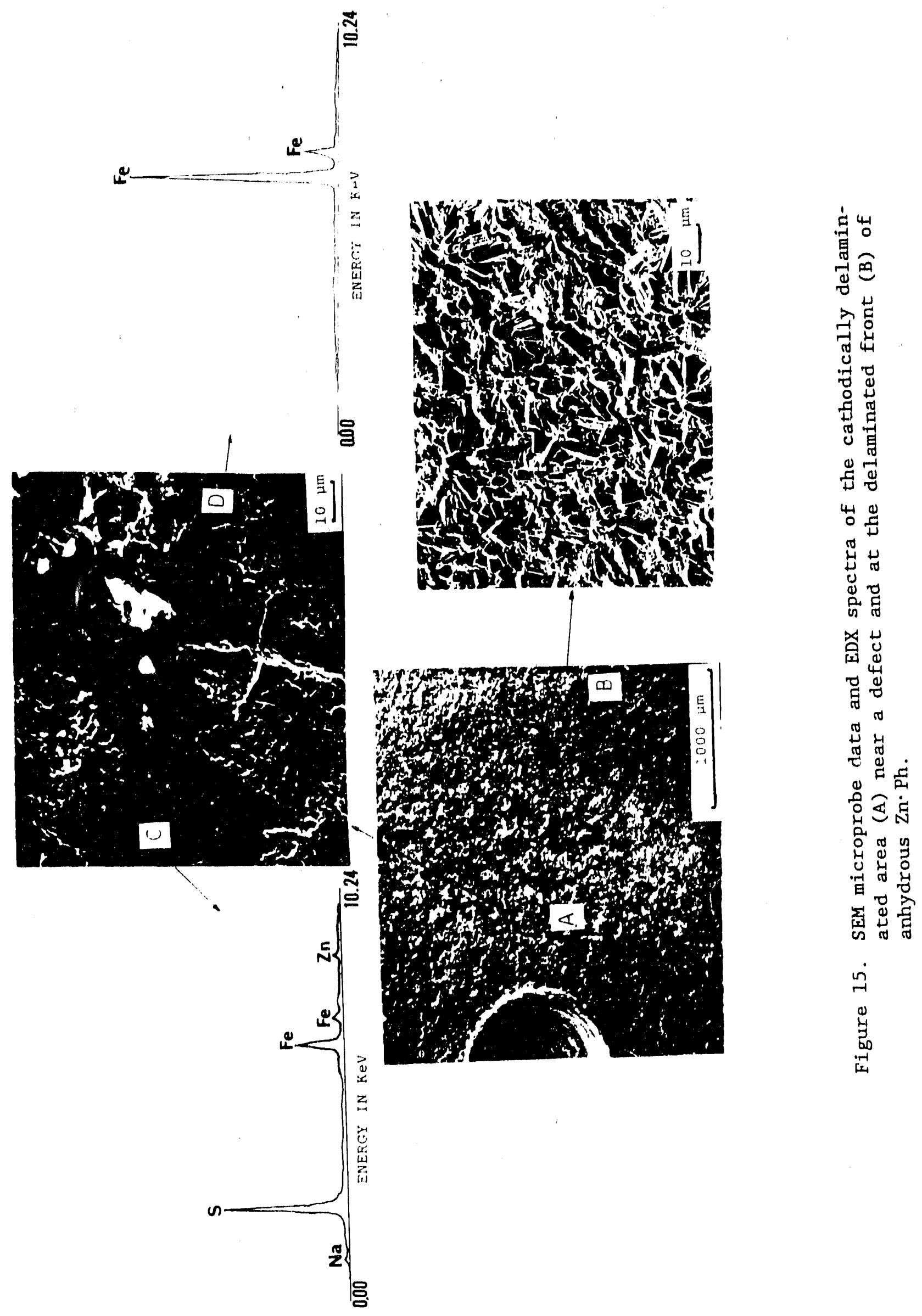




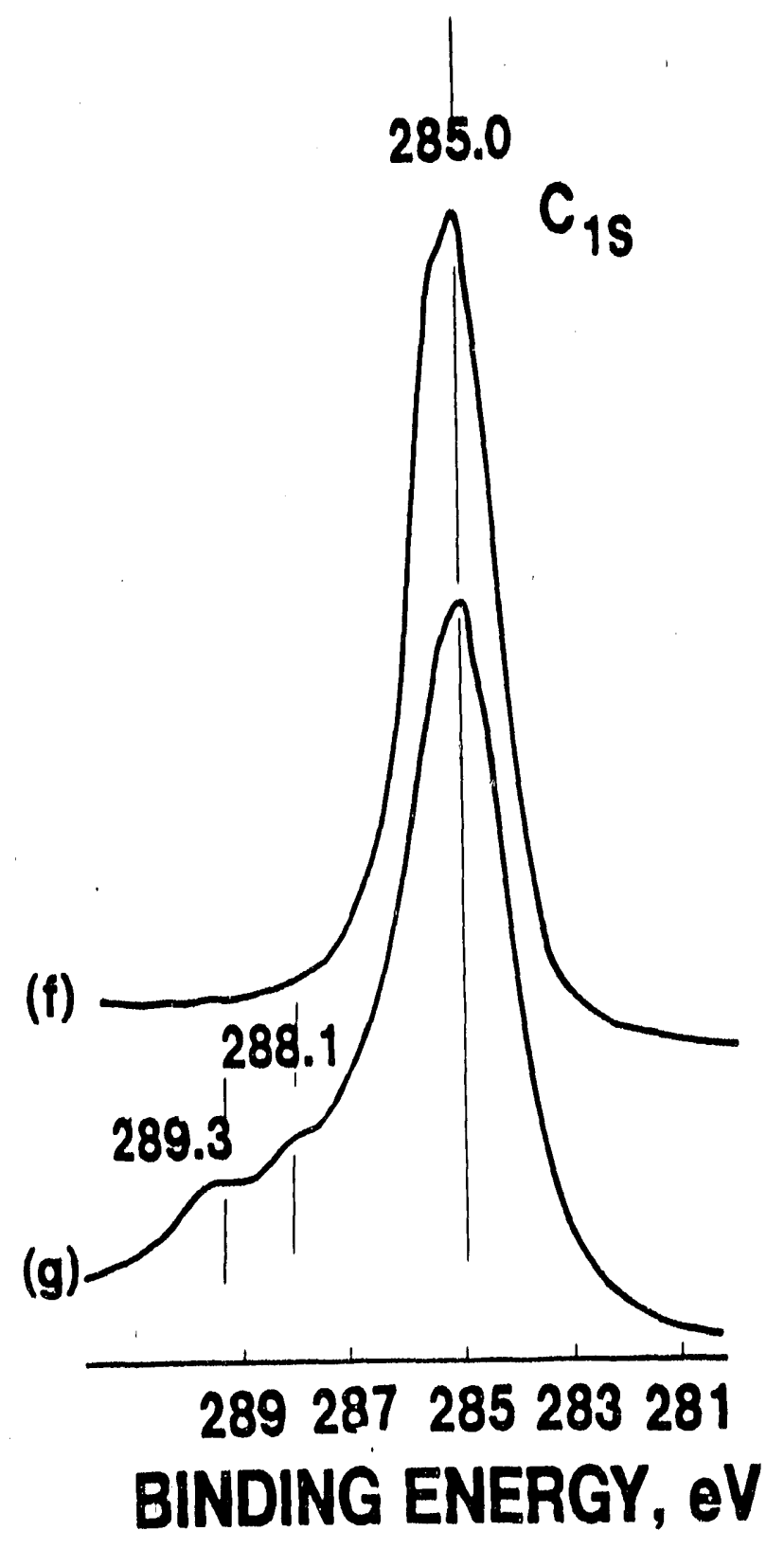

Figure 16, $C_{18}$ spectra for bulk PPS (f) and PPS interface (g) removed from poly (acid) anhydride-primed steel. 


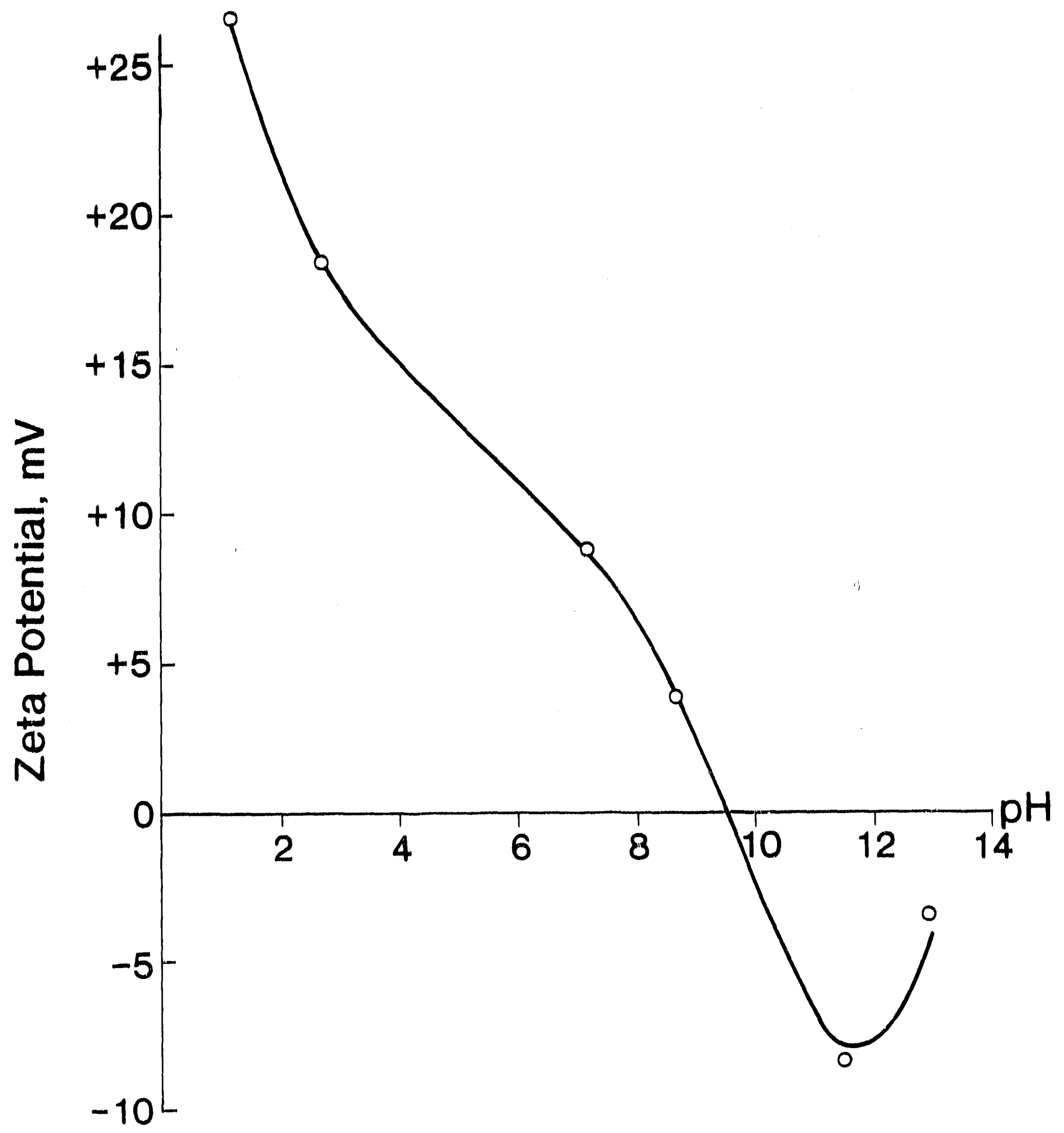

Figure 17. Changes in zeta potential of sol precursors as a function of pll. 

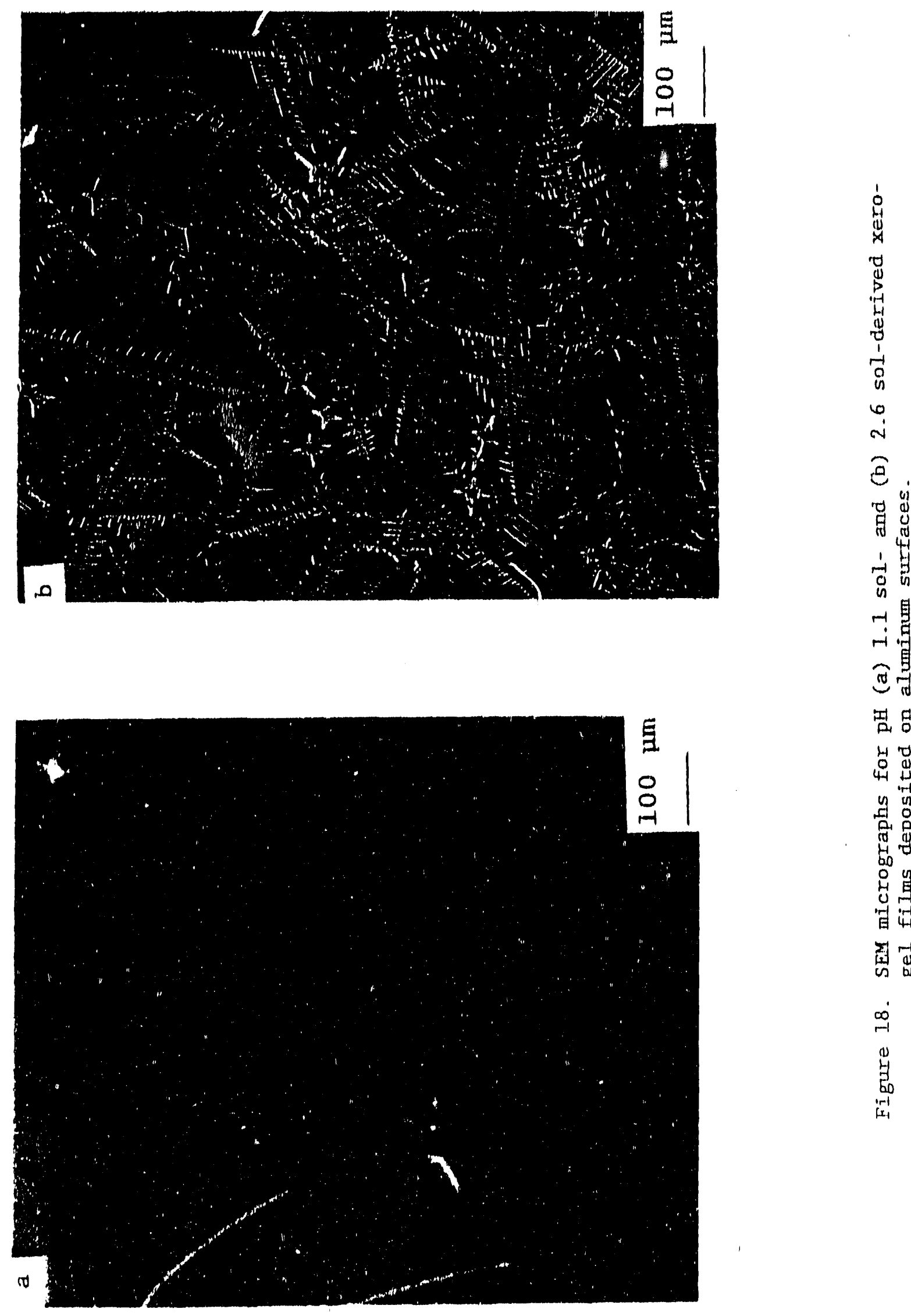


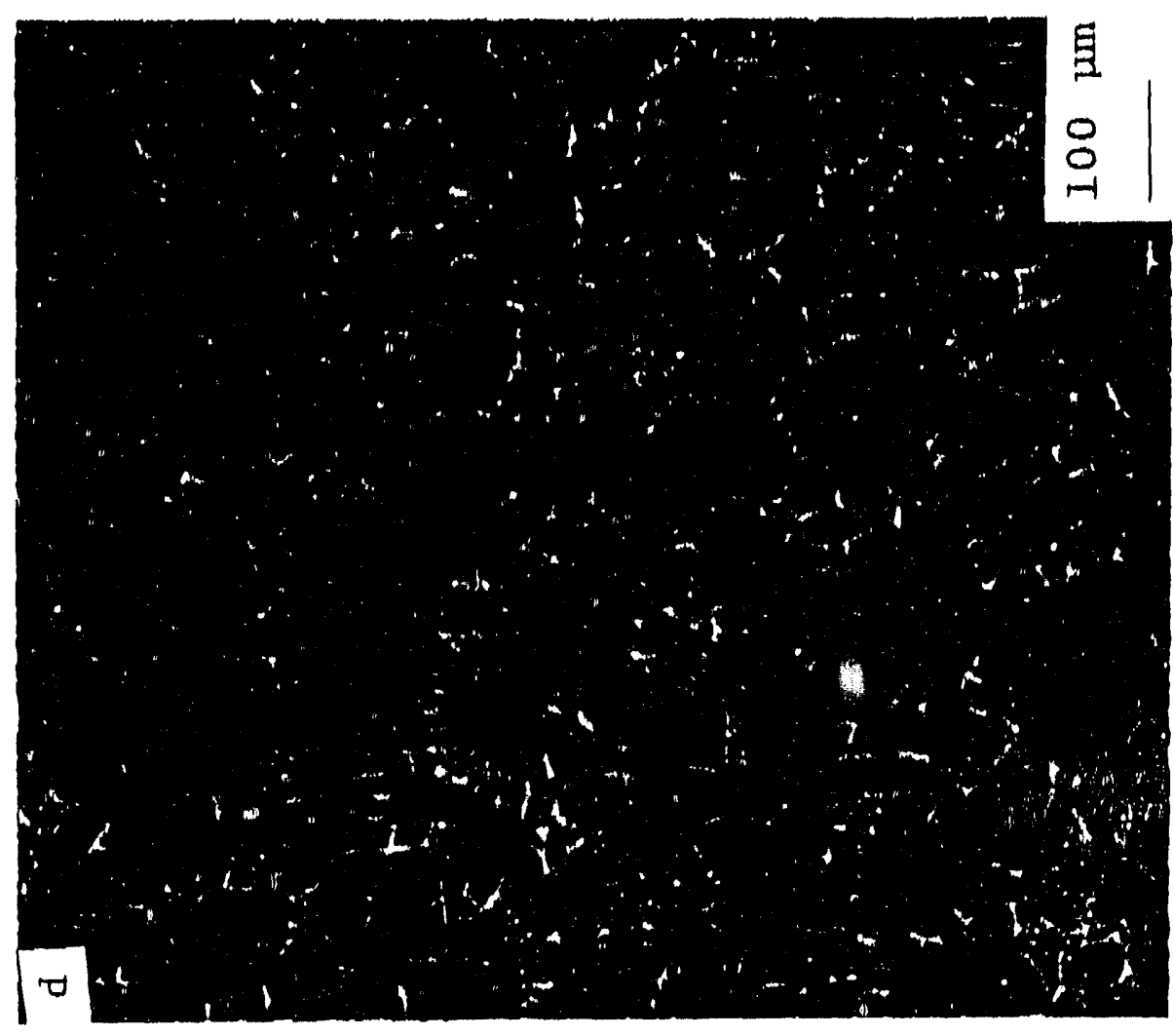

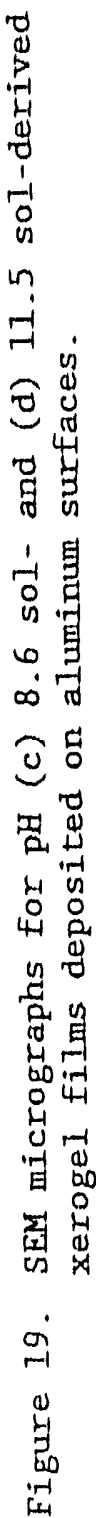

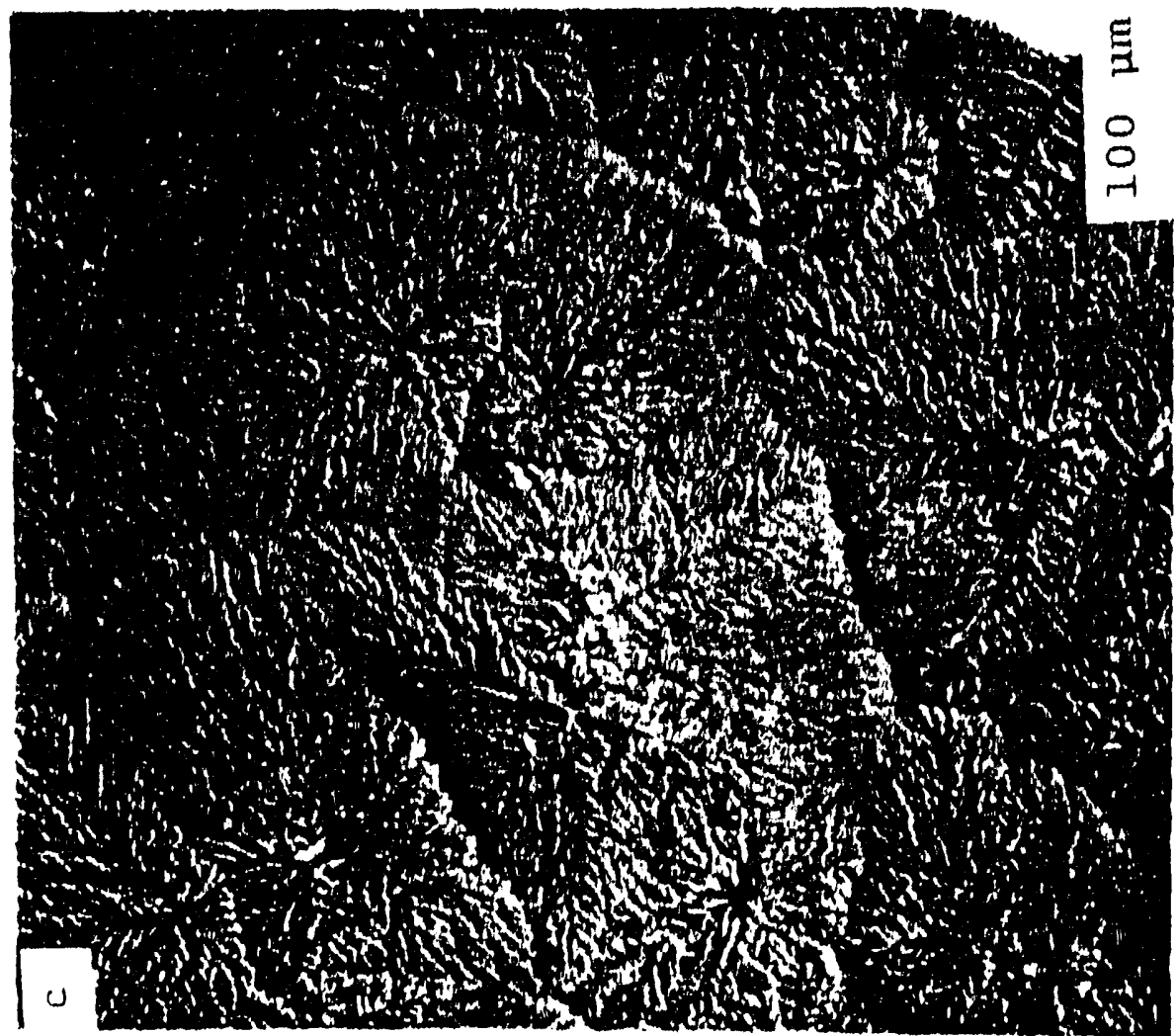




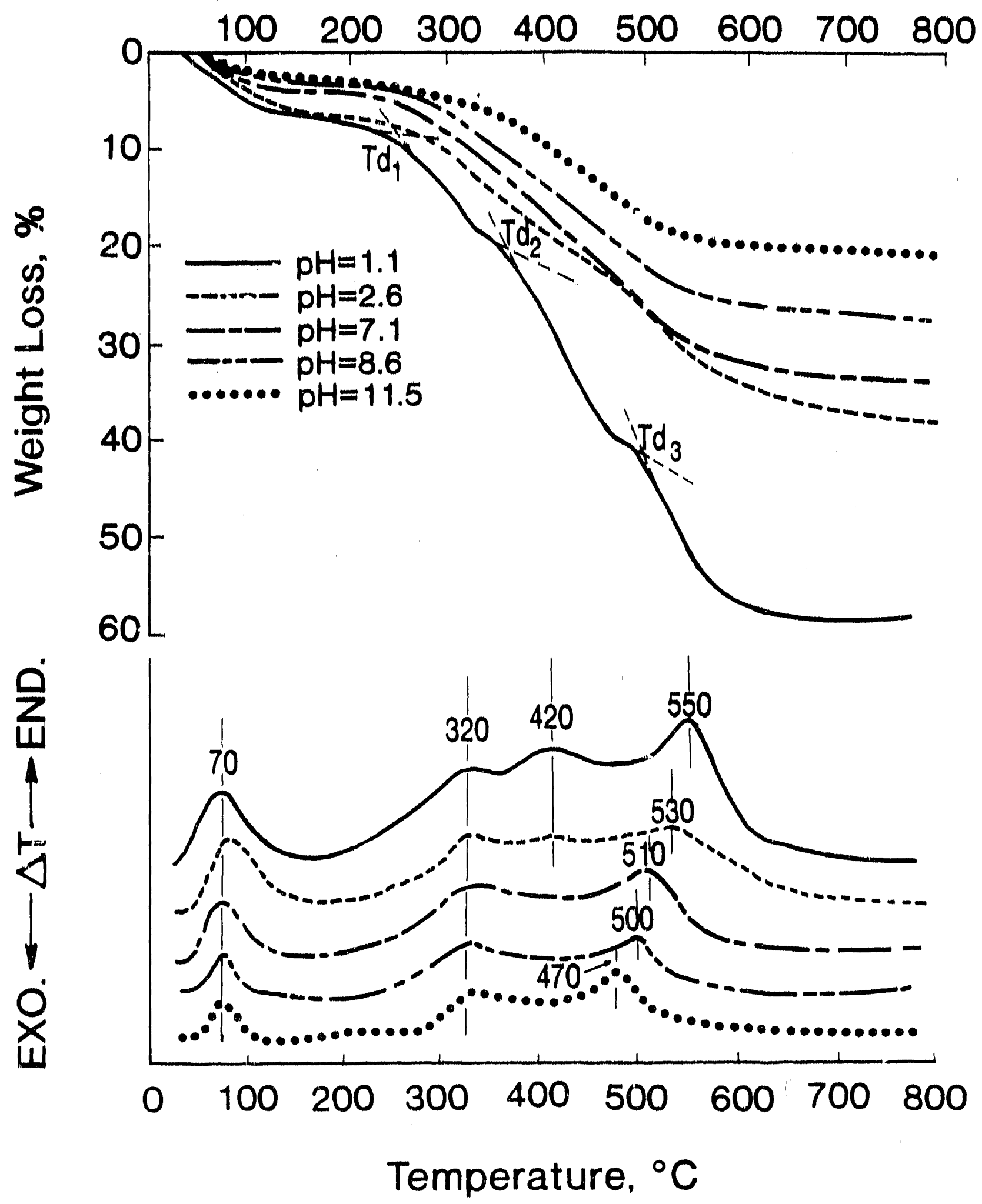

Figure 20, TGA and DTA curves for the pyrolysis of xerogels heated in air at a rate of $10^{\circ} \mathrm{C} / \mathrm{min}$. 


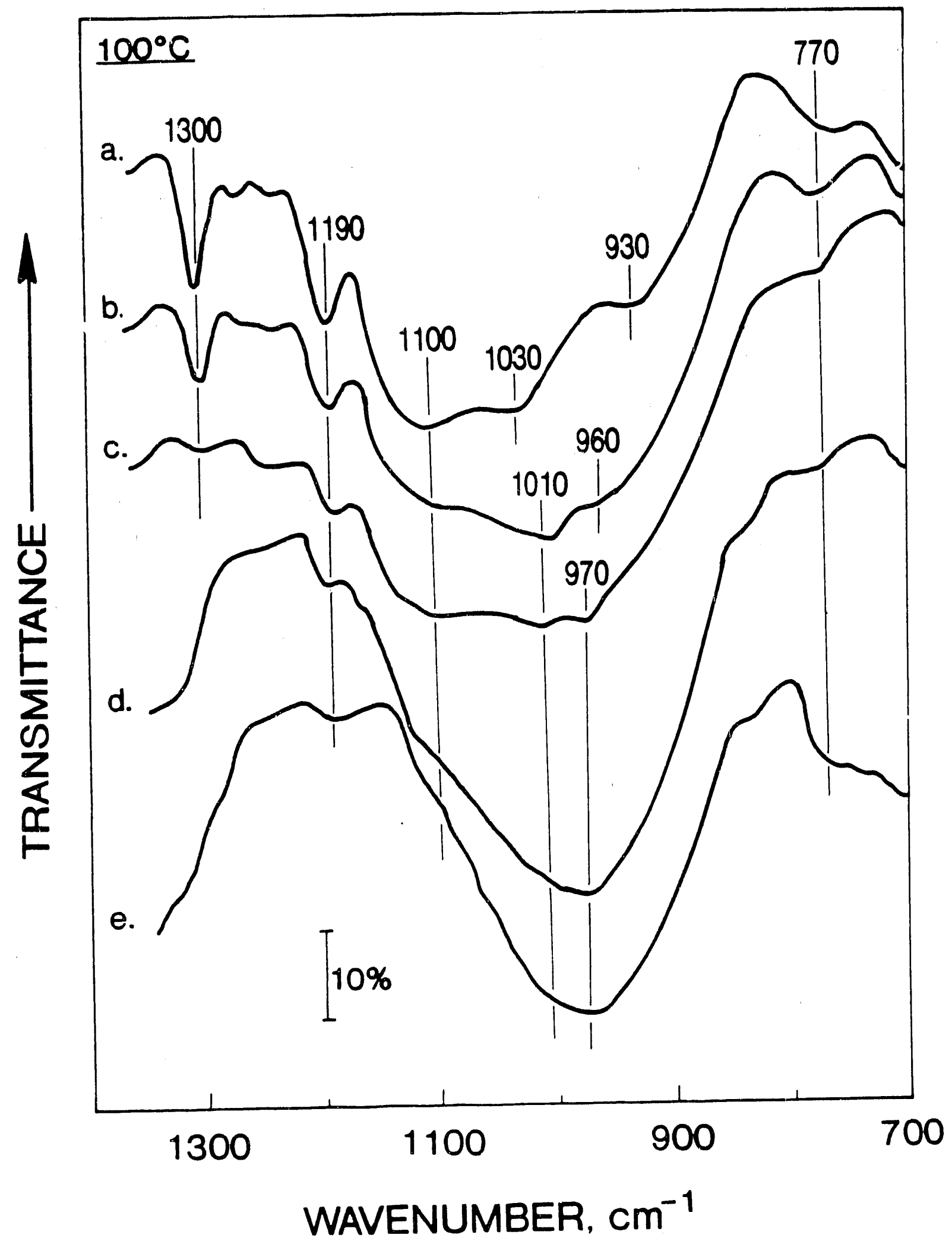

Figure 21. IR absorption spectra for $100^{\circ} \mathrm{C}$-sintered xerogels at $\mathrm{pH}$ (a) 1.1 , (b) 2.6, (c) 8.6, (d) 11.5 , and (e) 12.8 . 


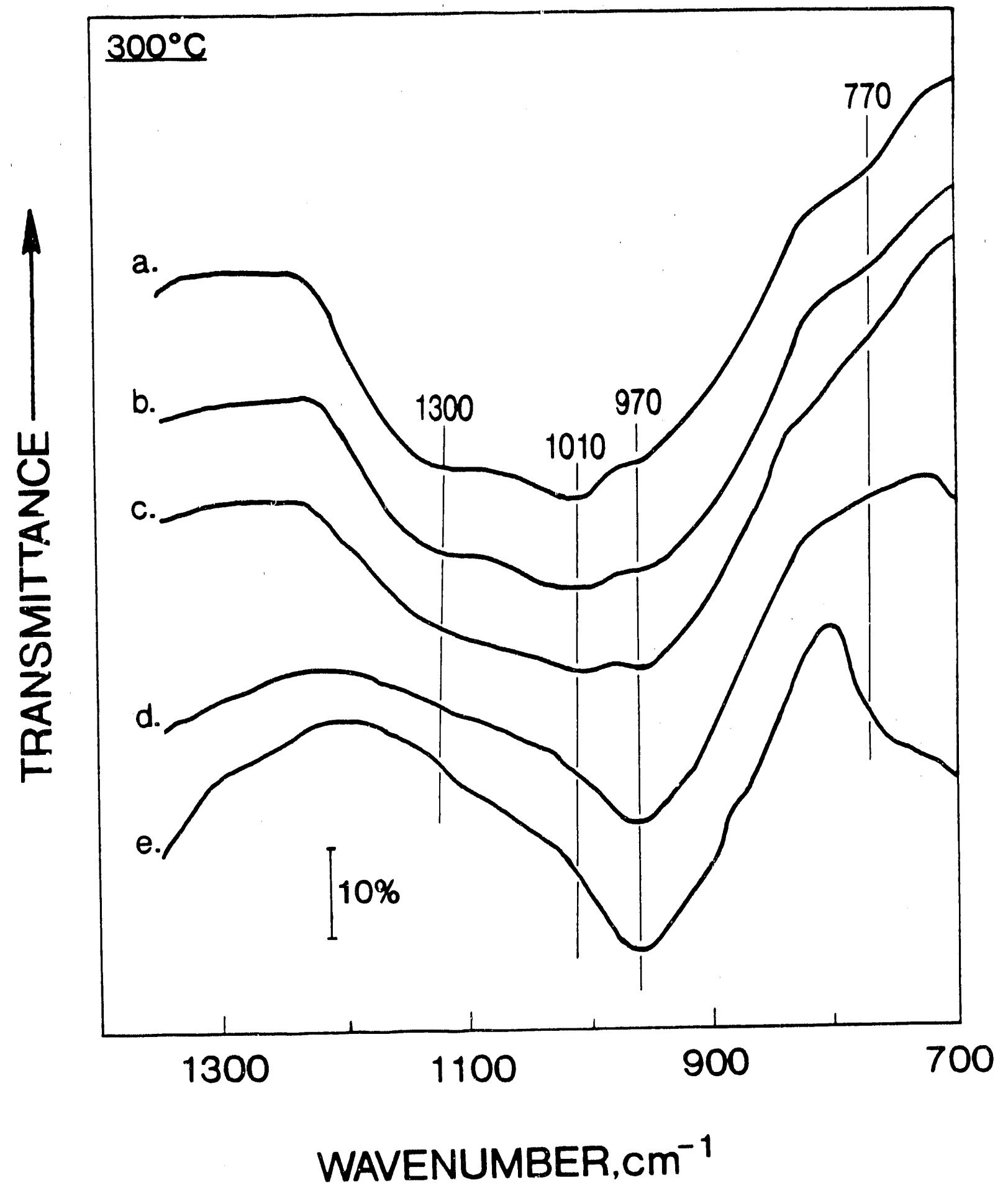

Figure 22. IR spectra for $300^{\circ} \mathrm{C}$-pyrolyzed xerogeis at pii (a) i.i. (i) 2.6, (c) 8.6, (d) 11.5 , and (e) 12.8 . 

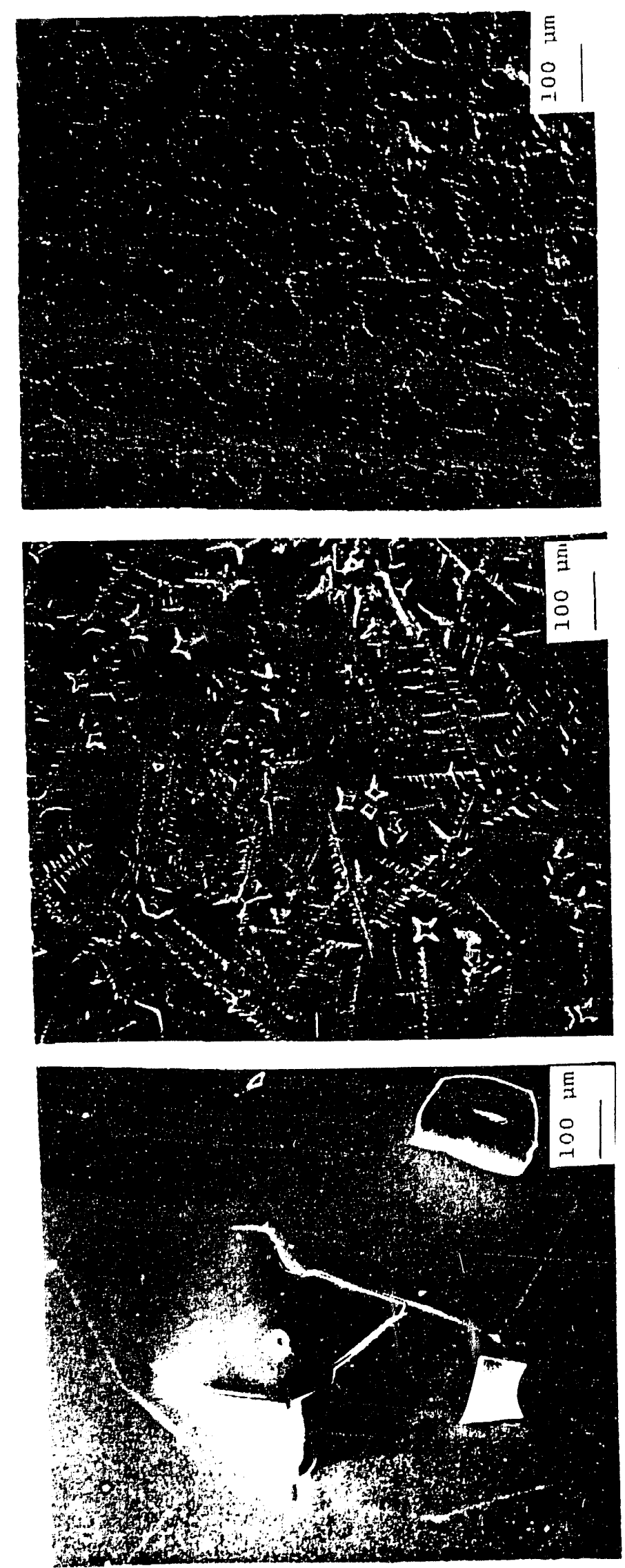
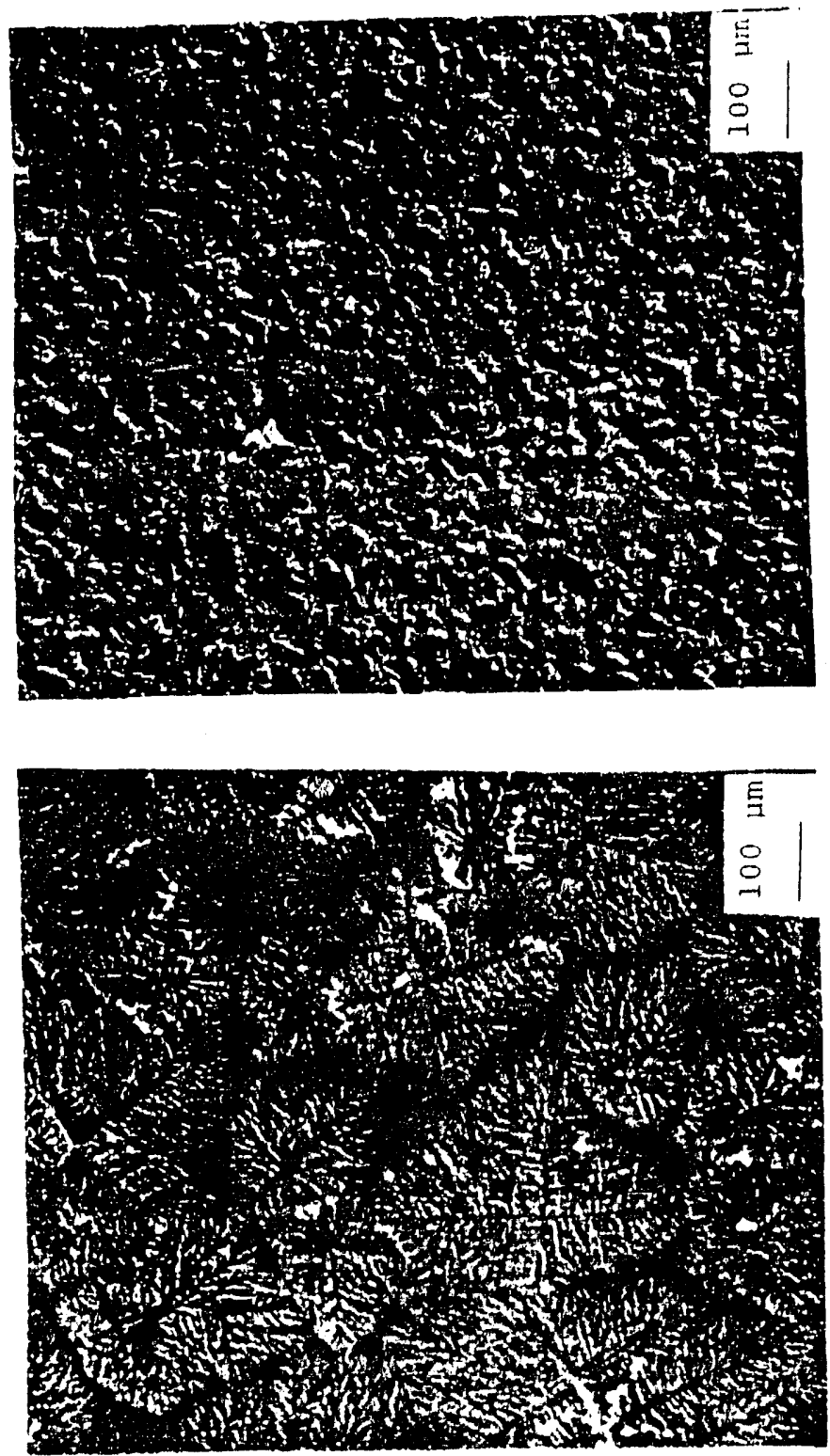


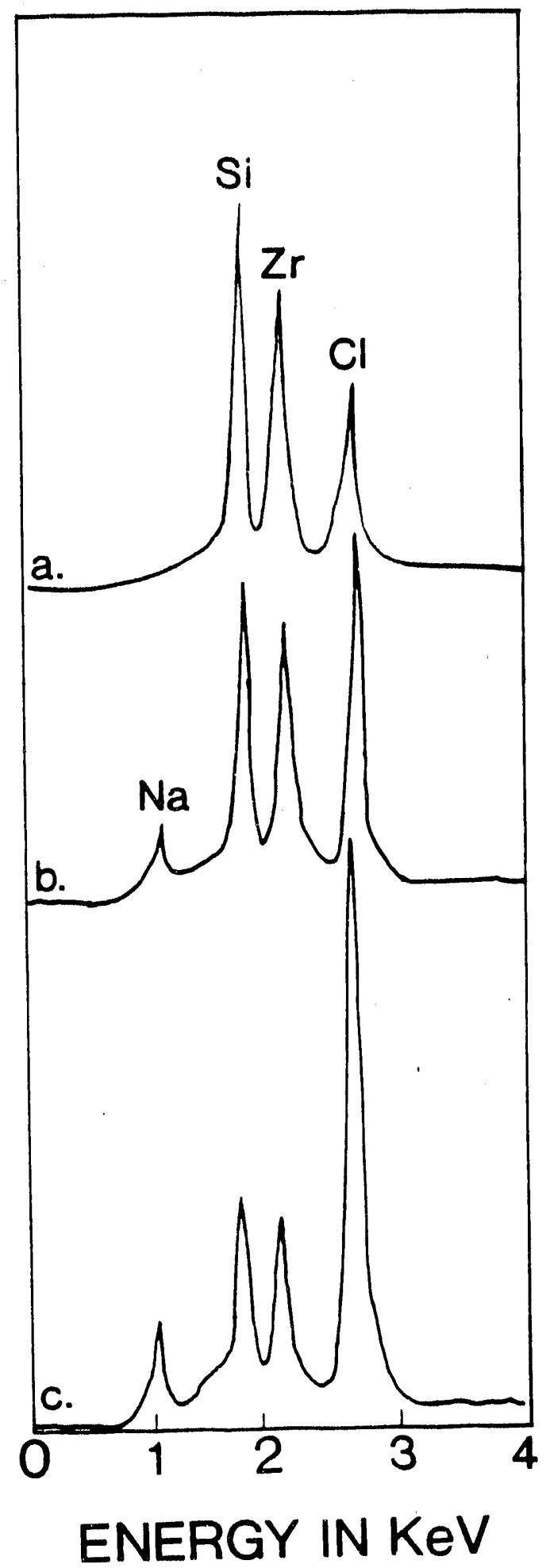

Figure 24. EDX spectra for $300^{\circ} \mathrm{C}$-pyrolyzed xerogel film surfaces at pH (a) 1.1 , (b) 2.6 , and (c) 8.6 . 
a.

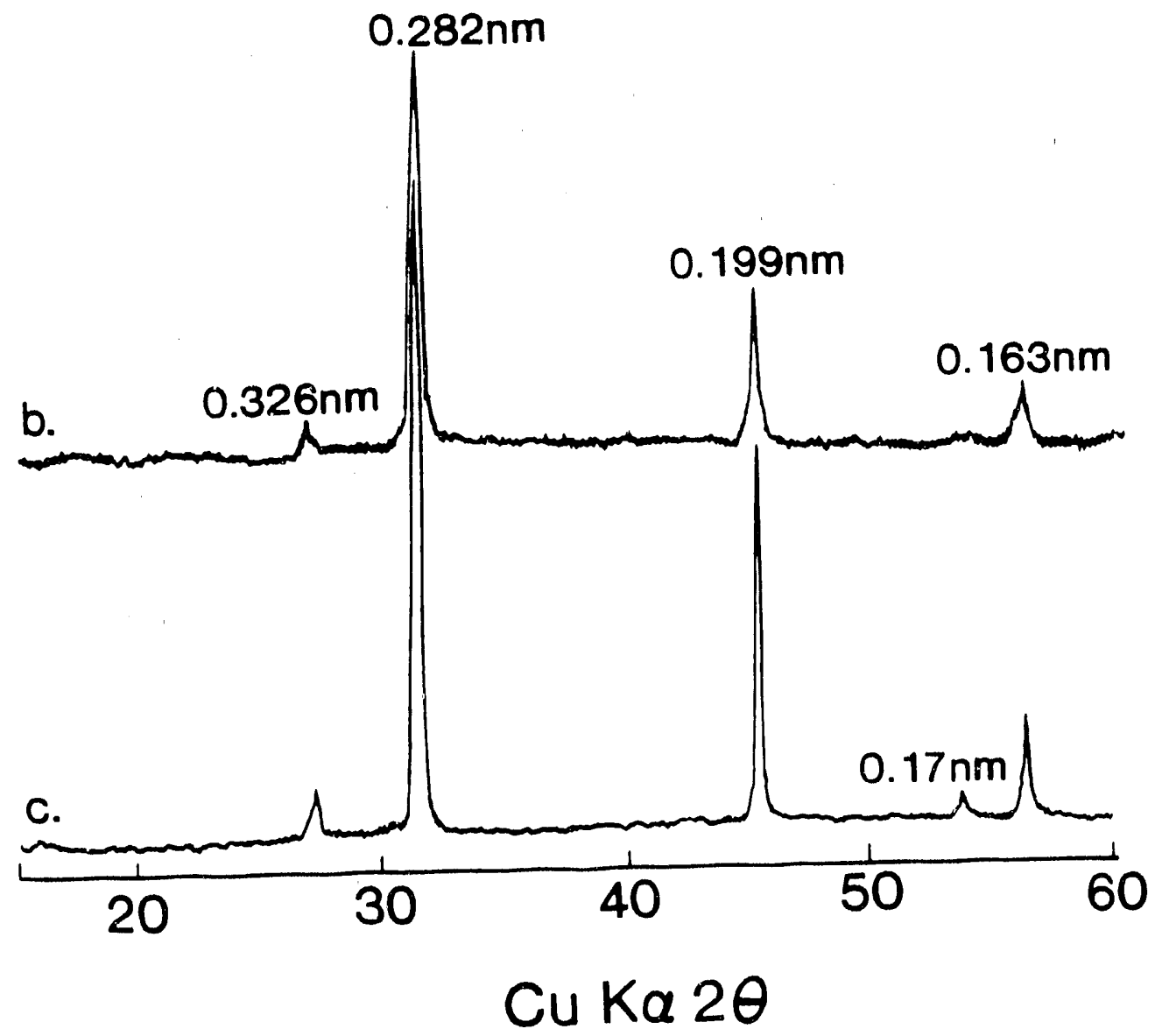

Figure 25. XRD patterns for $300^{\circ} \mathrm{C}$-pyrolyzed xerogels at $\mathrm{pH}$ (a) 1.1 , (b) 2.6 , and (c) 8.6 . 


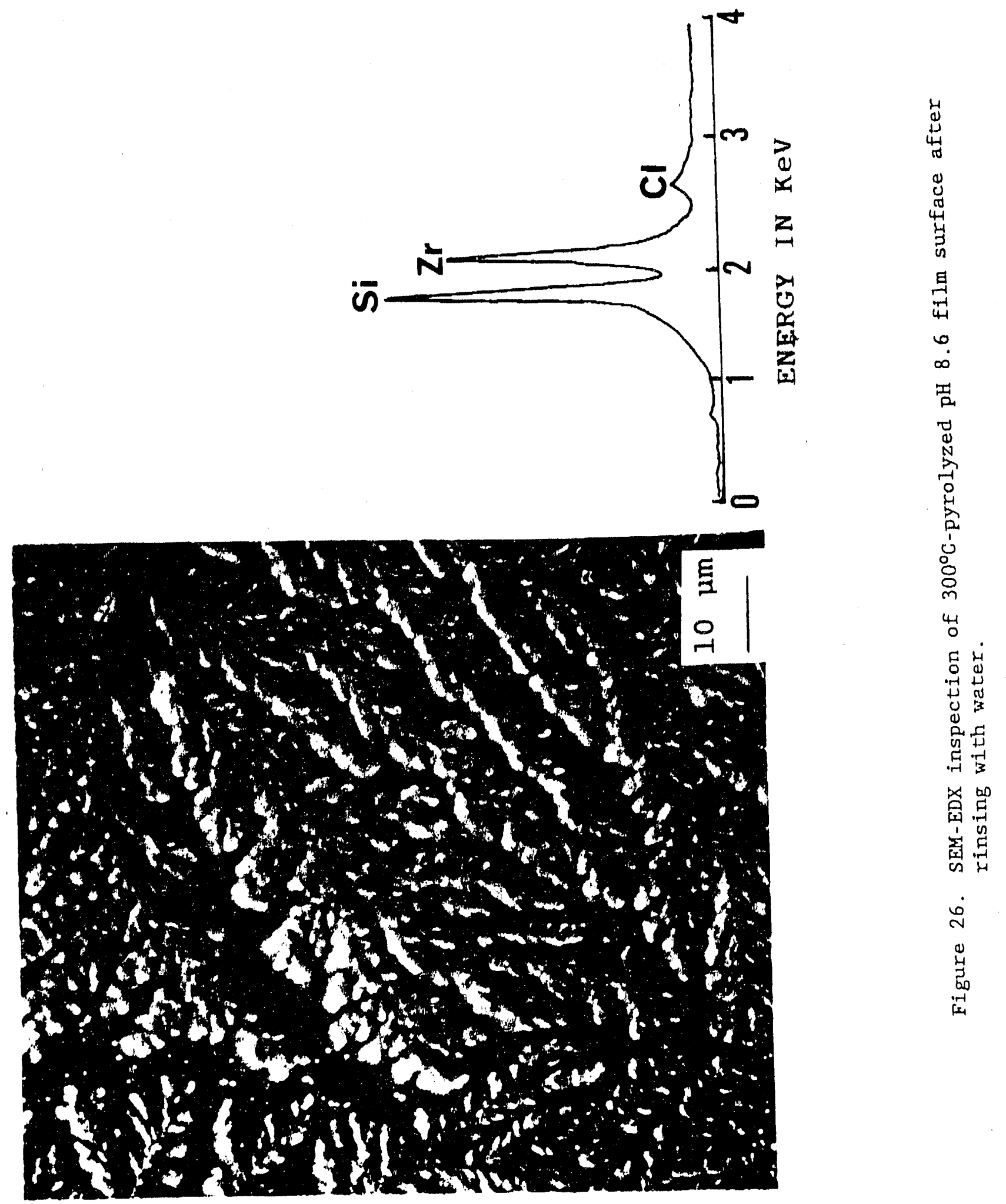




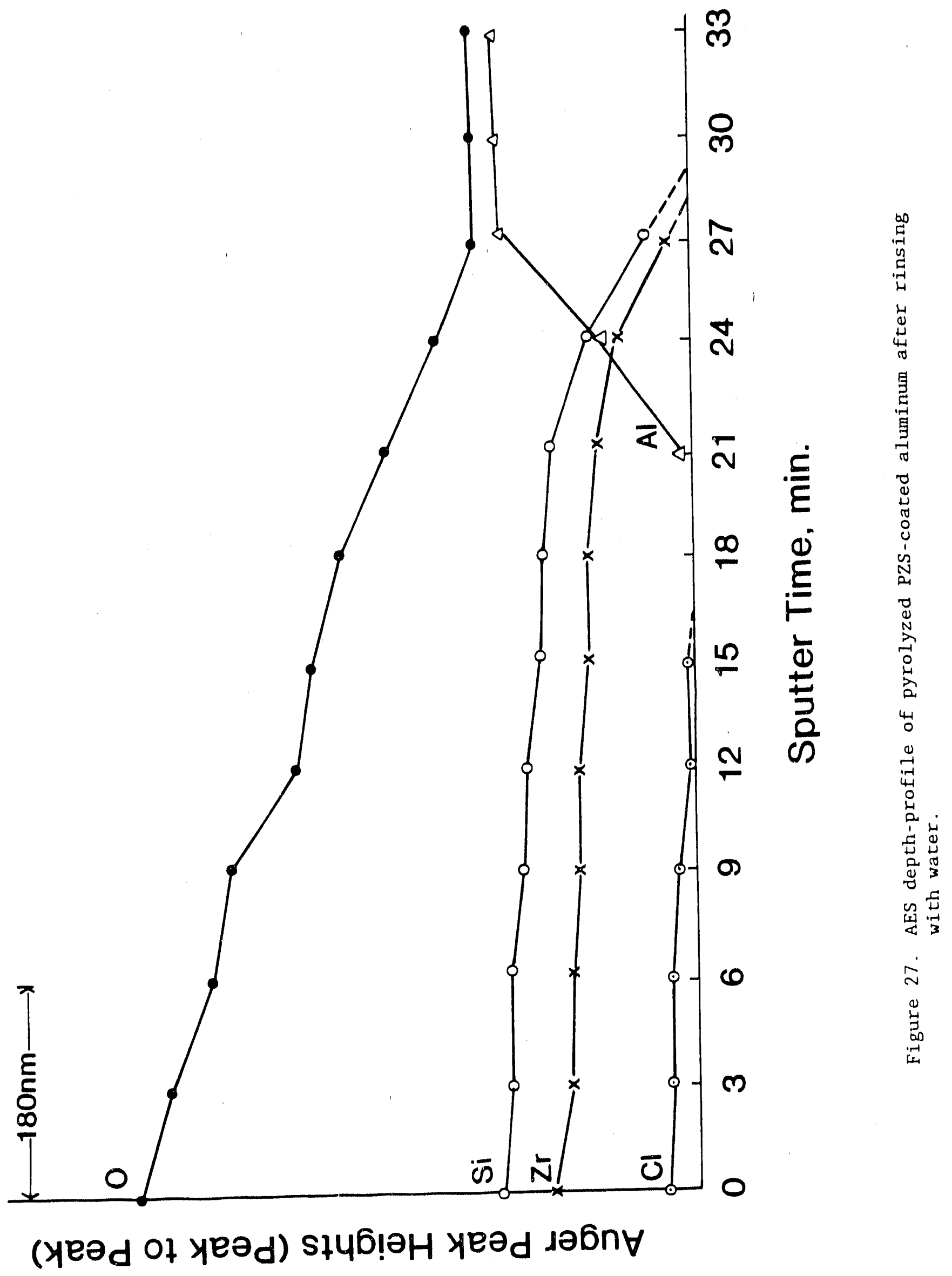




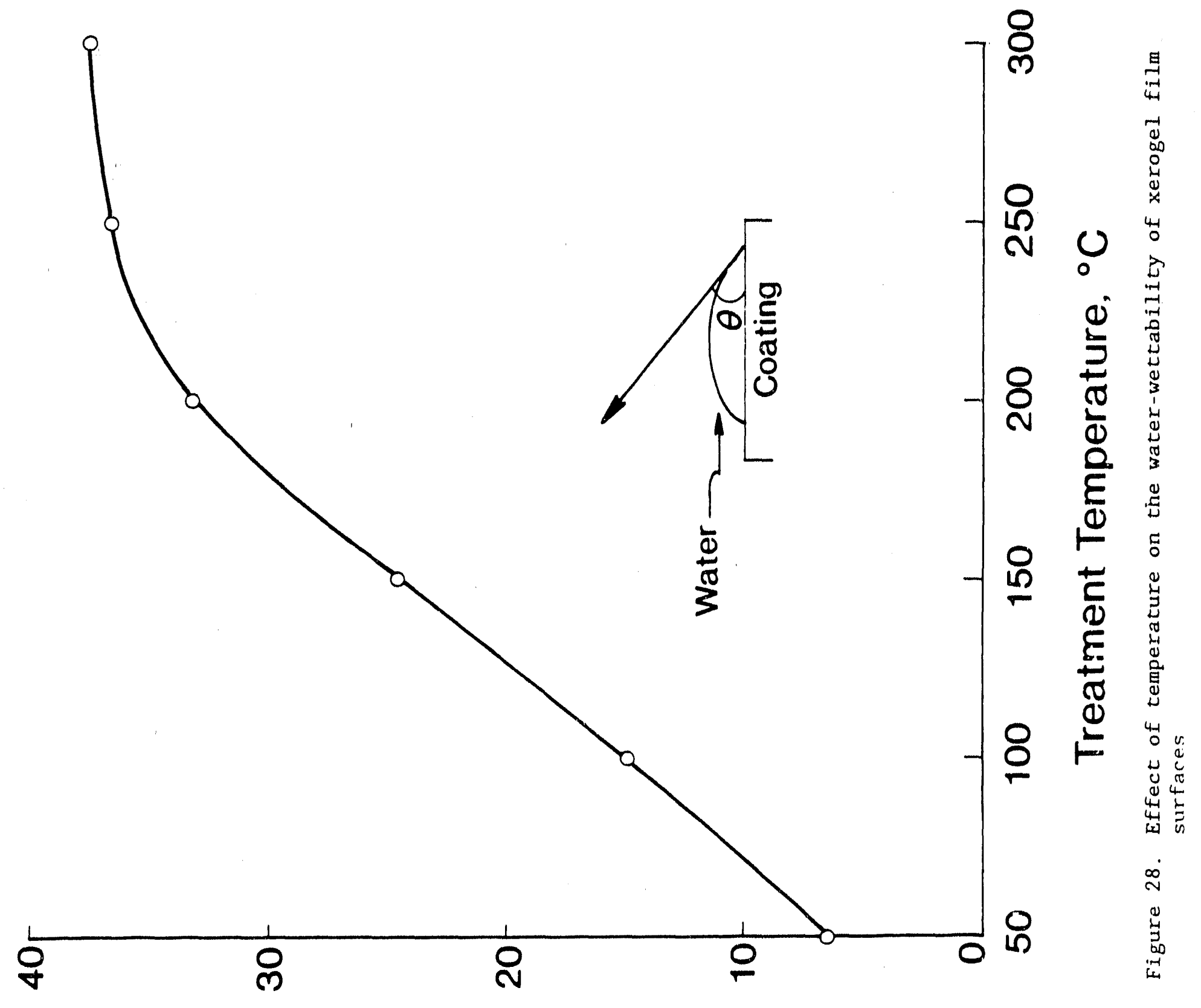

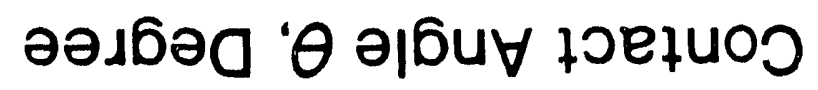




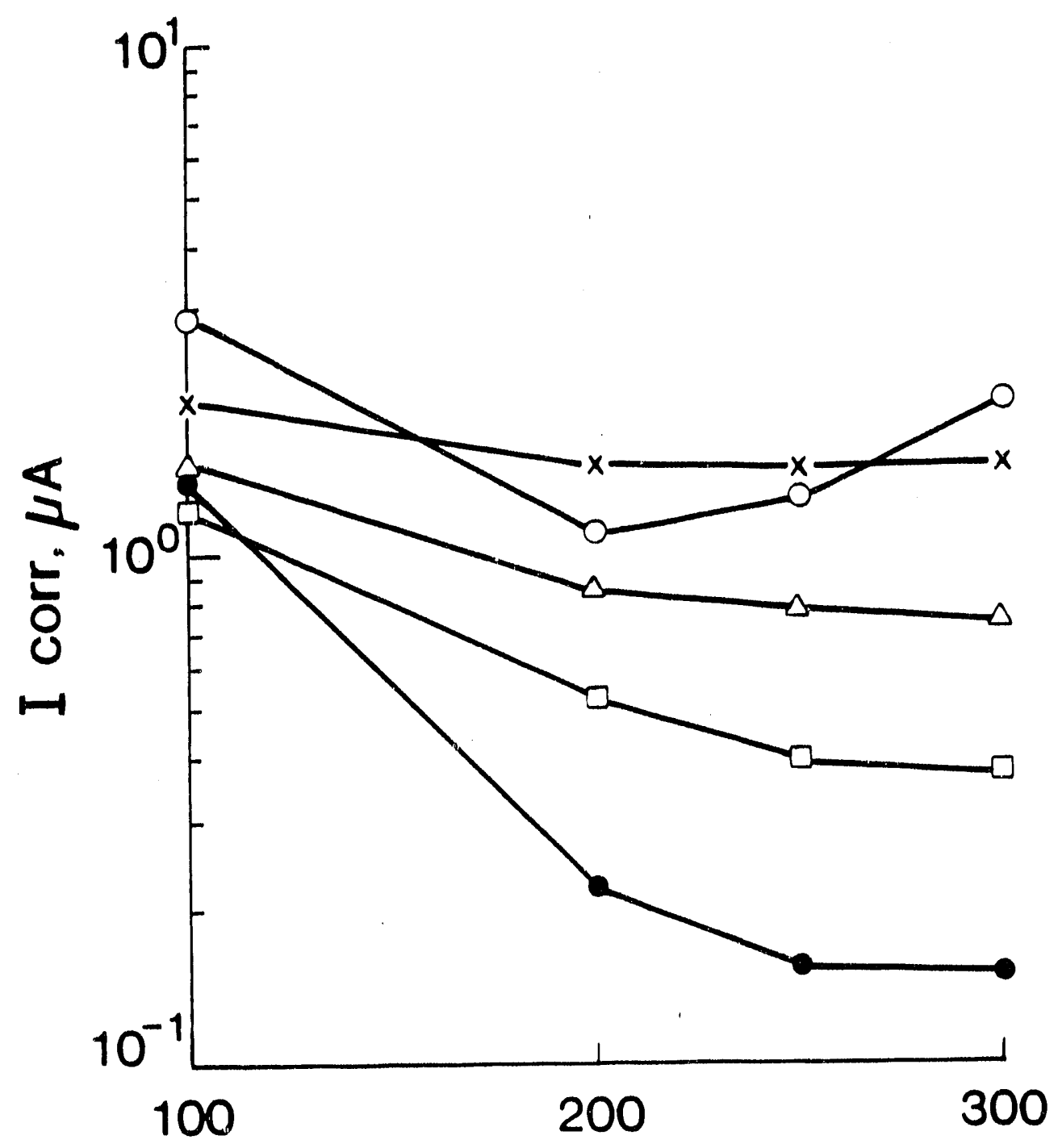

Treatment Temperature, ${ }^{\circ} \mathrm{C}$

Figure 29. Changes in the corrosion current, $I_{\text {corr }}$ of PZS xerogel-coated aluminum substrates as a function of coating treatment temperature; $\mathrm{pH} 1.1(0), 2.6(\Delta), 7.1(0), 8.6(\bullet)$, and $12.8(\mathrm{x})$. 

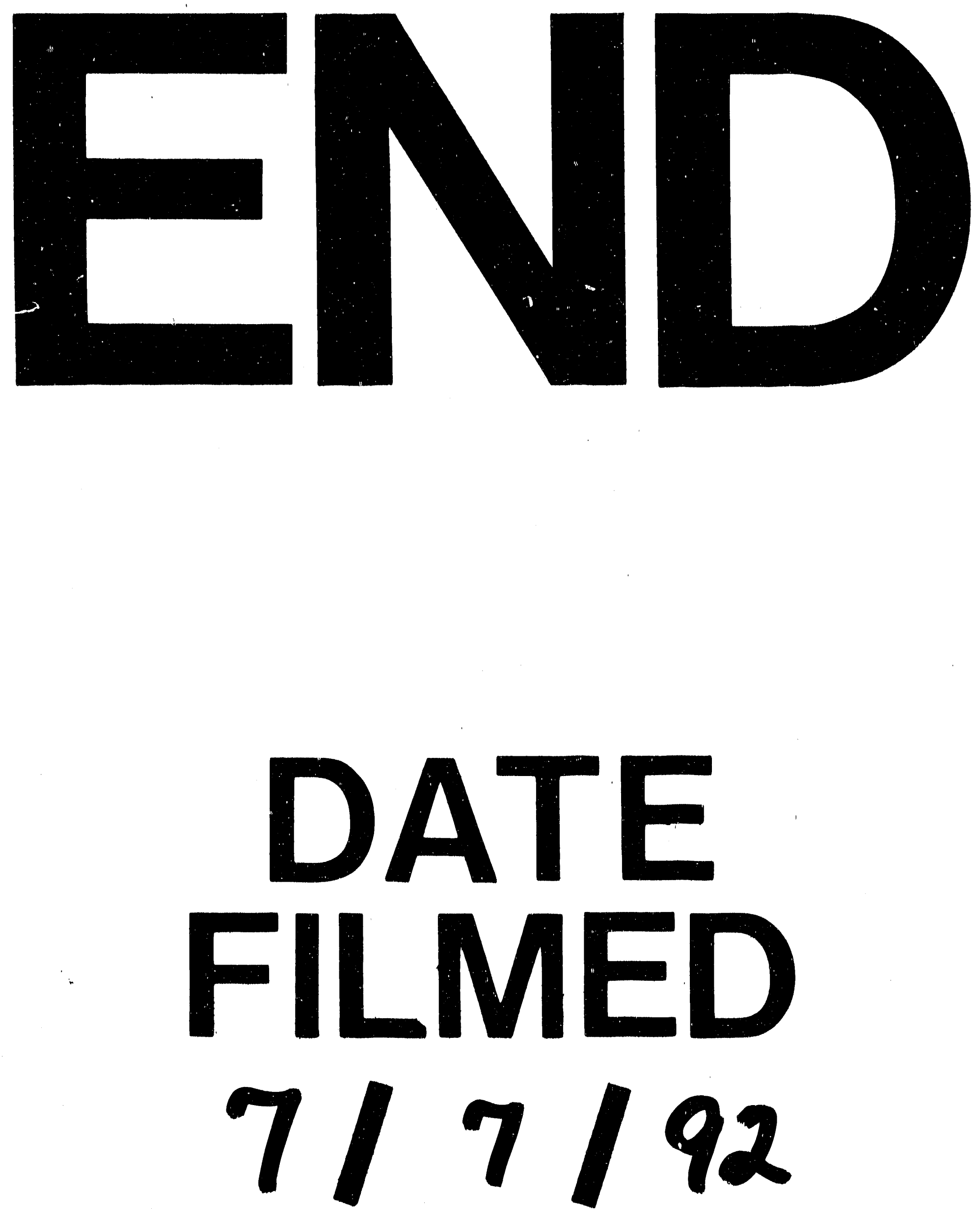
- 